Top Wealth in America: New Estimates and Implications for Taxing the Rich

by

Matthew Smith, U.S. Treasury Department Owen Zidar, Princeton and NBER Eric Zwick, Chicago Booth and NBER

Griswold Center for Economic Policy Studies Working Paper No. 264, April 2020 


\title{
Top Wealth in America: New Estimates and Implications for Taxing the Rich*
}

\author{
Matthew Smith, US Treasury Department \\ Owen Zidar, Princeton and NBER \\ Eric Zwick, Chicago Booth and NBER
}

April 24, 2020

\begin{abstract}
This paper uses administrative tax data to estimate top wealth in the United States. We build on the capitalization approach in Saez and Zucman (2016) while accounting for heterogeneity within asset classes when mapping income flows to wealth. Our approach reduces bias in wealth estimates because wealth and rates of return are correlated. We find that the top $0.1 \%$ share of wealth increased from $7 \%$ to $14 \%$ from 1978 to 2016. While this rise is half as large as prior estimates, wealth is very concentrated: the top $1 \%$ holds nearly as much wealth as the bottom $90 \%$. However, the "P90-99" class holds more wealth than either group after accounting for heterogeneity. Private business and public equity wealth are the primary sources of wealth at the top, and pension and housing wealth account for almost all wealth of the bottom $90 \%$. Our approach substantially reduces estimates of mechanical wealth tax revenue and top capital income in distributional national accounts, which depend on well-measured estimates of top wealth. From 1980 to 2014, capital income accounts for 2.4 out of 8.1 percentage points of the rise of the top $1 \%$ income share.
\end{abstract}

${ }^{*}$ This work does not necessarily reflect the views of the US Treasury Department. Mechanical tax revenue calculations in the paper do not include behavioral responses and should not be construed as true revenue estimates. We thank Anmol Bhandari, Jediphi Cabal, Curtis Carlson, John Cochrane, Anil Kashyap, Pete Klenow, Henrik Kleven, Pat Kline, Wojciech Kopczuk, Ilyana Kuziemko, Dave Lee, Moritz Lenel, Janet McCubbin, Ellen McGrattan, Luigi Pistaferri, Emmanuel Saez, Natasha Sarin, Juan Carlos Suárez Serrato, Larry Summers, Chris Tonetti, Rob Vishny, Danny Yagan, and Gabriel Zucman for helpful conversations. Joseph Battles, Coly Elhai, Joseph Hancuch, Stephanie Kestelman, Laurence O'Brien, Dustin Swonder, Samuel Wallach-Hanson, and Caleb Wroblewski provided excellent research assistance. We thank Michael Batty, Joseph Briggs, John Sabelhaus, Natasha Sarin, Alexi Savov, Kamilla Sommer, and their coauthors for sharing data. Zidar and Zwick thank the Kauffman Foundation for financial support. Zidar also thanks the National Science Foundation for support under Grant Number 1752431, and Zwick also thanks the Neubauer Family Foundation, the Polsky Center, and the Hultquist Faculty Research Endowment at Chicago Booth. 
How rich are the richest Americans? A thorough answer to this question is necessary to address public concern over rising inequality, whether the distribution of resources is fair, and how policy ought to respond. Evaluating tax policies that target the rich depends upon the quality of top wealth estimates. Measuring the concentration of wealth also matters for economic analysis of growth, savings, and capital accumulation.

There are three main approaches for estimating top wealth (Kopczuk, 2015). The first approach combines estate tax data and mortality statistics to map the wealth of decedents to estimates for the wealth of the living (Mallet, 1908; Kopczuk and Saez, 2004a). However, tax avoidance, evasion, and differences in mortality rates along the wealth distribution can bias estimated wealth levels and trends. The second approach uses surveys such as the Federal Reserve's Survey of Consumer Finances (SCF), which oversamples high-income people and collects detailed information on income and wealth (Wolff, 1998; Bricker, Henriques, Krimmel and Sabelhaus, 2016). Yet the voluntary nature of responding, the preference for privacy among the wealthy, and the unwillingness to answer long surveys make the SCF subject to uncertainty, especially at the very top. The SCF also intentionally excludes the Forbes 400. The third approach scales up, or "capitalizes," income observed on tax returns to estimate top wealth (Giffen, 1913; Stewart, 1939; Saez and Zucman, 2016). However, this approach relies upon having an accurate mapping of income to wealth, or, equivalently, knowing the rates of return earned on different types of income by different groups of people. The current state-of-the-art deploys the simplifying assumption of equal returns within asset class to map income flows to wealth estimates.

The most recent estimates from these approaches tell starkly different stories about the level and evolution of top $0.1 \%$ wealth (Figure 1A). The estate tax series suggests the share of wealth held by the top $0.1 \%$ was around $10 \%$ in recent years, has changed little since 1975 , but was twice as high in the era before the Great Depression. In contrast, the capitalization approach shows a dramatic U-shape in wealth concentration: top $0.1 \%$ wealth matched the estate tax series in the early years, then diverged and surged spectacularly since 1980 to around $20 \%$ recently. The survey data from the SCF, available every three years since 1989, has hovered between the estate and capitalization series and shows modest growth. This pattern holds even when adding the Forbes 400 to the SCF sample.

The composition of top $0.1 \%$ wealth also differs greatly across these approaches (Figure 1B). Fixed income assets of the top $0.1 \%$ account for $7 \%$ of total US household wealth in the capitalization series and less than $2 \%$ in the SCF. Private business wealth accounts for $3 \%$ in the capitalization series and $8 \%$ in the SCF.

This paper builds on the pioneering work of Saez and Zucman (2016) by providing new estimates of top wealth that account for heterogeneity when capitalizing income flows. Ac- 
counting for heterogeneity reduces estimated wealth concentration, especially at the very top. Figure 1A shows how our preferred approach alters estimated wealth for the top $0.1 \%$. The top $0.1 \%$ wealth share in 2016 is $14 \%$ when accounting for return heterogeneity, and around $20 \%$ when assuming equal returns. Top $1 \%$ and $0.01 \%$ shares fall by 22 percent and 36 percent, respectively. The growth in top wealth shares is also less dramatic. Our approach reduces the growth in top shares since 1978 by half, leaving the recent wealth estimates above the estate tax series and closer to the SCF. Overall, wealth is very concentrated: the top $1 \%$ holds nearly as much wealth as the bottom 90\%. However, the "P90-99" class holds more wealth than either group.

Our approach also alters the composition of top wealth. We find a larger role for private business wealth and a smaller role for fixed income wealth, consistent with the composition of top wealth in the SCF and estate tax data. Private business and public equity wealth are the primary sources of wealth at the top, and pension and housing wealth account for almost all wealth of the bottom $90 \%$.

The first part of the paper presents our approach to capitalization, which estimates wealth $W$ as a function of observed income $y$ using the relationship, $W=\beta y$, where $\beta$ is the capitalization factor. In the simple case of a bond, $\beta$ is $1 / r$ where $r$ is the interest rate. Our approach allows $\beta$ to vary across groups of people within each major asset class: fixed income, C-corporation equity, pass-through business, housing, and pensions. For each of these asset classes, we first describe our capitalization approach, and then provide new evidence to support it.

First, for fixed income wealth, we allow capitalization factors $\beta(y)$ to vary by the amount of observed interest income $y$. We show that fixed income portfolios of the rich skew toward high-yield bonds and loans, whereas the fixed income portfolios of the non-wealthy are mostly bank deposits. This compositional difference results in higher returns and lower implied capitalization factors at the top. Within data sets that have both income flows and reported wealth, we show that capitalizing flows with unequal returns much more closely matches the actual wealth data than an equal-returns approach.

Second, we use both dividends and realized capital gains to estimate C-corporation equity wealth because both flows are informative about stock ownership. Including realized capital gains improves estimates by accounting for non-dividend-paying stocks. However, most realized capital gains do not reflect C-corporation stock. In addition, realized capital gains are lumpy, which makes them less informative about underlying ownership and also contributes to capital gains being more concentrated than C-corporation dividends. Our preferred approach uses the convex combination of dividends and realized capital gains that balances these forces by minimizing prediction error in the SCF, which puts $90 \%$ weight on 
dividends.

Third, we use linked firm-owner data and industry-specific valuation multiples from public markets to estimate pass-through business wealth. We also account for liquidity discounts of private firms and for labor income recharacterized as profits following Smith, Yagan, Zidar and Zwick (2019). Collectively, top 0.1\% pass-through wealth increases by $30 \%$ under our approach relative to an equal-returns, profits-based approach with Financial Accounts aggregates, such as in Saez and Zucman (2016).

Fourth, for pension wealth, we capitalize an age-group specific combination of wages and pension distributions. This approach allows us to parsimoniously incorporate the lifecycle patterns in pension wealth and associated income flows. While less important for top wealth, pension wealth accounts for $70 \%$ of wealth for the bottom $90 \%$ and $30 \%$ for the P90-99 group. Although we do not account for the value of Social Security in our main specification, doing so would further increase the role of this category of wealth and flatten the trend in measured wealth concentration (Sabelhaus and Henriques Volz, 2019; Catherine, Miller and Sarin, 2020).

Finally, for housing wealth, we allow effective property tax rates to vary across U.S. states when mapping property tax deductions to estimated housing assets. This heterogeneity matters less for the level of top wealth and more for its geographic distribution and evolution. For example, a dollar of property taxes paid in California is associated with four times as much housing wealth as a dollar paid in Illinois.

In the second part of the paper, we present our new wealth estimates and explore the implications of our approach for estimating top capital income in distributional national accounts, the taxation of top wealth and income, and the geography of wealth inequality. A recent strand of the income inequality literature uses wealth estimates to apportion components of national income not captured by fiscal income data (Piketty, Saez and Zucman, 2018; Auten and Splinter, 2017; Smith, Yagan, Zidar and Zwick, 2019; Garbinti, Goupille-Lebret and Piketty, 2018). For example, the top 1\% share of C-corporation retained earnings, which are not immediately distributed to their owners, is assumed to equal that group's share of Ccorporation wealth within the household sector. Similar imputations are required for other components of national income that are not included on individual tax returns: untaxed interest income; pension income; corporate, property, and sales taxes; and imputed rents for owner-occupied housing. As a result, changes in top wealth estimates imply changes in the distribution of capital income.

Relative to an equal-returns approach, our preferred wealth estimates reduce top capital income and imply a lower level of top income shares. However, the growth in top income shares is very similar. Lower top capital income and similar top income shares indicate that 
income inequality is driven less by capital than labor, including the labor component of pass-through business income. Specifically, from 1980 to 2014, the rise in the top 1\% share due to capital income is only 2.4 out of 8.1 percentage points in total growth. For the top $0.1 \%$, capital's contribution was 1.9 out of 5.2 percentage points of total growth.

For wealth taxation, we consider different proposals for a new tax on wealth. A one percent tax on the top $0.1 \%$ in 2016 generates mechanical tax revenue estimate of $\$ 112 \mathrm{~B} .{ }^{1}$ A graduated tax, which taxes wealth above $\$ 50 \mathrm{M}$ at $2 \%$ and adds a surtax of $1 \%$ of wealth exceeding $\$ 1 \mathrm{~B}$, would mechanically raise $\$ 117 \mathrm{~B}$ in 2016 using our preferred estimates, which is $57 \%$ of the estimate of $\$ 207 \mathrm{~B}$ using equal-returns assumptions. We find a larger role for illiquid wealth categories where valuations are more contentious, which could imply higher administrative burdens for a wealth tax or proposals to tax unrealized capital gains.

For income taxation, our estimates affect both the numerator and denominator for measuring broad effective tax rates along the income distribution. They also can inform the mechanical revenue consequences of various proposals that target top incomes by providing an estimate of the capital tax base. Our estimates provide some information about the distribution of corporate tax incidence for equity held directly by households and indirectly through pensions.

We also provide state-level estimates of wealth and explore the evolution of wealth inequality across regions, focusing on the evolution of wealth-to-GDP ratios and wealth per capita between 1980 and 2016. The data reveal vast disparities in wealth across regions. For example, wealth in Massachusetts is $\$ 500 \mathrm{~K}$ per capita, whereas the poorest states like Mississippi and West Virginia have just over $\$ 200 \mathrm{~K}$ per capita (half of which is pension wealth). The coastal states have experienced substantial wealth growth since 1980, with wealth-to-GDP ratios increasing by between $100 \%$ and $300 \%$ of GDP, while inland states have seen much more modest growth. Thus, the period of aggregate wealth growth in the United States has coincided with striking regional divergence.

This paper contributes to the wealth literature in several ways. First, we provide new estimates of top wealth inequality in the U.S. at both the national and state levels. These estimates are essential inputs to economic analysis of the distribution of capital and policy analysis of capital taxation. Second, we present new evidence quantifying the importance of heterogeneous returns when capitalizing income flows to estimate wealth. Kopczuk (2015) suggests these adjustments are especially important when average returns are close to zero, such as when interest rates are near the zero lower bound or for property tax rates, which average 1\% across states. Other papers, especially Bricker, Henriques and Hansen (2018)

\footnotetext{
${ }^{1}$ Mechanical tax revenue calculations presented here include no behavioral response and should not be construed as a true revenue estimate.
} 
and Fagereng, Guiso, Malacrino and Pistaferri (2020), emphasize that higher returns at the top affect wealth estimates. ${ }^{2}$ Our contribution is to build on these insights by implementing proposed adjustments in the tax data and combining them with other first-order refinements to all other major asset categories. Third, by combining these refinements, we shed new light on the composition of top wealth. In particular, relative to an equal-returns approach, top wealth depends less on fixed income and public equity and more on housing and private equity. Our refined portfolio shares line up more closely with the SCF and estate tax data for fixed income, although SCF private equity substantially exceeds private equity estimates from capitalized income flows. We also demonstrate that our assumptions perform much better in a goodness of fit sense in data sets that enable us to compare predicted versus actual values for different approaches.

Piketty (2014) and Piketty, Saez and Zucman (2018) emphasize the rising importance of non-human capital for top income and wealth, while Smith, Yagan, Zidar and Zwick (2019) show that much of the recent rise of top incomes represents a return to human capital, including the labor income of private business owners characterized as capital income for tax purposes. A larger role for pass-through business wealth, lower concentration of financial wealth, and a less rapid rise in recent years in financial wealth and capital shares at the top all point to a larger role for human capital and a smaller role for non-human capital in top income growth. Providing this reconciliation would not have been possible without the comprehensive framework of Saez and Zucman (2016) and Piketty, Saez and Zucman (2018) for estimating the joint distribution of wealth and national income. We hope our estimates of geographic disparities in wealth can inform research on intergenerational mobility, migration, and regional divergence.

Last, we make a methodological contribution by clarifying how capitalization works in practice and by emphasizing both heterogeneity and the concomitant uncertainty that arises. These clarifications can help others implement the capitalization approach in other countries and settings, which is especially important as the BEA and other statistical agencies consider adopting this approach to compute distributional national accounts (Zwick, 2019). Accordingly, our estimates suffer from important limitations inherent to the method of estimating an unknown quantity of wealth in an environment with tax avoidance, tax evasion, difficulty linking pensions and other indirectly held assets to individuals, and other missing data. We therefore view this work as a step forward in the literature on wealth in the United States, but underscore the uncertainty that remains and the importance of continued refinements to this powerful approach.

\footnotetext{
${ }^{2}$ Other contributions include Arrow (1987); Piketty (2014); Gabaix, Lasry, Lions and Moll (2016); Bach, Calvet and Sodini (2016); Guvenen, Kambourov, Kuruscu, Ocampo and Chen (2017).
} 


\section{Data}

Aggregate wealth data come from the U.S. Financial Accounts (formerly the Flow of Funds) at the Federal Reserve Board, and national income data come from the National Income and Product Accounts at the U.S. Bureau of Economic Analysis (BEA). Fiscal income data comes from the IRS Statistics of Income (SOI) stratified random samples for 1965 to 2016. These data provide the core inputs for our wealth estimates. ${ }^{3}$

We compare our estimates to those from alternative approaches, including the Survey of Consumer Finances (SCF) for 1989 through 2016, supplemented with the Forbes 400 list, and the estate tax series following Kopczuk and Saez (2004a) and updated through 2016. We separately use public aggregate data from SOI on portfolio composition from estate tax filings. We also consider the recent Distributional Financial Accounts series, which maps the SCF onto Financial Accounts categories, providing a useful bridge between the SCF and the aggregate series in the capitalization approach. ${ }^{4}$

We use numerous data sources to estimate wealth and validate our estimates for each asset class. First, for fixed income, we combine data on asset holdings and fixed income flows from the SCF, yields on fixed income securities over time and bank deposits from Federal Reserve Economic Data (FRED) and Alexi Savov, respectively, and data on fixed income wealth and fixed income flows from a sample of estate tax filings merged to prior year individual tax filings. Second, for C-corporation equity, we use data from the IRS Sales of Capital Assets files and population-level information returns (Form $1065 \mathrm{~K} 1$ ) to explore the composition of realized capital gains. Third, for pass-through business, we draw on public company filings from Compustat to construct alternative multiple-based valuation models. We combine these data with fiscal income data on S-corporations and partnerships at the 4-digit-industry-by-owner-group level. We estimate liquidity discounts for private firms using transaction data from Thomson Reuters SDC. Fourth, for housing wealth, we combine data on effective property tax rates by state from ATTOM, assessed tax values for all residential properties from DataQuick, house price indexes by state from CoreLogic, and state-by-year property tax revenues and population from the Census of States. Fifth, for pension wealth, we incorporate estimates of defined benefit pension wealth from Sabelhaus and Henriques Volz (2019) into the SCF.

\footnotetext{
${ }^{3}$ Our Financial Accounts aggregates draw directly from Saez and Zucman (2016), updated through 2014 in Piketty, Saez and Zucman (2018), and updated through 2016 by us. These aggregates make some modifications to the Financial Accounts, for example, to divide closely-held business into C-corporation and S-corporation equity wealth. We use the term "Financial Accounts" to refer to these aggregate series and explicitly discuss when we depart from them.

${ }^{4}$ See Batty, Bricker, Briggs, Holmquist, Hume McIntosh, Moore, Nielsen, Reber, Shatto, Sommer, Sweeney and Henriques Volz (2019) for details.
} 
Appendix D, E, and F provide detailed definitions for each wealth component in the tax data, the SCF, and the DFA, respectively. Appendix G describes how we estimate portfolio composition for the Forbes 400. Appendix H gives sources for other data used in this paper.

\section{Capitalizing Income to Measure Top Wealth}

\subsection{The Level and Composition of Aggregate Wealth}

Our goal is to estimate the distribution of wealth across individuals in the United States using aggregate wealth data and individual-level income data. We define aggregate wealth as total assets minus liabilities of individuals at market value, excluding durable goods, Social Security, non-profits, and human capital. This wealth concept is therefore closer to private financial wealth than it is to permanent income. ${ }^{5}$

Figure 2A decomposes aggregate national wealth from the Financial Accounts into five components and plots their evolution relative to national income. In 2016, national wealth amounts to $471 \%$ of national income. The largest component is pensions, which equals $164 \%$ of national income. Housing net of mortgages is the next largest (96\%), followed by fixed income assets (94\%), C-corporation equity (72\%), and pass-through business, which includes proprietorship, partnership, and S-corporation equity (72\%). Combined C-corporation and pass-through business wealth gives $144 \%$, fifty percent more than the amount of fixed income wealth and commensurate with pension wealth.

At the aggregate level, wealth has increased from $306 \%$ in 1966 to $471 \%$ of national income. Of that increase, 125 percentage points are from pensions, 19 are from net housing, 17 are from corporate and non-corporate equity, 14 are from fixed income, with the residual including non-mortgage household debt modestly reducing aggregate wealth. Pension growth largely reflects the transition from defined benefit to defined contribution plans and the growth of defined contribution plans after policy reforms in the early 1980s. ${ }^{6}$ Both aggregate housing and equity components mirror the rise and fall of asset prices associated with the stock market boom in the late 1990s and the housing boom and bust in the mid-2000s. Fixed

\footnotetext{
${ }^{5}$ Our definition is broader than in Saez and Zucman (2016) because we include estimates of unfunded defined benefit pension wealth, made possible by new data from Sabelhaus and Henriques Volz (2019). We also depart from Saez and Zucman (2016) and follow Piketty, Saez and Zucman (2018) in focusing on individual-level estimates rather than tax unit-level estimates, which helps account for evolving household structure over time and across the income distribution.

${ }^{6}$ For consistency with Saez and Zucman (2016) and Piketty, Saez and Zucman (2018), this graph excludes the unfunded portion of defined benefit pension wealth, which is approximately half the size of total defined benefit pension wealth and has declined to $10-15 \%$ of total pension wealth in recent years. Below, when we estimate the distribution of pension wealth, we include both the funded and unfunded portions of defined benefit pensions, which amounts to an additional $\$ 1.9 \mathrm{~T}$ of pension wealth in 2016 .
} 
income wealth has grown the least among these components, though it has increased since its low point at $44 \%$ of national income in 2000 to a level last seen in the early 1990s.

The Financial Accounts are not perfect measures of wealth. First, they do not include Social Security wealth, nor do they reflect the stock of human capital. ${ }^{7}$ Second, data limitations imply the value of non-public equity is imperfectly estimated. A significant share of non-public equity comes from multiplying the book value of private company assets by market-to-book ratios at the two-digit industry level and then applying a $25 \%$ discount for illiquidity. This procedure may significantly understate the value of private equity, which motivates our bottom-up approach for valuing private business assets. Third, they may miss wealth held abroad by U.S. persons, which Zucman (2013) estimates to be $4 \%$ of U.S. financial wealth. Last, the household sector is a residual category that includes hedge funds and other entities with unclear ultimate ownership. Each of these considerations may affect the total wealth to be distributed.

\subsection{How Capitalization Works}

The flow of income of person $i$ in year $t$ of asset class $j$ can be decomposed into a return multiplied by a stock of wealth, i.e., $y_{i t}^{j}=r_{i t}^{j} \times W_{i t}^{j}$. We can therefore estimate wealth by multiplying the flow $y_{i t}^{j}$ by a capitalization factor $\beta_{i t}^{j} \equiv \frac{1}{r_{i t}^{j}}$,

$$
W_{i t}^{j}=\beta_{i t}^{j} \times y_{i t}^{j}
$$

This procedure takes as inputs observed income and capitalization factors by type. Since wealth $W_{i t}^{j}$ and annual person- and asset-class specific capitalization factors $\beta_{i t}^{j}$ are unknown, this approach requires making assumptions about the relationship between flows $y_{i t}^{j}$ and stocks $W_{i t}^{j}$ to proceed.

\subsubsection{Equal Returns}

The main approach in Saez and Zucman (2016), the most prominent recent paper using capitalization to estimate the wealth distribution, is to assume equal returns across individuals $i$ within asset classes $j$, i.e., $r_{i t}^{j}=\bar{r}_{t}^{j} \forall i$. These average returns $\bar{r}_{t}^{j}$ equal the ratio of aggregate

\footnotetext{
${ }^{7}$ Catherine, Miller and Sarin (2020) estimate the value and distribution of Social Security wealth over time. Section 9.3 discusses how their approach would affect estimates of wealth concentration including Social Security.
} 
flows to aggregate stocks in asset class $j$ in year $t$. The resulting capitalization factor is:

$$
\bar{\beta}_{t}^{j} \equiv \frac{\sum_{i} W_{i t}^{j}}{\sum_{i} y_{i t}^{j}}
$$

Applying equation (1) delivers wealth estimates:

$$
\hat{W}_{i t}^{j}=\bar{\beta}_{t}^{j} \times y_{i t}^{j} .
$$

where $\bar{\beta}_{t}^{j}=\frac{1}{\bar{r}_{t}^{j}}$ is the equal-returns capitalization factor for asset class $j$ in year $t$. An advantage of this equal-returns approach is that it only requires aggregate stocks to estimate capitalization factors and the distribution of wealth. A disadvantage is that the true relationship between stocks and flows may not be linear, so using equation (3) to estimate wealth may generate biased wealth estimates.

\subsubsection{Unequal Returns}

If, for example, the true stock-flow relationship is concave in flows, then allowing those with high flows to have a smaller capitalization factor will produce more accurate wealth estimates.

Suppose that those in the top $1 \%$ of income flows enjoy return $r_{t}^{T}$ and everyone else enjoys return $r_{t}^{B}$ in asset class $j$. Then the resulting wealth estimates would be:

$$
\hat{W}_{i t}^{j}=\left\{\begin{array}{ll}
\frac{1}{r_{t}^{T}} \times y_{i t}^{j} & \text { if } P_{i t}^{j} \geq 99 \\
\frac{1}{r_{t}^{B}} \times y_{i t}^{j} & \text { if } P_{i t}^{j}<99
\end{array},\right.
$$

where $P_{i t}^{j}$ is the percentile of the income distribution of flow $y_{i t}^{j}$. If $r_{t}^{T}>r_{t}^{B}$, then the stock-flow relationship would be concave since the capitalization factor for the top group $\beta_{t}^{T}=\frac{1}{r_{t}^{T}}$ is smaller than the capitalization factor $\beta_{t}^{B}=\frac{1}{r_{t}^{B}}$ for those with smaller income flows. Applying the equal-returns approach of equation (3) instead of (4) would overstate the wealth of those in the top group, and understate it for the bottom group.

More generally, if there are other types of heterogeneity in $r_{i t}^{j}$ and thus $\frac{1}{r_{i t}^{j}}$, then using group-specific capitalization factors will generate more accurate wealth estimates than those obtained from the equal-returns approach. 


\subsection{The Level and Distribution of Observed Capital income}

Implementing the capitalization approach starts with fiscal income data broken up by capital income component. Figure 2B plots six types of capital income relative to national income from 1966 to 2016. ${ }^{8}$ Aggregate interest income of U.S. individuals increased in the late 1970s and boomed in the early 1980s. It then fell in the 1990s back to its initial share of national income. Since 2000, aggregate interest income has been falling and amounted to $0.6 \%$ of national income or $\$ 102$ billion in 2016 .

Pension and pass-through income are now the largest sources of fiscal capital income. Pension income has risen tenfold from $0.7 \%$ to $6 \%$ of national income from 1966 to 2016. Pass-through income was $6.8 \%$ of national income in 1966, fell to $4 \%$ in the early 1980 s, and then recovered following the Tax Reform Act of 1986 to $7.4 \%$ of national income in 2016. The relative constancy of this income source masks a substantial shift toward formal pass-through income earned in S-corporations and partnerships (Smith, Yagan, Zidar and Zwick, 2020).

Aggregate dividend income of U.S. individuals amounts to $1.6 \%$ of national income and has fluctuated mildly around that level over this period. In contrast, aggregate capital gains of U.S. individuals is much more volatile and ranges from $2 \%$ to over $8 \%$ of national income. Aggregate property tax payments, which are capitalized to estimate housing assets, amount to approximately $1.2 \%$ of national income and grew modestly during the boom and bust of the 2000s.

Figure 3 shows how the concentration of fiscal income flows has evolved. Each series shows the share of fiscal income for each category accruing to the top $10 \%$, top $1 \%$, top $0.1 \%$, and top $0.01 \%$, where the ranks are defined using the respective fiscal income flow distribution. Figure 3A shows that concentration has risen dramatically for interest income. The top 1\% received approximately 30\% of all taxable interest income from 1965 to 1985. This share started climbing steadily to above $40 \%$ in the 1990 s, to above $50 \%$ in the mid2000s, and then rapidly rose after 2009 to nearly $80 \%$. Under the equal returns assumption, this growth in interest income concentration implies spectacular growth in the concentration of fixed income wealth.

Figures 3B-H show that the evolution of other capital income components has been less dramatic over time. Property tax payments are much less concentrated than the other components, reflecting the broad holdings of owner-occupied real estate across people. Top $1 \%$ shares have hovered around $20 \%$ since the late 1980s.

\footnotetext{
${ }^{8}$ We use the term "capital income" because these flows will be used to allocate wealth. However, such income may also reflect labor income characterized as capital income for tax purposes (Smith, Yagan, Zidar and Zwick, 2019).
} 
For C-corporation equity wealth, the extent of concentration depends on the measure being used. Concentration is higher for capital gains than dividends, though both are very concentrated. The top $1 \%$ dividend share exceeded $70 \%$ in the late 1960 s, hovered around $60 \%$ from 1980 to 2000, and recovered to around 70\% since the early 2000s. Top 1\% capital gains, in contrast, started near $80 \%$ and have fluctuated between 80 and $100 \%$ since 2000 . As shown in Figure 2B, the aggregate capital gains series is also more volatile than the other series, reflecting the accumulation of past gains and losses and the importance of timing decisions for realization. Income concentration among S-corporations and partnerships is higher than for C-corporation dividends and has been stable over time. Proprietorship income is less concentrated. ${ }^{9}$

As pensions have grown in popularity and breadth over time and the population has aged, the concentration of pension income has fallen from the top $1 \%$ receiving $60 \%$ of income in 1966 to just $20 \%$ in 2016 . Wage income shows a modest increase in concentration relative to other components.

\section{Fixed Income}

This section describes how we use each individual's flow of taxable interest income to estimate fixed income assets. Note that this component of wealth does not include fixed income assets held through pensions or life insurance, which are allocated when estimating pension wealth.

\subsection{Capitalization with Unequal Returns}

We begin with taxable interest income $y_{i t}^{f i x}$ for person $i$ in year $t$. We partition the distribution of taxable interest income into three groups: P0-99, P99-99.9, and P99.9-100. For each group, we assign a capitalization factor to estimate fixed income assets. For the P99.9-100 and P99-99.9 groups, we apply the capitalization factors $\frac{1}{r_{A a a, t}}$ and $\frac{1}{r_{U S T, t}}$, respectively, where $r_{A a a, t}$ is the Moody's seasoned Aaa-rated corporate bond yield and $r_{U S T, t}$ is the 10-year Treasury constant maturity rate. For the bottom group, we apply the capitalization factor implied by the residual from removing the top groups' collective flows and estimated assets. By construction, the sum of all groups' estimated assets is the Financial Accounts aggregate for directly held fixed income assets.

In 2016, the resulting capitalization factors for P0-99, P99-99.9, and P99.9-100 are 443, 54 , and 27, respectively. The capitalization factors for those with higher flows reflect higher

\footnotetext{
${ }^{9}$ S-corporation income concentration is somewhat higher than in Cooper, McClelland, Pearce, Prisinzano, Sullivan, Yagan, Zidar and Zwick (2016) because we rank by flow component rather than total fiscal income.
} 
rates of return earned by these groups. For those at the top, $\$ 1$ of flows corresponds to $\$ 27$ of assets; for those at the bottom, $\$ 1$ of flows corresponds to $\$ 443$ of assets. If we instead followed the equal-returns approach, we would assign all three groups the capitalization

factor $\frac{1}{\bar{r}_{f i x, 2016}}$ of 124 , which is the ratio of aggregate fixed income assets $(\$ 12.6 \mathrm{~T})$ to aggregate taxable interest income $(\$ 102 \mathrm{~B})$. Under this approach, $\$ 1$ of flows corresponds to $\$ 124$ of assets for everyone and an aggregate rate of return $\bar{r}_{f i x, 2016}$ of $0.81 \%$.

\subsection{Evidence of Higher Returns at the Top}

High-fixed-income people earn materially higher returns within the category of assets that generate taxable interest income. Simply put, fixed income portfolios for the wealthy differ in nature, risk, and liquidity from those for the less wealthy. The result is unequal effective returns along the wealth distribution, which is reflected in the observed distribution of taxable interest income. This heterogeneity is well approximated by our three-group specification.

As a starting point, consider the instructions for Form 1099-INT, the information return for taxable fixed income that financial institutions provide taxpayers and the IRS. Box 1 is to "include interest on bank deposits, accumulated dividends paid by a life insurance company, indebtedness (including bonds, debentures, notes, and certificates other than those of the U.S. Treasury)." In other words, taxable interest income is a broad bucket that comprises many different categories of assets delivering fixed income to owners.

How different are the fixed income portfolios of top and non-top households? Figure 4A uses the 2016 SCF to decompose all fixed income holdings into broad categories, including liquid assets and deposits, bonds, and fixed income mutual funds excluding money market funds. We present portfolio shares separately for the top 0.1\%, P99-P99.9, P90-99, and for the bottom $90 \%$ of respondents, ranked in terms of SCF household net worth. Among fixed income assets, high net worth households have more of their fixed income assets in the form of bonds and other securities. The top $0.1 \%$ hold just $20 \%$ of their fixed income portfolio in liquid assets and bank deposits. Bonds and fixed income mutual funds account for over $80 \%$. In contrast, the bottom $90 \%$ hold $80 \%$ of their fixed income assets in the form of bank deposits. Bank deposits and liquid assets have significantly lower yields than longer duration and illiquid fixed income securities. Thus, portfolio differences within fixed income are large enough to generate heterogeneous returns along the wealth distribution.

Figure 4B uses data sets with both fiscal flows and stocks to quantify the differences in overall fixed income rates of return. The red bars plot the ratio of taxable interest income to taxable fixed income assets in the SCF for four groups along the taxable interest income 
distribution. ${ }^{10}$ The blue bars plot the ratio of taxable interest income to taxable fixed income assets in estate tax filings. The income flow data come from matching each estate tax filing to the income tax filing for the year prior to death. ${ }^{11}$ We plot average rates of return across all SCF and estate years between 1998 and 2016.

The average return on fixed income for the bottom $90 \%$ is approximately zero and rises significantly within the top decile, from $2 \%$ for P90-99 to as high as $6 \%$ for P99.9-100. We superimpose the average Moody's Aaa rate, the 10-year U.S. Treasury rate, and the bank deposit rate from Drechsler, Savov and Schnabl (2017). Our capitalization factor for the top group corresponds to the Moody's Aaa rate and closely fits the observed returns in both data sets. The next group has somewhat lower returns, which are well approximated by the 10-year Treasury rate. The residual wealth, the vast majority of which is in the P90-99 group, is well approximated by the deposit rate. ${ }^{12}$

Figure $4 \mathrm{C}$ plots alternative interest rates over time and compares them to the equalreturns rate $\bar{r}_{f i x, t}$, and Figure $4 \mathrm{D}$ plots the corresponding capitalization factors over time. All interest rates reached a peak in the 1980s during the Volcker tightening and have been falling since then. The equal-returns rate fell from $8.8 \%$ to $0.81 \%$ in 2016 . Consistent with the equal-returns rate reflecting a mix of high-yield fixed income assets and low-yield deposits, the equal-returns yield is always considerably lower than the other yields. Notably, the capitalization factors show this gap is especially relevant in the low interest rate environment of the 2000s. The difference in factors rapidly rises as aggregate interest rates approach zero from 2000 through 2016. In contrast to an equal-returns factor of 124 in 2016, the Aaa and Treasury series imply factors of $\frac{1}{3.67 \%}=27$ and $\frac{1}{1.84 \%}=54$, respectively. When interest rates were further from zero in the 1990s, the equal-returns factor ranged from 18 to 30, whereas the more conservative Moody's Aaa factor ranged from 11 to 15.

Figures $4 \mathrm{C}$ and $4 \mathrm{D}$ also compare these interest rates and capitalization factors to those for the P99.9-100 SCF and estate tax rates, estimated using the approach in Figure 4B. In the years since 1989, these rates have hovered near the Aaa rate and exceeded the equal-returns

\footnotetext{
${ }^{10}$ We follow Bricker, Henriques and Hansen (2018) in defining taxable fixed income assets to include liquid assets, CDs, and all taxable bonds and savings bonds, as well as mutual funds comprised of taxable bonds. In addition, it includes a share of the value of mutual funds with a mix of stocks and bonds (combination mutual funds) and the portion of annuities and trusts not invested in equity.

${ }^{11}$ Saez and Zucman (2016) present a related analysis with earlier data in their Figure VB. In 2011, the aggregate interest rate is $1.2 \%$, whereas the interest rate for estates with greater than $\$ 20 \mathrm{M}$ is $1.9 \%$. Our series differ from theirs for two reasons. First, we use the distribution of taxable interest income flows to define groups. Second, we use inverse mortality weights to construct a distribution that represents the living population, as advocated but not implemented by Saez and Zucman (2016). We discuss our improved mortality weight data in Section 10.

${ }^{12}$ Appendix Figure A.5 shows that this correspondence holds in recent years, when low levels of interest rates amplify the sensitivity of estimates to assumed rates of return.
} 
rate in all years and the 10-year Treasury rate in almost all years. ${ }^{13}$ This fact supports using the Moody's Aaa rate to capitalize the flows of those with substantial interest income.

\section{Public Equity}

This section describes how we use each individual's flow of taxable dividends and realized capital gains to estimate C-corporation equity. As with fixed income assets, this component of wealth does not include stocks held indirectly through pensions or life insurance.

\subsection{Capitalizing Dividends and Capital Gains}

We begin with dividends $y_{i t}^{d i v}$ and realized capital gains $y_{i t}^{k g}$ for person $i$ in year $t$. We construct the composite flow using the convex combination: $\left(0.9 y_{i t}^{d i v}+0.1 y_{i t}^{k g}\right)$. For each individual, we estimate C-corporation equity wealth by scaling this composite flow by a common capitalization factor:

$$
\bar{\beta}_{t}^{c c o r p}=\frac{W_{t}^{c c o r p}}{\sum_{i}\left(0.9 y_{i t}^{d i v}+0.1 y_{i t}^{k g}\right)} .
$$

In 2016, aggregate dividend flows are $\$ 254 \mathrm{~B}$, aggregate realized capital gains are $\$ 614 \mathrm{~B}$, and directly held C-corporation equity from the Financial Accounts is $\$ 11.6 \mathrm{~T}$. Thus, the resulting capitalization factor is $\$ 11.6 T /(0.9 \times \$ 254 B+0.1 \times \$ 614 B)=40$.

To decompose C-corporation equity into public and private components, we estimate the average share of C-corporation profits and dividends accruing to public companies using the SOI corporate sample. Both shares average around $80 \%$ and appear stable over the period 1994 to 2016 (see Appendix Figure A.6). We apply this share to decompose estimated Ccorporation wealth into public and private components when comparing our estimates to those from other sources.

\subsection{Dividends are More Informative than Capital Gains for Esti- mating Stock Wealth}

Dividends and capital gains both provide information about C-corporation ownership. While dividends derive exclusively from C-corporation ownership, realized capital gains do not.

\footnotetext{
${ }^{13}$ During the post-crisis period, the Federal Reserve conducted significant intervention in the US Treasury market through Quantitative Easing, which likely depressed rates on Treasuries relative to what top fixed income portfolios would have experienced.
} 
Therefore, it is useful to consider the relative informativeness of capital gains versus dividends when estimating how much capital gains to use to infer C-corporation ownership.

As the IRS acknowledges in its instructions for reporting realized capital gains, the sale of capital assets comprises sales for a broad class of assets: "most property you own and use for personal purposes or investment is a capital asset. For example, your house, furniture, car, stocks, and bonds are capital assets" (Instructions for Form 1040, Schedule D, 2018, p.2). In their analysis of the composition of reported capital gains, the IRS SOI division lists 22 distinct categories.

Figure 5A presents the capital gains composition from the SOI Sale of Capital Assets study files for the years 1997 to 2012. While sale of corporate stock is one of the largest categories, it accounts for only $20 \%$ to $30 \%$ of total realized capital gains. The largest category of realized capital gains is pass-through gains or losses, which refers to distributed gains from pass-through entities owned by taxpayers, for which the IRS has not compiled additional information about the underlying transactions. ${ }^{14}$

While it is possible pass-through gains represent the sale of corporate stock as well, they likely also reflect sales in other categories and "carried interest" compensation to investment managers. The latter source of compensation is an important source of income for highwealth individuals working as general partners in hedge funds, venture capital, and private equity. Using a combination of information returns from the population of partnerships and SOI's Sale of Capital Assets study, we estimate that general partner distributed gains range from $15 \%$ to $35 \%$ of top $0.1 \%$ capital gains in recent years, or $\$ 50 \mathrm{~B}$ to $\$ 100 \mathrm{~B}$ per year between 2012 and 2016. ${ }^{15}$ This result supports putting less weight on capital gains in the capitalization formula, because carried interest does not map to current or future ownership of C-corporation stock. Carried interest can be thought of as reflecting deferred risky compensation treated as capital gains for tax purposes.

Figure 5B explores the flow-stock relationship for different combinations of dividends and capital gains in the SCF. An advantage of this approach is that we can directly see how

\footnotetext{
${ }^{14}$ See https://www.irs.gov/pub/irs-pdf/i1040sd.pdf for the Instructions for Form 1040, Schedule D, and https://www.irs.gov/pub/irs-soi/soi-a-inca-id1604.pdf for SOI's Sale of Capital Assets study for tax years 2007-2012. Smith, Yagan, Zidar and Zwick (2019) make a similar point in the context of allocating C-corporation retained earnings in their Online Appendix Section E.

${ }^{15}$ Appendix Figure A.7 presents evidence supporting our estimate. We combine the realized capital gains flows used in our capitalized income estimates with data from SOI's Sale of Capital Assets study and information returns from different population-level databases. Fund managers are identified via the General Partner checkbox on information returns. We first validate that SOCA capital gains closely track the SOI realized capital gains in our capitalized income estimates. We then show that the pass-through component of SOCA gains is large relative to SOI realized gains and the gains derived from different information return databases are comparable in magnitude and time series. General partners consistently receive $20 \%$ of all distributed gains and $60 \%$ of all distributed ordinary income, which strongly supports our approach to identifying active managers.
} 
informative alternative flows are for predicting stock wealth. Specifically, the blue bars show the ratio of different flows to stock wealth in the SCF. The red bars report these ratios while partitioning flow distributions into respective groups in an analogous way to Figure 4B.

The concavity of the flow-stock relationship is more severe for composite flows that place more weight on realized capital gains. Intuitively, realizations can be quite large relative to assets, which can result in an average implied yield of 35\% for the P99.9-100 group of realized gains compared to less than 5\% for the P90-99 group. Reducing the weight on realized gains to $50 \%$ results in a yield of $15 \%$ for P99.9-100 versus $3 \%$ for P90-99. Moving to a 10\% weight on realized gains further shrinks the spread.

Reducing the weight on realized capital gains to zero, however, may be problematic because some people only hold non-dividend-paying stocks. ${ }^{16}$ It is also not sufficient to use a heterogeneous returns approach for realized capital gains because there are many stockholders with zero realized gains, for whom we cannot define a correspondence between flows and underlying stocks. Figure 5C uses the SCF data to evaluate the fit for each convex combination of dividends and realized gains between 0 and 1 . A weight on dividends of approximately 0.9 minimizes the mean squared error for predicted stock holdings relative to actual stock holdings. ${ }^{17}$

Figure 5D plots the capitalization factors for different combinations of dividends and realized capital gains. Two features are worth noting. First, because aggregate realized capital gains are much larger than aggregate dividends, even applying equal $50 \%$ weights to both flows results in a capitalization factor that closely tracks the realized capital gains series. Second, our preferred capitalization factor closely tracks the stock market's fall during the 1970 s and rise in the 1990s because dividend flows are fairly stable (Figure 2B).

\footnotetext{
${ }^{16}$ Scholz (1992); Kawano (2014) test the dividend clientele hypothesis (Miller and Modigliani, 1961; Miller, 1977; Auerbach and King, 1983; Auerbach, 1983; Poterba, 2002) and provide evidence that high-income households reduce their exposure to dividend-yielding equities for tax reasons. This finding suggests that relying exclusively on dividend payments may not be optimal because it might underweight these high-income households.

${ }^{17}$ Appendix Figure A.8 uses panel data from the population of individual tax returns to compare the year-over-year persistence of realized capital gains to that for dividends, interest, wages, and adjusted gross income. For those in the top $1 \%$ of realized gains in year $t$, the average rank in year $t+1$ is the 75 th percentile. In contrast, dividends, interest, wages, and adjusted gross income are much more persistent over time, with the top $1 \%$ having average rank of 99th, 97th, 97th, and 96th percentile, respectively, in the next year. This fact helps explain why dividends are a better predictor than realized capital gains for stock holdings in the SCF.
} 


\section{$5 \quad$ Pass-Through Equity}

This section describes how we use each individual's owner-firm links to estimate pass-through equity wealth. This component of wealth includes equity wealth associated with formal passthroughs (i.e., S-corporations and partnerships) and informal pass-throughs (i.e., sole proprietorships). We use an industry-specific capitalization approach for formal pass-throughs because the relationship between profits and value varies widely across industry. We do not have industry data for sole proprietorships, so we use a simple capitalization approach for this category of wealth.

\subsection{Estimating Pass-through Equity using Firm Characteristics}

For sole proprietorships, we begin with positive taxable proprietors' income $y_{i t}^{\text {sole }}$ for person $i$ in year $t$. For each individual, we estimate proprietors' equity by scaling this flow by a common capitalization factor:

$$
\bar{\beta}_{t}^{\text {sole }}=\frac{W_{t}^{\text {sole }+ \text { part }}}{\sum_{i}\left(y_{i t}^{\text {sole }}+y_{i t}^{\text {part }}\right)},
$$

where $y_{i t}^{\text {part }}$ is positive partnership income for person $i$ in year $t$ and $W_{t}^{\text {sole }+ \text { part }}$ is the aggregate wealth of unincorporated business in the Financial Accounts.

In 2016, aggregate proprietor and partnership flows are $\$ 421 \mathrm{~B}$ and $\$ 320 \mathrm{~B}$, respectively, and aggregate unincorporated business wealth is $\$ 8.5 \mathrm{~T} .{ }^{18}$ Thus, the resulting capitalization factor is $\$ 8.5 T /(\$ 421 B+\$ 320 B)=11$. We use both proprietors' and partnership income to compute the capitalization factor because the Financial Accounts aggregate does not separate these types of businesses. Because we are only capitalizing proprietors' income using this factor, aggregate sole proprietorship wealth will be smaller than $W_{t}^{\text {sole+part }}$, equal to $57 \%$ of the Financial Accounts total (which includes both proprietorships and partnerships).

For each formal pass-through firm $j$ and owner $i$ in year $t$, we begin with sales $y_{i j t}^{\text {sale }}$, assets $y_{i j t}^{a s s e t}$, and modified EBITD $y_{i j t}^{\text {ebitd }}$, each apportioned to the owner based on his or her pro rata share of distributed profits or losses. ${ }^{19}$ Modified EBITD equals interest plus depreciation plus $25 \%$ of profits, which reflects the non-human-capital contribution of pass-through profits estimated in Smith, Yagan, Zidar and Zwick (2019). Our estimate of the owner's equity wealth across all firms is a liquidity-adjusted, equal-weighted average of capitalized pro rata

\footnotetext{
${ }^{18}$ Approximately $\$ 20 \mathrm{~B}$ of the proprietor flows are royalty flows and estate and trust flows earned from pass-through business.

${ }^{19}$ For firms with zero profits, we use a $1 / N$ weight to apportion firm characteristics across owners.
} 
sales, assets, and modified EBITD:

$$
\hat{W}_{i t}^{\text {pthru }}=0.9 \times \sum_{j(i)} 1 / 3\left(\beta_{t}^{s a l e, k(j)} \times y_{i j t}^{\text {sale }}+\beta_{t}^{\text {asset }, k(j)} \times y_{i j t}^{\text {asset }}+\beta_{t}^{e b i t d, k(j)} \times y_{i j t}^{\text {ebitd }}\right),
$$

where $j(i)$ indicates that person $i$ owns firm $j, k(j)$ denotes NAICS 4-digit industry $k$ for firm $j$ and $\beta_{t}^{X, k(j)}$ denotes the valuation multiple for factor $X \in\{$ sale, asset, ebitd $\}$ for industry $k(j)$. For example, $\beta_{t}^{s a l e, k(j)}$ is the valuation multiple for sales and $y_{i j t}^{\text {sale }}$ is sales at firm $j$ in industry $k(j)$ apportioned to owner $i$ in year $t$. We define industry-specific multiples for all NAICS 4-digit industries using data from Compustat:

$$
\beta_{t}^{X, k}=\frac{\sum_{j \in k} V_{j t}}{\sum_{j \in k} X_{j t}}
$$

where $V_{j t}$ is the market value of equity for firm $j$. Industries with insufficient data or outlier multiples are assigned the market aggregate multiple for that factor. ${ }^{20}$ We apply the factor 0.9 to the estimated values to reflect a $10 \%$ liquidity discount. ${ }^{21}$

To illustrate how this approach works, consider applying equation (5) to a typical topowned pass-through firm: auto dealers (NAICS 4411) in S-corporation form. In 2016, auto dealers (NAICS 4411) have $\$ 580 \mathrm{~B}, \$ 168 \mathrm{~B}$, and $\$ 6.15 \mathrm{~B}$ dollars of sales, assets, and modified EBITD, respectively, and the corresponding multiples are 0.3, 0.56, and 6.36. We then average the three values to estimate S-corporation business wealth in that industry and apply the $10 \%$ liquidity discount. In the case of auto dealers, this estimate amounts to $\$ 92 \mathrm{~B}$ in 2016. Note our method accounts for the relatively low profit margins in this industry (i.e., $\$ 6.15 B / \$ 580 B=1.1 \%$ ) by averaging the high sales-based valuation with the low modifiedEBITD-based valuation. This overall valuation implies a per-firm valuation of $\$ 3 \mathrm{M}$, in line with industry approaches to valuing auto dealerships. ${ }^{22}$

Unlike for fixed income and C-corporation equity, we depart from the simple capitalization approach in the case of pass-through equity. An alternative approach would be to derive and apply industry-specific capitalization factors for pass-through income. This alternative

\footnotetext{
${ }^{20}$ Equity values are defined as the price of common stock (PRCC_C) times the number of common shares outstanding (CSHO). We consider multiples based on assets (AT), sales (SALE), and EBITD (profits before $\operatorname{tax}+$ XINT + DP). Outlier multiples are below 0 or above 5 for assets and sales, and above 50 for profits before tax. In cases with negative apportioned EBITD, we set the implied EBITD-based value to zero. We do not adjust Compustat EBITD using the $25 \%$ correction of profits, because that estimate is not appropriate for public C-corporations.

${ }^{21}$ Our liquidity adjustment is the approximate median estimate using EBITDA multiples from data on 167 private acquisitions over 1984-2019 recorded in SDC. Our methodology for computing discounts follows Koeplin, Sarin and Shapiro (2000). Appendix I describes this calculation in more detail.

${ }^{22}$ See https : / www . forbes . com/2009/06/30/auto-dealership-valuation-entrepreneurs-finance-taulli . html for an example analysis and discussion by an industry practitioner.
} 
would only use a profits multiple, in which $\beta_{t}^{\text {profits }, k(j)}$ is the valuation multiple for industry $k$. However, certain industries have techniques that reduce profits relative to the value of the firm, for example, due to interest and depreciation deductions in the real estate sector. Our approach incorporates assets and sales to make valuations more accurate for these industries. We apply this method to estimate S-corporation and partnership wealth and follow the simpler approach for valuing proprietors, as we do not have industry information for these firms. Proprietors income accounts for a small share of pass-through income at the top. A sound valuation model is a necessary ingredient for the process of taxing business wealth, whether via an estate or wealth tax. Thus, this challenge is not only relevant for our measurement purposes, but also for implementing tax policy.

\subsection{Aggregate Private Business Wealth}

Our bottom-up approach does not require that aggregate private business wealth equal Financial Accounts totals, which may understate the value of private business wealth due to data limitations. ${ }^{23}$ Our approach is useful for three reasons. First, SCF total private business wealth considerably exceeds the Financial Accounts totals. Second, within the $\mathrm{SCF}$, private business is the largest category of wealth at the top, whereas an equal-returns profits-based approach suggests a smaller contribution. Third, pass-through business income features prominently for top incomes, yet pass-through business wealth in the equal-returns approach only modestly contributes to top wealth.

Consider the aggregate private business valuation implied by applying this methodology to S-corporations, partnerships, and private C-corporations. Figure $6 \mathrm{~A}$ plots these aggregates as a share of national income by year and compares them to analogous measures from the U.S. Financial Accounts and from the SCF. We plot a long time series from 1989 through 2016 that applies the model average method to S-corporation and partnership equity after 2001, the first year in which our linked firm-owner data are available. Prior to 2001, we use the sole proprietorship capitalization factor to estimate partnership wealth and an analogous approach for S-corporation income.

The Financial Accounts-based measure de-emphasizes private business wealth relative to our approach and the SCF-based measure. Our aggregates fall in between the Financial

\footnotetext{
${ }^{23}$ Based on conversations with economists who produce the Financial Accounts, closely-held business is likely understated in the accounts for several reasons. First, closely held C-corporations with less than \$1-2B in revenues are not included because of data limitations. Second, S-corporation equity is estimated using ratios of market value of equity to book value of assets at the 2-digit sector level, which may understate firm value in the asset-light service sector firms that predominate among S-corporations. Third, non-corporate business equity is estimated using a mix of market values for real estate and fixed income assets and book values for other assets, which may understate the value of these firms. Fourth, financial partnerships are not currently included in the accounts, which are among the largest 4-digit industries in our data.
} 
Accounts and SCF series in recent years and track the time series reasonably well. We also plot a version of our private business estimate without our liquidity and human-capital adjustments. In this series, private business aggregates come closer to but still do not reach the level reported in SCF.

\subsection{Unequal Returns across Industry}

To compute industry-level returns, we divide aggregate industry profits before tax by our estimate of industry-specific wealth. ${ }^{24}$ Figure $6 \mathrm{~B}$ plots these returns for the thirty largest industries in aggregate S-corporation wealth and compares them to the aggregate S-corporation return. High return industries tend to be the industries in which we think the primary input is human capital, broadly defined, rather than non-human capital, including architects, engineers, lawyers, and doctors (Smith, Yagan, Zidar and Zwick, 2019). This fact implies that these industries will have lower valuations compared to an equal-returns approach. Conversely, pass-through owners with significant capital (e.g., real estate) should be capitalized more because of low relative returns. Our industry-specific approach affects wealth concentration and tilts the composition away from low-capital to high-capital firms. ${ }^{25}$

Quantitatively, the figure shows substantial dispersion in implied returns across industries. The aggregate return is $10.5 \%$, implying an equal-returns capitalization factor of 9.5. The low returns for real estate $(0.4 \%)$ and high returns for lawyers (34.1\%) respectively imply capitalization factors of 277 and 3. Thus, industries with returns far from the aggregate return will correspond to wealth estimates that can be understated or overstated by an order of magnitude. Recall that our approach for valuing these firms does not use these implied capitalization factors directly, so our estimates are not vulnerable to bias from implied rates of return close to zero.

To provide more texture on which industries contribute to top pass-through wealth, Appendix Table B.1 presents characteristics of top-0.1\%-owned pass-through equity for the largest thirty 4-digit industries. The largest five industries are other professional and technical services $(5419, \$ 393 \mathrm{~B})$, restaurants $(7225, \$ 367 \mathrm{~B})$, activities related to real estate (5313, $\$ 336 \mathrm{~B})$, other financial investment activity $(5239, \$ 256 \mathrm{~B})$, and other investment pools or funds (5259, \$209B). More capital-intensive industries in real estate, finance, and oil and

\footnotetext{
${ }^{24}$ We focus on S-corporations in this returns analysis because they are more comparable than partnerships to traditional corporations. For example, C-corporations and S-corporations have similar accounting for compensation of active owners. This comparability makes it easier to build intuition about implied rates of return, especially for closely held firms.

${ }^{25}$ Smith, Yagan, Zidar and Zwick (2019) document heterogeneous returns within industry as well. Our interpretation of this fact is that these excess returns within industry may reflect labor characterized as profits for tax reasons, which should not to be capitalized into wealth estimates.
} 
gas have high value per firm and are worth less than $\$ 1 \mathrm{M}$ per owner. In contrast, less capital-intensive industries such as law firms and consultancies are worth $\$ 3-8 \mathrm{M}$ per owner on average but are smaller and more numerous.

\section{Pensions}

This section describes how we use each individual's flow of wages and pension income to estimate pension wealth. This component of wealth includes both defined contribution pensions and defined benefit pension entitlements, including an estimate of the value of unfunded defined benefit entitlements from Sabelhaus and Henriques Volz (2019).

\subsection{Capitalizing Wages and Pension Income}

We begin with wages $y_{i t}^{\text {wage }}$ and pension income $y_{i t}^{\text {pen }}$ for person $i$ in year $t$. Wages are more informative for pension wealth for younger workers who have not yet begun to draw pension payments. Pension income is more informative for older workers who have already begun to draw pension payments and for retirees.

For each flow, we apply an age-group-specific capitalization factor:

$$
\beta_{t}^{\text {penw,wage }, a}=\frac{\sum_{i \in a} \gamma_{a} \bar{W}_{i t}^{p e n}}{\sum_{i \in a} y_{i t}^{\text {wage }}} \quad \beta_{t}^{\text {penw,pen }, a}=\frac{\sum_{i \in a} \gamma_{a} \bar{W}_{i t}^{p e n}}{\sum_{i \in a} y_{i t}^{p e n}},
$$

where age group $a$ is either "peak age" (i.e., aged 45 to 75 ) or not and $\gamma_{a}$ is the ratio of pension wealth per capita within an age group to aggregate pension wealth per capita. ${ }^{26}$ Our pension wealth estimate is an age-group-specific convex combination of capitalized wages and capitalized pension income:

$$
\hat{W}_{i t}^{\text {penw }}=\theta^{\text {penw }, a}\left(\beta_{t}^{\text {penw }, \text { wage }, a} \times y_{i t}^{\text {wage }}\right)+\left(1-\theta^{\text {penw }, a}\right)\left(\beta_{t}^{\text {penw,pen }, a} \times\left(y_{i t}^{\text {pen }}\right)\right),
$$

where $\theta^{\text {penw,a }}$ is the weight on capitalized wages and $\left(1-\theta^{\text {penw,a }}\right)$ is the weight on capitalized pension income for age group $a$. For peak-age individuals, $\theta^{\text {penw }}$ is 0.58 ; for non-peak-age individuals, $\theta^{\text {penw }}$ is $0.71 .^{27}$

\footnotetext{
${ }^{26}$ We construct $\gamma_{a}$ using the mean $\gamma_{a t}$ in the SCF from 1989 to 2016 . This ratio is fairly stable over time. Our measure of pension wealth is the defined-benefit-augmented SCF from Sabelhaus and Henriques Volz (2019). We find that $\gamma_{a}$ is 1.37 for the peak-age group and 0.53 for the non-peak-age group, indicating that peak-age and non-peak-age individuals have $37 \%$ more and half as much pension wealth relative to the overall population, respectively.

${ }^{27}$ We obtain these weights by estimating regressions of pension wealth in the SCF on capitalized wages and capitalized pensions and setting the weight equal to the coefficient on capitalized wages divided by the sum of coefficients. The ratio of coefficients is fairly stable over time when we estimate the regression separately
} 
In 2016, this approach results in the following formula for estimated pension wealth using the defined-benefit-augmented SCF:

$$
\hat{W}_{i, 2016}^{\text {pen }, S Z Z}=\left\{\begin{array}{ll}
.58\left(4.9 \times y_{i, 2014}^{\text {wage }}\right)+(1-.58)\left(62.9 \times\left(y_{i, 2016}^{\text {pen }}\right)\right) & \text { if } 45<\text { age }<75 \\
.71\left(2.3 \times y_{i, 2014}^{\text {wage }}\right)+(1-.71)\left(12.9 \times\left(y_{i, 2016}^{\text {pen }}\right)\right) & \text { otherwise }
\end{array} .\right.
$$

The formula shows that peak-age individuals have substantially higher capitalization factors for both flows and a modestly higher weight on capitalized pension income. The higher capitalization factors reflect the feature that a dollar of flows corresponds to more pension wealth for peak-age people, who have accumulated significant savings and not yet decumulated.

\subsection{Evidence on the Life Cycle of Pension Holdings}

Figure 7A uses the SCF to plot average wages, pension income, and pension wealth in 2016 dollars, averaging across cohorts from 1989 to 2016. Wage income grows over the life cycle and then declines starting around age 55 to near zero by age 75 . In contrast, pension income is nearly zero until age 60 . Pension wealth has an inverse- $U$ shape that reflects the accumulation and decumulation of savings.

These life cycle dynamics result in flow-to-stock ratios that vary by age. Figure 7B summarizes this heterogeneity by plotting the ratio of wage and pension income to total pension wealth, respectively. The blue bars depict the population average and the red bars show the ratios for three age groups: below 45, age 45 to 75 , and above 75 . Wage income of adults younger than 45 amounts to $84 \%$ of their pension wealth on average, whereas average wages for those above age 75 are only $3 \%$ of their pension wealth. The patterns for pension income are reversed. The ratios for peak-aged individuals are closer to the population average in blue.

Overall, the heterogeneity in pension wealth and flow-to-stock ratios across age groups means that an age-group-invariant approach will induce bias. Our approach parsimoniously accounts for this heterogeneity by allowing capitalization factors and the relative importance of wage versus pension income to vary by age group.

\section{Housing}

This section describes how we use each individual's flow of property tax and mortgage interest deductions to estimate housing wealth. This component of wealth does not include rental each year. 
real estate. ${ }^{28}$

\subsection{Capitalization with Unequal Property Tax Rates}

We separately estimate owner-occupied housing assets and mortgage liabilities. For assets, we begin with property tax deductions $y_{i t}^{\text {ptax }}$ for itemizer $i$ in year $t$. We estimate housing assets by scaling $y_{i t}^{\text {ptax }}$ by a location-year-specific capitalization factor $\beta_{s t}^{\text {ptax }}$, which is the ratio of housing values to property tax payments in state $s$ in year $t$. To derive capitalization factors for each state over time, we combine state-level data from four sources: (1) effective property tax rate data from ATTOM, (2) property tax assessor data from 2012 from DataQuick, (3) CoreLogic state-level house price indexes, and (4) state-level property tax revenues and population from the US Census of States. Appendix C describes our approach to estimating these capitalization factors.

For mortgage debt, we begin with mortgage interest deductions $y_{i t}^{\text {mid }}$ for itemizer $i$ in year $t$. We then apply an equal-returns capitalization factor to estimate mortgage debt. For non-itemizers, we assign average housing asset and mortgage values from the SCF for demographic groups $g$ (i.e., income decile $\times$ married $\times$ old). Net housing wealth is given by assets less liabilities, each defined as:

$$
\hat{A}_{i t}^{\text {hou }}=\left\{\begin{array}{ll}
\beta_{s t}^{\text {ptax }} y_{i t}^{\text {ptax }} & \text { if itemizer } \\
\bar{A}_{g t}^{\text {hou }, S C F} & \text { otherwise, } i \in g
\end{array} \quad \hat{D}_{i t}^{\text {hou }}= \begin{cases}\bar{\beta}_{t}^{\text {mid }} y_{i t}^{\text {mid }} & \text { if itemizer } \\
\bar{D}_{g t}^{\text {hou }, S C F} & \text { otherwise, } i \in g\end{cases}\right.
$$

where $\bar{\beta}_{t}^{\text {mid }}=\left(\sum_{i} D_{i t}^{\text {hou }}\right) /\left(\sum_{i} y_{i t}^{\text {mid }} / 0.8\right)$ is the capitalization factor for itemizers, whose mortgage interest deductions are assumed to account to $80 \%$ of aggregate mortgages. ${ }^{29}$

\subsection{Evidence on Unequal Property Tax Rates}

Figure 8A plots a map of average state-level effective property tax rates collected from deeds data and computed by ATTOM. Property tax rates vary across the United States, from below $0.5 \%$ in the Southwest and Deep South to more than $2 \%$ in the Midwest and some states in the Northeast.

\footnotetext{
${ }^{28}$ Most rental housing is likely included in private business wealth. We estimate informal rental housing wealth by capitalizing rental income payments under equal-returns following Saez and Zucman (2016).

${ }^{29}$ Our approach for housing follows Saez and Zucman (2016) except for the estimation of state-year-specific capitalization factors. In years prior to 1980, we follow Saez and Zucman (2016) for housing assets as well because state-level house price indices are not available. In those years, we use a capitalization factor for the property tax deductions for itemizers of $\bar{\beta}_{t}^{\text {hou }}=\frac{\sum_{i} A_{i t}^{\text {hou }}}{\sum_{i} y_{i t}^{\text {ptax }} / 0.75}$, whose property taxes are assumed to account for $75 \%$ of aggregate property tax payments.
} 
Figure 8B plots the capitalization factor implied by dividing aggregate housing assets by aggregate property tax payments. The factor varies between 90 and 120 over time but hovers around 100 from 1977 to 2016. Recall that a factor of 100 implies an average property tax rate of approximately 1\%. Because property tax rates are low, small departures from the national average can lead to large bias in wealth estimates across states. Given the variation in actual rates between $0.4 \%$ and $2.3 \%$, the equal-rates assumption for allocating housing assets assigns more than twice the amount to high-tax states and less than half to low-tax states. This issue is analogous to the bias for fixed income wealth estimated under an equal-returns assumption during low-interest-rate periods.

Figure $8 \mathrm{~B}$ shows the effect of our unequal property tax rate estimates by comparing the implied California capitalization factor over time to the equal-rate benchmark. Three facts stand out. First, the factor we apply to property tax deductions in California in 2016 doubles relative to the equal rate benchmark, implying that California owns significantly more real estate under the unequal rate assumption. Second, our estimate reveals the amplified exposure of California to the housing boom and bust in the mid-2000s, as the California factor rises and falls much more dramatically than the national factor. Third, the 1978 passage of Proposition 13, which capped future property tax increases, causes a sharp and immediate increase in the California factor. This increase reflects house prices immediately capitalizing the value of reduced future property taxes.

\section{Adding It Up: New Top Wealth Estimates}

\subsection{The Level and Composition of Top Wealth}

Panels A and B in Table 1 show the number of individuals in each wealth group and the wealth thresholds defining each group. We then report average wealth and the share of total wealth for these groups when altering the assumptions to apply the equal-returns approach of Saez and Zucman (2016) and Piketty, Saez and Zucman (2018) for the same group of people. ${ }^{30}$ Panels $\mathrm{C}$ and D repeat this exercise using ranks based on the equal-returns approach.

Panel A focuses on top wealth groups. The full population includes 239 million individuals whose average wealth is $\$ 317 \mathrm{~K}$ in 2016 . The top $1 \%$ includes 2.4 million individuals with wealth of at least $\$ 3.1 \mathrm{M}$ and average wealth equal to 30 times average wealth in the full population. In terms of shares, this group's share of total wealth is $29.6 \%$ under our preferred approach, compared to $34.5 \%$ under equal returns. Similarly, for the top $0.1 \%$,

\footnotetext{
${ }^{30}$ Section 10.1 discusses differences between our preferred approach and the equal-returns approach in more detail and component-by-component.
} 
who have wealth exceeding $\$ 14 \mathrm{M}$, our estimates reduce their share from $18.5 \%$ under equal returns to $14.3 \%$ in our preferred specification. Thus, the combined effect of accounting for heterogeneity, adjusting the private business aggregates, and including unfunded pension wealth materially affects the estimated concentration of top wealth. These adjustments are increasingly important within the very top group, as the top $1 \%$ share falls by $14 \%(4.9 / 34.5)$, the top $0.1 \%$ share falls by $23 \%(4.2 / 18.5)$, and the top $0.01 \%$ share falls by $29 \%(2.8 / 9.6)$.

Panel B focuses on intermediate wealth groups. A key result is that the group within the top decile but below the top $1 \%$ receives $50 \%(2.3 / 4.9)$ of the reallocated wealth. This "P90-99" class, a group with more than $\$ 660 \mathrm{~K}$ but less than $\$ 3.1 \mathrm{M}$ in preferred wealth, hold $36.0 \%$ of total wealth, more than either the bottom $90 \%$ or the top $1 \%$.

Panels $\mathrm{C}$ and D show how these statistics change when using equal-return ranks to define top groups. For example, the top $1 \%$ and top $0.1 \%$ shares are $38.1 \%$ and $20.2 \%$ under equal returns, respectively, and only $26.8 \%$ and $12.8 \%$ using our preferred approach for these groups. Hence, allowing for reranking narrows the gap between estimated top shares under alternative specifications and helps clarify the roles of assumptions versus reranking. For example, the difference between our preferred approach and the equal-returns approach for the top $0.1 \%$ is $14.3 \%$ versus $20.2 \%$. Different assumptions account for 4.2 percentage points (71\%) of this gap, with the remainder due to reranking.

Panels A and B in Table 2 show the wealth composition in 2016 for each wealth group under our preferred approach. Private business, public equity, and fixed income account for $36 \%, 33 \%$, and $19 \%$ of top $0.1 \%$ wealth, respectively, with the remainder in housing and pensions. At the very top, public equity is the largest component, accounting for $41 \%$ of top $0.01 \%$ wealth, but private business looms large at 36\%. In contrast, the wealth composition for the bottom $90 \%$ is $69 \%$ pensions and $24 \%$ in housing. The portfolios of the P90-99 are more balanced, with approximately equal shares from fixed income, public plus private equity, housing, and pensions.

\subsection{The Growth of Top Wealth}

Figure 1 plots our preferred estimates for the top $0.1 \%$ from 1966 to $2016 .{ }^{31}$ Top wealth falls from $10 \%$ in the late 1960 s to a low of $6.6 \%$ in 1978 , then steadily rises to around $15 \%$ in recent years. Relative to the equal-return series, our preferred series not only shows a lower level in recent years but much less growth since 1980. The equal-return top $0.1 \%$ series grew from $7.0 \%$ in 1978 to $20.2 \%$ in 2016 ; our preferred series grew by about half as much from $6.6 \%$ to $14.3 \%$.

\footnotetext{
${ }^{31}$ As noted above, due to data availability, the series accounts for heterogeneous returns in housing and pensions starting in 1980 and in private business starting in 2001.
} 
Figure 10A plots top 1\%, P90-99, and P0-90 wealth shares over this time period under both our preferred and the equal-return approaches. The difference in growth between the equal-return and preferred approaches is similar for the top $1 \%$ and the top $0.1 \%$, with the growth of the top 1\% share from 1978 to 2016 falling from 16.1 to 8.5 percentage points. Appendix Figure A.4 decomposes the 1978-2016 and 2000-2016 growth in concentration by asset class for the top $0.1 \%$ and top $1 \%$. For both periods, fixed income accounts for a small share of the growth, whereas private business is more important. Overall, wealth in our preferred series is still concentrated: the top $1 \%$ holds nearly as much wealth as the bottom 90\%. However, the "P90-99" class holds more wealth than either group.

\subsection{The Geography of Wealth Inequality}

Income and opportunity vary substantially across regions (Chetty, Hendren, Kline and Saez, 2014; Kline and Moretti, 2014; Chetty and Hendren, 2018a,b). Yet we know relatively little about regional disparities in wealth, despite its potential importance in enabling intergenerational mobility. These considerations also matter for policies that seek to address regional disparities in well-being.

Figure 9A plots the change in wealth-to-GDP ratios from 1980 to 2016 for each state. The coastal states have experienced substantial wealth growth, with wealth-to-GDP ratios increasing by between $100 \%$ and $300 \%$ of GDP, while inland states have seen much more modest growth. Figure 9B shows this disparity in per capita terms (in 2016 dollars) by comparing wealth per capita in 1980 to the change in wealth per capita from 1980 to 2016. For example, Wisconsin had $\$ 150 \mathrm{~K}$ in wealth per capita in 1980 and experienced an increase of $\$ 164 \mathrm{~K}$ over the subsequent period. In contrast, coastal states like Washington and Massachusetts that had the same per capita wealth in 1980 have seen more than twice as much growth over the same period. Wealth per capita in Massachusetts is nearly $\$ 500 \mathrm{~K}$, whereas Mississippi and West Virginia have approximately \$200K. Thus, the period of aggregate wealth growth in the United States has coincided with striking regional divergence. ${ }^{32}$

These new state-level statistics can provide a key input for policy analysis and other exercises such as growth accounting, which decomposes output into contributions from capital accumulation, labor, and productivity growth. Further decomposing changes in measured capital accumulation into savings versus asset price growth can shed light on the importance of capital flows and the causes and consequences of wealth disparities. Moreover, the extent to which differences across region in wealth growth are driven by asset prices versus savings matters for interpreting wealth differences as reflecting differences in current and future

\footnotetext{
${ }^{32}$ Appendix Figure A.10 shows that wealth composition also varies considerably across states. For example, pension wealth plays a much larger role in West Virginia than in richer states.
} 
consumption and the consequences for welfare.

\section{Implications for Income Inequality and Top Taxation}

\subsection{Top Capital Income and Income Inequality}

Our top wealth estimates have important implications for understanding the evolution of top incomes. Recent work attempts to impute income not observed on tax returns in proportion to wealth estimates. Piketty, Saez and Zucman (2018) use the wealth estimates from Saez and Zucman (2016) to allocate components of national income not observed on tax returns, such as fixed income earned in non-taxable accounts, the retained earnings of C-corporations, the accumulated returns to assets held in pension accounts, and taxes whose statutory incidence does not fall on individual owners. Auten and Splinter (2017) use observed income flows and other survey data to perform the same exercise as Piketty, Saez and Zucman (2018), but arrive at somewhat different conclusions about the rise of top incomes, reflecting in part the uncertainy inherent in these calculations.

In Figure 11, we use our wealth estimates and follow the methodology of Piketty, Saez and Zucman (2018) to impute national income and estimate "Distributional National Accounts" from 1980 to 2014. For each capital income component in national income, we allocate that income in proportion to estimated wealth corresponding to that component. For example, interest income in the national accounts is allocated in proportion to estimated fixed income wealth. Similar allocations are made for unobserved labor income components, such as health benefits, as well as taxes. Because this methodology effectively imputes national income based on the observed distribution of fiscal income, we refer to it as Imputed National Income (INI).

INI can be decomposed into labor and capital components. Capital income includes all relevant categories in national income, including income from equity and debt assets, owner-imputed housing rents, corporate and property taxes, and the capital component of pension income and pass-through business income. We follow Smith, Yagan, Zidar and Zwick (2019) in allocating 25\% of pass-through business income, including S-corporation profits and proprietors-and-partnership income, to capital and the remainder to labor.

Top Fixed Income. Figure 11A shows estimates for top 1\% INI in the form of interest income using our preferred estimates versus the equal-return approach. ${ }^{33}$ We also plot the

\footnotetext{
${ }^{33}$ Appendix Figure A.11 presents plots as in Figure 11 for the top $0.1 \%$. The results are similar and show an even larger reallocation of top $0.1 \%$ INI from capital to labor.
} 
underlying taxable fixed income flows for each group. In 2014, our approach results in $\$ 223 \mathrm{~B}$ ( $1.5 \%$ of NI) less fixed income accruing to the top $1 \%$ relative to the equal-return series. As a share of national income, top- $1 \%$ fixed income has been trending up over time in the equalreturn series, whereas it has been flat in our preferred series. Moreover, our preferred series more closely tracks the aggregate fixed income wealth and flow series in recent years (Figure 2). As in our wealth analysis, changing the approach for estimating INI will cause the ranks to differ across approaches, i.e., the top $1 \%$ in our series are not the same individuals as the top $1 \%$ in the equal-return series. Nonetheless, fiscal interest series are very similar across ranks, which implies that reranking plays a minor role.

Top Capital Income and Income Shares. Figure 11B plots capital income for the top $1 \%$ as a share of total national income under alternative approaches. In our preferred series, top capital income rises modestly as a share of national income from $4.9 \%$ in 1980 to $7.3 \%$ in 2014. In contrast, the equal-returns series shows a dramatic increase in top capital income, which nearly doubles as a share of national income over this period. Figure 11C shows the effect of combining these series with top $1 \%$ labor income on the evolution of top income shares. Our preferred series shows a lower level of top income but the trends are very similar - overall top income shares have been growing steadily since 1980. Consequently, the rise in top incomes in our series appears to be driven more by rising labor income than capital income. ${ }^{34}$

Figure 12 illustrates this point. From 1980 to 2014, the rise in the top 1\% share due to capital income is only 2.4 out of 8.1 percentage points in total growth. For the top $0.1 \%$, capital's contribution was 1.9 out of 5.2 percentage points of total growth. In contrast, the contributions from capital under the equal returns approach is 5 percentage points of 9 percentage points of total growth for the top 1 and 3.7 out of 5.7 for the top $0.1 \%$.

Top Capital Share. Figure 11D plots the top $1 \%$ capital income share over time. In 2014, $41 \%$ of top-1\% income in our preferred series comes from capital. This estimate contrasts with the equal-returns series' top-1\% capital share of $56 \%$. Approximately half of this adjustment comes from differences in wealth estimates and the remainder from the Smith, Yagan, Zidar and Zwick (2019) allocation of pass-through income to labor. In the equal-return series, the top-1\% capital share bounced back 10 percentage points from a low

\footnotetext{
${ }^{34}$ Appendix Figure A.12 compares the time series for income shares of the top 1\% to the P90-99 and P0-90 groups ranked in terms of INI. The top $1 \%$ has seen the largest growth. Growth among the P90-99 group was about half as large. In contrast, the P0-90 group has seen a decline in its income share. Note that comparisons of top income shares over long time periods are statements about distributions, not individuals, because individuals switch groups over time (Auten, Gee and Turner, 2013; Kopczuk, Saez and Song, 2010).
} 
in 2000 to recover its early 1980s level. In our preferred series, the top $1 \%$ capital share remains well below its 1980s level. Thus, the gap between the equal-return series and our preferred series is larger in recent years, reflecting the low interest rate environment and the rise of pass-through income at the top.

Appendix Table B.4 decomposes top income into labor income, C-corporation income, fixed income, and other capital income for different income groups in our preferred series and the equal-return series. In our preferred series, top fixed income is approximately $6 \%$ of total top income, compared to $5 \%$ for the population. In the equal-returns series, the top fixed income share rises dramatically within the top decile, from 4\% for P90-99 to 9\% for P9999.9 to $14 \%$ for P99.9-99.99 to $22 \%$ for the top $0.01 \%$. Thus, accounting for heterogeneity in estimating top fixed income wealth also materially reduces the share of top incomes coming from capital and especially fixed income.

Income Tax Implications. Our estimates have several implications for top income taxation. First, they serve as inputs into measurement of broad effective tax rates, which include not only income tax, but also corporate tax, sales tax, and property tax allocations that are not directly observable using income tax data. Piketty, Saez and Zucman (2018) and Saez and Zucman (2019d) estimate effective tax rates as a function of INI. The denominator of the effective tax rate is smaller using our estimates of top income. The numerator is also somewhat larger because the distribution of top incomes shifts towards labor income, which faces a higher effective tax rate. Together, our estimates imply somewhat greater tax progressivity in recent years than in Saez and Zucman (2019d). Nevertheless, as the tax burden on capital and top labor income has fallen over the past twenty years, tax progressivity at the top of the income distribution has declined substantially.

Our approach can also help inform the mechanical revenue consequences of various proposals that target top incomes. First, they inform proposals that seek to harmonize labor and capital taxes by providing an estimate of the capital tax base. Second, our results help clarify questions about the burden of corporate and non-corporate business tax. As Auerbach (2006) highlights, little is known about who bears the corporate tax and it is hard to follow the money, given the many layers of indirect ownership. Our estimates provide some information about the distribution of corporate tax incidence for equity held directly by households. For equity held indirectly through pensions, our estimates serve as a reminder that the burden can fall in part on workers with defined contribution pension accounts and by the residual claimants (e.g., state and local governments) on defined benefit plans. Last, the importance of private business at the top, especially pass-through business, suggests the personal income tax can play a large role in taxing top incomes, depending on the relative 
attractiveness of realizing income in pass-through form.

\subsection{Wealth Taxation}

This section analyzes three wealth tax proposals: a $1 \%$ tax on the wealth of the top $0.1 \%$, an ultra-millionaire tax that taxes wealth above $\$ 50 \mathrm{M}$ at $2 \%$ and adds an additional $1 \%$ surcharge on wealth above $\$ 1 \mathrm{~B}$, and a sharply progressive wealth tax. We stress that the following mechanical tax revenue calculations do not include behavioral responses and should not be construed as a true revenue estimates.

Wealth Tax on the Top $\mathbf{0 . 1 \%}$ The tax base for a wealth tax on the top $0.1 \%$ is the product of total wealth and the top wealth share. Under our preferred estimates, the tax base for the top $0.1 \%$ of individuals in 2016 is $\$ 11.2 \mathrm{~T}(\approx \$ 75 T \times 0.143)$, so the mechanical tax revenue from a $1 \%$ tax on all wealth would amount to $\$ 112 \mathrm{~B}$ per year. If the tax restricted the base to marketable securities (i.e., fixed income assets and C-corporation equity wealth), which amounts to $\$ 6.2 \mathrm{~T}$ for the top $0.1 \%$, then the mechanical tax revenue would be $\$ 62 \mathrm{~B}$ per year.

Ultra-Millionaire Wealth Tax Saez and Zucman (2019b,c) score an ultra-millionaire wealth tax on those with more than $\$ 50 \mathrm{M}$ in wealth and a billionaire surtax. The mechanical tax revenue depends on which assumptions are used for capitalization. Under the equalreturns assumption in 2016, there are 69,430 tax units with more than $\$ 50 \mathrm{M}$ in wealth and 1,250 billionaires. ${ }^{35}$ Collectively, under equal returns, $\$ 50+$ millionaires have $\$ 12.6 \mathrm{~T}$ of wealth, of which $\$ 3.7 \mathrm{~T}$ is owned by billionaires. The annual mechanical tax revenue is thus:

$$
.02 \times(\$ 12.6 T-69430 \times \$ 50 M)+.01 \times(\$ 3.7 T-1250 \times \$ 1 B)=\$ 207 B .
$$

Using alternative assumptions affects both the number of billionaires and $\$ 50+$ millionaires, as well as their collective wealth. Using our preferred wealth estimates, there are 51,500

\footnotetext{
${ }^{35}$ These equal-returns estimates align closely with comparable estimates reported by Saez and Zucman. For example, in a September 22, 2019 memo on wealth tax plans https://eml.berkeley.edu/ saez/ saez-zucman-wealthtax-sanders-online.pdf, the table entitled "Basic Statistics on the Sanders and Warren Wealth Tax Plans" reports 70,187 tax units with more than $\$ 50 \mathrm{M}$ in wealth, 982 of which are billionaires. Total wealth of those with at least $\$ 50 \mathrm{M}$ is $\$ 12.4 \mathrm{~T}, \$ 3.1 \mathrm{~T}$ of which is held by billionaires. These numbers are based on 2016 figures, which are aged to 2019 by multiplying by 1.17 , and then discounted by $16 \%$ to account for evasion, so they are quite comparable to our raw 2016 estimates since the adjustments for 2019 aging and for tax evasion discounting roughly offset each other (i.e., $1 \times 1.17 \times(1-.16)=.983)$. In addition, footnote 4 of Saez and Zucman (2019b) highlights that the initial score Saez and Zucman (2019c) (https: //eml.berkeley.edu/ saez/saez-zucman-wealthtax-warren-online.pdf) reported slightly higher estimates of 75,000 households and $\$ 210 \mathrm{~B}$ in revenue.
} 
$\$ 50+$ millionaires and 640 billionaires and their wealth amounts to $\$ 7.9 \mathrm{~T}$, of which $\$ 1.7 \mathrm{~T}$ is owned by billionaires. The annual mechanical tax revenue under these assumptions from the ultra-millionaire wealth tax is:

$$
.02 \times(\$ 7.9 T-51500 \times \$ 50 M)+.01 \times(\$ 1.7 T-640 \times \$ 1 B)=\$ 117 B .
$$

A related proposal added a higher surtax on billionaires (changing the $1 \%$ surtax to a $4 \%$ surtax); the corresponding estimates of total revenue under equal returns and our preferred estimates are $\$ 281 \mathrm{~B}$ and $\$ 149 \mathrm{~B}$, respectively.

Implementing an ultra-millionaire tax using the capitalization method would effectively introduce additional category-specific income taxes on capital income. For example, consider someone whose capitalized income amounts to $\$ 60 \mathrm{M}$ of wealth. If she earned $\$ 1$ more of fixed income, her wealth would increase by $\$ 124$ under the equal-returns assumption since the capitalization factor in 2016 is 124 . The $2 \%$ tax would amount to $\$ 2.48$, which is a $248 \%$ marginal tax rate on fixed income for ultra-millionaires (and a 372\% tax rate for billionaires) under the equal-returns assumptions. This marginal rate would be in addition to the existing income tax schedule, so the all-in marginal tax rate would be even higher.

Under heterogeneous returns, these effective marginal tax rates would be lower. Recall that the Aaa capitalization factor in 2016 was 27. Therefore, this person's marginal tax rate on a dollar of fixed income would be $52 \%$ (not including the existing marginal income tax rate). ${ }^{36}$ Furthermore, because higher yield categories such as public and private equity are more important in our series than fixed income wealth, the effective marginal tax rates on capital income from a $2 \%$ tax would be lower than implied by the equal-returns asset composition.

A Sharply Progressive Wealth Tax Saez and Zucman (2019b) also score a wealth tax with a graduated schedule starting at $1 \%$ above $\$ 32 \mathrm{M}, 2 \%$ above $\$ 50 \mathrm{M}, 3 \%$ above $\$ 250 \mathrm{M}$, $4 \%$ above $\$ 500 \mathrm{M}, 5 \%$ above $\$ 1 \mathrm{~B}, 6 \%$ above $\$ 2.5 \mathrm{~B}, 7 \%$ above $\$ 5 \mathrm{~B}$, and $8 \%$ above $\$ 10 \mathrm{~B}$ for married couples (and half the thresholds for singles). Under the equal returns assumption, the mechanical tax revenue in 2016 is $\$ 364 \mathrm{~B} .{ }^{37}$ Under our preferred estimates, it is $\$ 199 \mathrm{~B}$.

\footnotetext{
${ }^{36}$ Applying the capitalization factor of 27 assumes that this person has enough taxable interest income to be in the top $0.1 \%$ of the taxable interest income flow distribution. Ultra-millionaires with little fixed interest income would have a dollar of interest income scaled by higher capitalization factors under our approach (e.g., by 54 if their taxable interest income is in P99-P99.9).

${ }^{37}$ The corresponding estimate of Saez and Zucman (2019b, p. 3) is $\$ 335 \mathrm{~B}$.
} 


\subsection{Savings Rates and Social Security}

It is possible to combine our wealth estimates with assumptions about asset price growth to infer savings rates for different groups. In Figure A.13, we follow Saez and Zucman (2016) and combine wealth estimates with asset price indices to estimate implied savings rates by wealth group. We follow their methodology and smooth out fluctuations in yearly savings rates by aggregating flows and rates by decade. Savings in decade $t$ are defined as flows of wealth for a particular group from $t$ to $t+1$ after removing asset price gains for each asset class.

In the equal-return series, savings disparities across the top 1\%, the P90-99, and the bottom $90 \%$ widened significantly in recent years. Our preferred series considerably attenuates savings rate disparities across groups. As a consequence, asset price growth is more important for understanding wealth growth in our series relative to the equal-returns approach.

A key driver of savings rates at the bottom is the extent of savings via social insurance programs, namely, Social Security. More savings in public programs likely crowds out private savings (Feldstein, 1974), which perversely exaggerates measured private wealth concentration despite implying additional resources available in retirement at the bottom. To gauge the importance of this idea, we use new estimates from Catherine, Miller and Sarin (2020) of the distribution of Social Security wealth. They estimate the value of Social Security wealth for U.S. households is $\$ 33 \mathrm{~T}$ in 2016 and increased since 1989 from $50 \%$ to $200 \%$ relative to national income (Appendix Figure A.14A). The reasons for this growth include demographic trends, increased program generosity, and lower interest rates. Were we to include this wealth in our household aggregate, the top $0.1 \%$ share in 2016 would fall by thirty percent, and the growth in the top $0.1 \%$ share would fall by sixty percent (Appendix Figure A.14B). The generosity of social insurance can therefore materially affect wealth concentration measures, with likely implications for disparities in private savings behavior across groups.

Analyzing savings behavior is relevant for tax policy for three reasons. ${ }^{38}$ First, differences in rates of time preference and thus in savings rates across groups can provide a theoretical basis for taxing capital income (Atkinson and Stiglitz, 1976; Saez, 2002). Moreover, the magnitude of savings rate disparities can affect the magnitude of optimal capital tax rates. Accounting for both public and private savings vehicles is crucial for implementing optimal tax rate formulas. Second, if the recent rise of top wealth inequality is mostly due to asset prices and not new savings, then forecasting future asset prices becomes more important for

\footnotetext{
${ }^{38}$ We note a few limitations of this savings rate exercise. First, by construction, conclusions about savings rates are sensitive to assumptions about asset prices, which are difficult to measure given unobserved differences in portfolio composition. Second, the graphs are based on repeated cross-sections in the underlying data, but imply conclusions that may be better suited for a panel analysis. To the extent that who is in the top $1 \%$ changes across decades, it may be difficult to draw conclusions about individual savings rates.
} 
the question of whether the recent growth in wealth concentration will continue. Indeed, if recent asset price changes reflect a transition from a high interest rate environment to a low one, then extrapolating into the future the trend in wealth concentration to measure the capital tax base may not be justified (Cochrane, 2020). Third, to the extent that wealth growth depends more on asset price growth, the magnitude of unrealized capital gains and corresponding potential tax revenues from taxing these gains are larger than if savings are more important. This consideration matters for evaluating capital tax proposals, such as repealing the "step-up" in basis at death for inheritances.

\section{Comparison with Other Data Sources and Approaches}

In this section, we first evaluate the fit of our capitalization approach versus an equal-returns approach. We assess alternative model assumptions and compare model performance using mean-squared-error criteria for various moments in the SCF, which has data for both stocks and flows for key asset classes. We then compare our preferred estimates to those from other data sources, including the SCF, Forbes, the DFA, and estate tax returns. For each data source, we describe the important differences due to methodology, unit of measurement, and reporting incentives. We consider the impact of adjustments designed to facilitate comparisons, though caution that these adjustments can introduce uncertainty into estimates.

\subsection{Our Approach versus Equal Returns}

We start by comparing our preferred estimates to those in Saez and Zucman (2016), which adopts the equal-returns approach for capitalizing income to estimate wealth within asset class. $^{39}$

\footnotetext{
${ }^{39}$ Appendix $\mathrm{J}$ discusses in more detail the concerns raised in Saez and Zucman (2020), which covers four topics: (1) the appropriate rates of return for fixed income assets for the rich; (2) the wealth of the richest 400 people across data sources and approaches; (3) consistency with the SCF in terms of the rise of wealth concentration; and (4) projected revenue from a wealth tax. On (1), we first reconcile our results and then show how conclusions change when ranking by flows rather than by stocks. We then show that our approach performs better in a goodness-of-fit sense than the proposed alternative and especially relative to the equal-returns approach in Section 10.1.1. On (2), we investigate how the Forbes 400 compares to different capitalization approaches in Section 10.3.2, showing that Forbes-based estimates of the total wealth and number of billionaires fall in between the equal-returns estimates and our preferred estimates, and that the Forbes data are more consistent with our preferred top wealth shares using Pareto techniques. On (3), we discuss in Sections 10.2 and 10.3.1 plausible reconciliations for each apparent discrepancy between our data and the SCF and clarify the nature of remaining uncertainty. In terms of the level, trends, and composition, our preferred series is generally closer to the SCF than the equal-returns approach. On (4), the preliminary wealth estimates discussed in Saez and Zucman (2020) showed larger gaps than our updated version, which uses new data, includes all of our refinements, and estimates statistics at the tax-unit level in 2016 . As discussed above, there remain large gaps due to differences in estimated wealth concentration.
} 


\subsubsection{Fixed income under equal returns}

For taxable fixed income wealth, the relevant flow is taxable interest income $y_{i t}^{f i x}$ for person

$i$ in year $t$. Under equal returns, the capitalization factor for all is $\frac{1}{\bar{r}_{f i x, t}}$, which equals the ratio of aggregate fixed income assets to aggregate taxable interest income in year $t$.

Figure $13 \mathrm{~A}$ shows the impact on estimated fixed income wealth of the top $0.1 \%$ of the taxable interest income distribution under different assumptions for $r_{f i x, t}$. The left panel focuses on levels in 2016, and the right panel shows the evolution relative to total household wealth. The equal-returns factor delivers an estimate in 2016 of $\$ 5.5 \mathrm{~T}$. Alternative factors deliver much lower estimates, ranging between $\$ 2.6 \mathrm{~T}$ and $\$ 1.6 \mathrm{~T}$. With the equal-returns factor and our preferred ranks, top $0.1 \%$ fixed income wealth hovers between $1 \%$ and $3 \%$ of total household wealth between 1965 and 2000, rising modestly from the 1980s into the 1990s, but then surges dramatically starting in 2000 to a peak of $7 \%$ of total household wealth in 2012. Top estimates using other factors show a significantly attenuated rise since 2000 .

Departing from the equal-returns assumption is quantitatively crucial for explaining the gap between our estimates and Saez and Zucman (2016) (see Figure 1B). Going back to Kopczuk (2015) and including follow-on work by Fagereng, Guiso, Malacrino and Pistaferri (2016), Bricker, Henriques, Krimmel and Sabelhaus (2016), and Bricker, Henriques and Hansen (2018), a number of critiques of the equal-returns assumption for fixed income have been offered along the lines argued above. Saez and Zucman (2019a) have subsequently acknowledged this approach introduces bias and make an adjustment to the equal-returns specification by adopting a higher interest rate for their top wealth group. Specifically, they scale down their top fixed income wealth estimate using the the interest rate differential from estate taxes matched to income tax returns for estates above $\$ 20$ million, which is closer to the 10-year US Treasury rate (UST10) than to the Aaa rate we use. They then combine this fixed income estimate with an adjusted private business estimate. Though the equal-returns assumption has been criticized by subsequent research, it still underlies leading estimates of inequality. For example, Piketty, Saez and Zucman (2018) incorporates the equal-returns assumption in assigning fixed income wealth to allocate macroeconomic fixed income flows, and Saez and Zucman (2019d) do the same when estimating the distribution of pretax income and tax payments.

There remains some disagreement about which capitalization factor to use and for whom. Saez and Zucman's (2020) view is that our approach sets too high a rate at the top, which therefore understates top fixed income wealth. They argue in favor of applying lower rates, such as the UST10 rate, for wealthiest top 1\%. Our approach disciplines assumptions based on the SCF and estate tax returns, which contain information on both stocks and flows. 
While the UST10 rate improves fit relative to the equal returns approach, a higher rate is necessary to fit the data for those in the top $0.1 \%$ of taxable interest flows (see discussion of Table 3 below). ${ }^{40}$

We also evaluate alternative assumptions more rigorously using a cross-validation approach in the SCF. The left panel of Figure 13C compares actual fixed income wealth in the SCF to predicted fixed income wealth using the equal-returns approach of Saez and Zucman (2016) versus our approach. Predicted fixed income wealth under equal returns vastly exceeds SCF wealth with a prediction error that increases with actual wealth. In 2016, the average top $1 \%$ household in the SCF has $\$ 1.8 \mathrm{M}$ of actual fixed income wealth, whereas the equal-returns estimate is $\$ 5.3 \mathrm{M}$ or $194 \%$ too high. For the top $0.1 \%$ and top $0.01 \%$, actual wealth is $\$ 6.5 \mathrm{M}$ and $\$ 29.6 \mathrm{M}$, respectively, whereas the equal-returns estimate is $\$ 28.2 \mathrm{M}$ and $\$ 136.3 \mathrm{M}$, respectively. The corresponding prediction errors are $334 \%$ and $360 \%$, respectively, because the linear model does not fit the concave relationship between stocks and flows.

Table 3 expands this analysis to additional moments; for five different interest income flow groups, we compare average fixed income levels, fixed income portfolio shares, the change in fixed income levels from 2001 to 2016, and the change in fixed income portfolio shares. Using a mean-squared-error metric, our model provides a better fit than both Saez and Zucman's (2016) equal-returns approach and Saez and Zucman's (2020) proposal of applying a lower rate like the UST10 to the top 1\%. This result holds across all four moments on average and for most subgroups, with the most pronounced gains at the top. The UST10 approach considerably improves model fit relative to the equal-returns approach, however it underperforms our estimates by overstating estimated wealth for the top $0.1 \%$ and top $0.01 \% .^{41}$

Differences in ranking provide some reconciliation between our findings and Saez and

\footnotetext{
${ }^{40}$ Saez and Zucman (2020) cite Bricker, Henriques and Hansen's (2018) estimated rate of return as partial motivation for applying a lower rate like the UST10 rate. However, Bricker, Henriques and Hansen (2018) focus on the top $1 \%$, not the top $0.1 \%$, and the rate of return for the top $1 \%$ ranked by net worth, not by interest income. Our results are consistent with Bricker, Henriques and Hansen (2018), which argues that capitalization with heterogeneous rates of return on fixed income assets is important for matching top $1 \%$ shares in the SCF.

${ }^{41}$ Appendix Figure A.2 uses a test similar to Saez and Zucman (2016) to show that capitalizing top fixed income in the SCF overstates actual SCF top fixed income wealth and its growth. However, our analysis of heterogeneity in SCF fixed income yields different results. We investigated the sources of difference. Appendix Figure A.2 replicates Figure IV.B. of Saez and Zucman (2016), which they use to test the capitalization approach within the SCF. We first successfully replicate their figure in panel A. Panel B shows that capitalizing fixed income within the SCF, however, results in overstated fixed income concentration, but Panel $\mathrm{C}$ shows this overstatement is masked by understated private business wealth concentration. Moreover, this exercise does not hold the ranks fixed when comparing actual to capitalized wealth. In addition, it applies SCF-based capitalization factors, which differ from the factors used in the tax data (e.g., the SCF-based capitalization factor in 2013 is $75,38 \%$ lower than the tax-based capitalization factor of 121). Our analysis in Appendix Figure A.2 holds ranks fixed and uses the tax-based capitalization factors.
} 
Zucman (2020). ${ }^{42}$ When evaluating the average rate of return for the top groups, we focus on those in the top of the interest income flow distribution, which is what we can observe in fiscal income data. In contrast, Saez and Zucman (2020) focus on top wealth holders, either in the SCF or in the estate tax data. This approach attenuates rate of return differences across groups because some top interest flow earners fall out of the top group and some wealthy individuals with low interest income rise into the top group. Because top wealth is not very dependent on fixed income in the SCF or estate tax returns, this attenuation can be sizable. In Appendix Figure A.15A, we replicate the "Rates of return on fixed-income claims" Figure in Saez and Zucman (2020), which plots the top interest rates for different groups in the SCF and estate tax returns. Appendix Figure A.15B then shows the same series after ranking by taxable interest flows, instead of by total wealth. Reranking removes the apparent discrepancies between the Aaa rate and the SCF and estate tax rates. ${ }^{43}$

\subsubsection{Public equity with more weight on capital gains}

For estimating C-corporation equity, the key difference between our approach and Saez and Zucman (2016) is that we reduce the relative weight on realized capital gains. Instead of a weight of 0.9 on dividends and 0.1 on realized capital gains, Saez and Zucman (2016) sum both flows, which is equivalent to using weights of 0.5 . Note that because aggregate realized capital gains are much larger than dividends - in 2016, total realized gains are $\$ 614 \mathrm{~B}$ versus $\$ 254 \mathrm{~B}$ for dividends - the relative contribution of capital gains to estimating C-corporation equity wealth exceeds 50\%. A second difference is that we apply our estimate that $20 \%$ of $\mathrm{C}$-corporation wealth is private business to allocate that wealth when differentiating between public and private equity.

The panels of Figure 13B quantify the effects of different assumptions about the relative weight on capital gains for top C-corporation equity wealth estimates. The $50 \%$ assumption yields $\$ 5.8 \mathrm{~T}$ for the top $0.1 \%$ with equal-returns ranks in 2016 . Using $10 \%$ and $0 \%$ result in $\$ 1.5 \mathrm{~T}$ and $\$ 2.2 \mathrm{~T}$ less, respectively. The right panel plots how top C-corporation equity wealth estimates with preferred ranks evolve relative to aggregate household wealth. Putting positive weight on capital gains implies a much larger increase in top equity wealth and higher volatility through the stock market boom and bust in the 1990s. Since dividends are less

\footnotetext{
${ }^{42}$ Saez and Zucman's (2020) comments are based on a preliminary version of our analysis, in which we applied the Aaa rate to the top $1 \%$ of the interest income flow distribution. While this rate best approximates the rate of return for the top $0.1 \%$, it slightly overstates the rate of return for the next $0.9 \%$. We subsequently updated our analysis to apply the intermediate UST10 rate for P99-99.9.

${ }^{43}$ For the estate tax returns, relative to Saez and Zucman (2020), we also apply inverse mortality rates, which is needed to estimate rates of return for the living. Saez and Zucman (2016) advocate applying this approach "one should weight matched estate-income observation by the inverse of the mortality rate conditional on age, gender, and wealth. We leave this difficult task to future research." (p. 549)
} 
volatile and less concentrated, the dividends-only series (i.e., $0 \%$ weight on capital gains) is more stable and lower. Relative to a dividends-only series, our preferred specification with $10 \%$ weight on capital gains better captures movements in the stock market.

We use cross validation in the SCF to assess fit for these different approaches. The right panel of Figure 13C compares actual public equity wealth in the SCF to predicted public equity wealth using the $50 \%$ weight on capital gains versus our approach. Predicted equity wealth under the $50 \%$ weight significantly exceeds SCF wealth with a prediction error that increases with actual wealth. Overall, the differences are less stark than is the case for fixed income, but remain sizable. Appendix Table B.3 repeats the cross-validation exercise from Table 3 for public equity, ranked by the sum of dividends and realized capital gains. Our model performs similarly for those with low levels of wealth and improves prediction error for those with substantial equity income.

\subsubsection{Private Equity, Housing, and Pensions}

For pass-through business, Saez and Zucman (2016) apply one equal-returns capitalization factor for the sum of positive proprietorship and positive partnership income and a separate equal-returns capitalization factor for positive S-corporation income. Three differences deserve note. First, relative to ours, this approach misses industry heterogeneity in the mapping of flows to stocks, including heterogeneity in financial and human capital components of pass-through business income. Second, it estimates wealth of zero for firms that generate zero or negative taxable income despite having significant assets, such as in the real estate sector. Third, it relies on the Financial Accounts aggregates for the value of private business, which may be understated due to incomplete source data (see below for details).

How do the equal-returns capitalization values compare to our approach? The equalreturns approach yields $\$ 2.3 \mathrm{~T}$ of pass-through wealth for the top $0.1 \%$ in 2016 , of which $\$ 0.9 \mathrm{~T}$ is S-corporation wealth, $\$ 1.2 \mathrm{~T}$ is partnership wealth, and $\$ 0.2 \mathrm{~T}$ is proprietor wealth. Our approach increases top $0.1 \%$ pass-through wealth by $30 \%$ to $\$ 3.0 \mathrm{~T}$, of which S-corporations, partnerships, and proprietors account for $\$ 1.3 \mathrm{~T}, \$ 1.4 \mathrm{~T}$, and $\$ 0.3 \mathrm{~T}$, respectively. The results are similar for the top $1 \%$. For this group, the equal-returns approach yields $\$ 5.1 \mathrm{~T}$, of which $\$ 1.7 \mathrm{~T}$ is S-corporation wealth, $\$ 2.6 \mathrm{~T}$ is partnership wealth, and $\$ 0.8 \mathrm{~T}$ is proprietor wealth. Our approach increases top 1\% pass-through wealth by $10 \%$ to $\$ 5.6 \mathrm{~T}$, of which Scorporations, partnerships, and proprietors account for $\$ 2.4 \mathrm{~T}, \$ 2.3 \mathrm{~T}$, and $\$ 0.9 \mathrm{~T}$, respectively.

One source of difference between the equal-returns approach and ours is the increased aggregate level of pass-through wealth, which rises modestly from $\$ 11.5 \mathrm{~T}$ in the equalreturns series to $\$ 11.7 \mathrm{~T}$ in our adjusted series in $2016 .{ }^{44}$ Another source of difference is

\footnotetext{
${ }^{44}$ Saez and Zucman $(2019 a)$ cite a prior version of this paper, which showed an increase in pass-through
} 
reranking, as pass-through owners are more likely to rise into the top groups after accounting for heterogeneity in other asset classes. Because S-corporation and partnership wealth are concentrated at the top, we observe a larger impact of our adjustment for the top $0.1 \%$ relative to the still large impact for the top 1\%. However, our adjustment has only a modest effect on the concentration of top $1 \%$ and top $0.1 \%$ pass-through wealth relative to the aggregate. One can infer from this result that the industry adjustment mostly allocates wealth across people within the top groups, consistent with the high concentration of passthrough income at the top.

For pensions, Saez and Zucman (2016) apply a convex combination of a capitalized function of wages and capitalized pension income. ${ }^{45}$ First, relative to ours, this approach does not account for the significant life-cycle pattern for pension wealth. We use age-specific capitalization factors and weights on wages versus pension income to fit this pattern. Second, we incorporate external estimates for the distribution of defined benefit pension wealth, which improves estimates especially for the bottom $90 \% .{ }^{46}$ Third, as noted by Auten and Splinter (2016), Saez and Zucman (2016) include nontaxable pension rollovers in their measure of pension income, which tends to overstate the concentration of pension wealth because rollovers are stock rather than flow measures and disproportionately accrue to the top. In contrast, we only use taxable pension distributions to estimate pension wealth.

For housing, we follow a similar approach to Saez and Zucman (2016), except they apply an equal-returns capitalization factor in a given year for mapping property tax deductions to housing assets. That approach ignores quantitatively relevant cross-state differences in property taxes and regional house price dynamics.

\subsection{Wealth Composition across Sources and Approaches}

Figure 14 compares our preferred series in 2016 to the equal-return series with equal-return ranks, to the SCF, and to the recently developed Distributional Financial Accounts (DFA). We modify the SCF to enable comparability between our aggregates and the SCF by adding the Forbes 400 and the Sabelhaus and Henriques Volz (2019) estimates of unfunded defined benefit pension wealth and by removing consumer durables. The DFA series shows how

wealth of $90 \%$ relative to the equal-returns aggregate. The prior version did not adjust valuations for illiquidity or for labor income recharacterized as profits.

${ }^{45}$ The function is $y_{i t}^{\text {wagetop } 60}=\left\{\begin{array}{ll}y_{i t}^{\text {wage }}-\operatorname{median}\left(y_{i t}^{\text {wage }}\right) & \text { if } P_{i t}^{\text {wage }} \geq .5 \\ 0 & \text { if } P_{i t}^{\text {wage }}<.5\end{array}\right.$. The goal is to correct for relatively low pension wealth among those with below median wages. They apply a weight of 0.4 for the wage-based estimate and 0.6 for the pension-income-based estimate.

${ }^{46} \mathrm{Saez}$ and Zucman (2016) construct their model to target the top $10 \%$ share of defined contribution and funded defined benefit wealth in the cross section and over time (see their footnote 24). They invite the use of new data to improve the allocation across the wealth distribution. 
mapping SCF categories onto the Financial Accounts affects the level and composition of top wealth. ${ }^{47}$ We also compare these estimates to a mortality-rate-adjusted series from estate tax returns above $\$ 10 \mathrm{M}$.

We define portfolio components as follows. For private business in our preferred approach, we allocate $20 \%$ of C-corporation wealth to private business, which also includes all Scorporation wealth, partnership wealth, and proprietorship wealth. We apply the same $20 \%$ allocation for estate tax data. For the DFA, we make the same $20 \%$ allocation after first using Saez and Zucman's (2016) share of S-corporation wealth relative to combined S-corporation and C-corporation wealth to decompose total equity wealth. ${ }^{48}$ For the SCF, we define private business using the SCF questions that cover both private C- and S-corporations, as well as non-corporate private business (see Appendix E for definitions). When allocating Forbes wealth, we use public information on Forbes individuals in 2016 who derive most of their wealth from public companies to allocate Forbes wealth to public and private equity. For each 2016 Forbes individual, we allocate fixed income, pension wealth, housing, and other wealth according to top $0.01 \%$ SCF portfolio shares, then allocate the remainder (81\%) to either public or private equity depending on whether they derive most of their wealth from public or private companies (see Appendix G for details). To highlight the relative importance of private C-corporations versus pass-through business, we do not apply the $20 \%$ adjustment to the equal-returns approach.

Figure 14A presents portfolio shares for the top $0.1 \%$ across different series. Our preferred fixed income portfolio share $(19 \%)$ is half that in the equal-return series (38\%). This shift is largely offset by private business wealth, which increases from $15 \%$ to $36 \%$. Part of this difference is the treatment of private $\mathrm{C}$-corporation wealth. Combining private $\mathrm{C}$-corporation wealth and our public equity estimate gives a C-corporation share of $41.8 \%(=33.4 \% / 0.8)$. Thus, relative to the equal-return series, the C-corporation, housing, and pension shares rise modestly. In our preferred series, illiquid private equity and pension wealth account for $40 \%$ of top wealth and housing accounts for an additional 8\%. Thus, liquid securities with clear market values account for only half of top wealth after accounting for our adjustments.

Our preferred shares match the SCF well. The fixed income share is very close, while the public equity share is somewhat higher than in the SCF. Private business wealth is larger in

\footnotetext{
${ }^{47}$ The DFA series is not available for the top 0.1\%. See Batty, Bricker, Briggs, Holmquist, Hume McIntosh, Moore, Nielsen, Reber, Shatto, Sommer, Sweeney and Henriques Volz (2019) for details.

${ }^{48}$ The USFA do not explicitly separate C- and S-corporations in their tables for non-financial corporate business. Saez and Zucman (2016) start with the USFA aggregates for closely held financial and non-financial equity, then divide this $35 \%$ into C-corporations and $65 \%$ into S-corporations based on revision notes to the Flow of Funds from 2008. For example, in 2008, total closely held shares were $\$ 2.4 \mathrm{~T}$, which implies that $\$ 1.6 \mathrm{~T}$ was S-corporation equity. Piketty, Saez and Zucman (2018) extend this series to 2014, and we extend it to 2016 and use this for aggregate S-corporation wealth in equal-returns estimates.
} 
the SCF (56\%) and in the estate tax (44\%), though our preferred private business estimate of $36 \%$ comes closer to the SCF composition than does the equal-returns approach.

Asset composition figures from estate tax returns align well with our estimates. Estate tax portfolio shares have less public equity and more housing wealth. A smaller public equity share may reflect the importance of private $\mathrm{C}$-corporations at the top, which are harder for us to distinguish from public equity because firm-owner links are not available for this type of firm. In addition, certain categories of managed assets on estate tax returns are difficult to allocate to underlying asset classes, which may account for some of the difference between our series and the estate series.

Figures $14 \mathrm{~B}$ and $14 \mathrm{C}$ plot the levels of top wealth by component. When compared to the equal-return estimates, fixed income wealth is significantly lower for both groups in both our preferred series and the SCF, as well as for the top 1\% in the DFA. Public equity wealth is lower in our preferred series than in the equal-returns series and matches the SCF + Forbes series closely for the top $0.1 \%$. With the private C-corporation adjustment (i.e., $\$ 5.8 \mathrm{~T} \times 0.8=\$ 4.6 \mathrm{~T})$, the equal-returns series exceeds our preferred estimate of $\$ 3.6 \mathrm{~T}$ by $30 \%$. For the top 1\%, the DFA estimates for public equity align closely with ours, while the SCF + Forbes series comes closer to the equal-returns estimate. Overall, the differences across sources and approaches are smaller for public equity than for fixed income.

Private business wealth in our preferred series exceeds the equal-returns approach and aligns with the DFA series, but is well below the SCF. Our housing estimate falls in between the equal-returns estimate and the SCF and DFA, but plays a small role overall for top wealth. Our pensions estimate is lower than in the equal-returns approach, with the difference being more important for the top $1 \%$ than for the top $0.1 \%$, and aligns closely with the DFA but is somewhat lower than in the SCF.

In the SCF + Forbes series, the total top $1 \%$ wealth share is similar to the equal-returns top $1 \%$ share. However, this apparent similarity reflects a starkly different underlying composition. First, the top group has substantially more private business wealth $(\$ 15.5 \mathrm{~T}$ versus $\$ 5.1 \mathrm{~T})$, and less fixed income wealth relative to the equal-return series ( $\$ 5.5 \mathrm{~T}$ versus $\$ 9.3 \mathrm{~T})$. Second, the SCF + Forbes public equity wealth is $\$ 500 \mathrm{~B}$ lower and net housing wealth is $\$ 1.6 \mathrm{~T}$ higher. Thus, compositional discrepancies reveal that the SCF's similar top 1\% share does not necessarily validate the equal-returns assumption.

Within the SCF + Forbes top 0.1\%, both the levels and composition depart significantly from the equal-return series. Furthermore, our preferred estimate for fixed income wealth closely aligns with the reported amount in the SCF + Forbes, which is $\$ 3.8 \mathrm{~T}$ below the equal-return series estimate. Thus, adjusting fixed income wealth estimates for unequal returns considerably improves the alignment between the capitalization approach and the 
SCF.

\subsection{Comparison with Other Data Sources}

\subsubsection{Survey of Consumer Finances}

To sharpen comparisons between estimates based on our preferred capitalization approach and the SCF, several additional adjustments are required. ${ }^{49}$ First, our approach defines the relevant observation at the individual level based on equal splits within tax units, whereas the SCF unit of observation is the household. Second, the SCF does not include estimates of defined benefit pension wealth. Third, as there is no flow concept on tax returns that corresponds to non-financial wealth, such as vehicles, jewelry, or art, our approach does not attempt to allocate these assets. Fourth, we incorporate liquidity discounts into our estimates of private business equity, while the SCF does not. Fifth, the SCF excludes the Forbes 400 from the sampling frame for privacy reasons.

Appendix Figure A.16 shows the relative importance of applying each adjustment and how the final series compares to our preferred approach for both the top $1 \%$ and top $0.1 \%$. The most quantitatively important adjustments for the SCF shares are changes to the unit of observation, the inclusion of defined benefit pension wealth, and for the top $0.1 \%$ inclusion of the Forbes 400. Specifically, going from household-level to an individual-level wealth concept materially reduces the top $1 \%$ and top $0.1 \%$ shares, as does adding defined benefit pension wealth because most of this wealth accrues to the bottom 99\%. Adding the Forbes 400 and ranking the SCF using effective tax unit ranks (which increases the number of SCF households in the top groups) increases top shares. Our preferred series closely fits the most comparable equal-split SCF series that makes all adjustments, trending similarly and matching the levels of the top $1 \%$ and rising somewhat above the top $0.1 \%$ in the 2000 s.

Relative to our data, the SCF has several limitations. First, because the underlying sample is small, estimates of wealth inequality at the geographic level are not possible. Second, while it is possible to estimate top shares for groups within the top $1 \%$, the underlying number of observations becomes small, resulting in considerable uncertainty due to sampling error and potential differences in response rates (Bricker, Henriques and Hansen, 2018; Bricker, Hansen and Volz, 2019). Third, a key outstanding difference between our estimates and the SCF owes to the high reported values of private business in the SCF. Such values are hard to verify (Bhandari, Birinci, McGrattan and See, 2019). Our approach uses actual

\footnotetext{
${ }^{49}$ When comparing results across data sources, there is a trade-off in terms of transparency versus precision regarding the choice to present raw data or to add degrees of freedom via adjustments. Figure 14 is closer to the raw data in not implementing these additional adjustments. Proceeding step-by-step allows us to separate the facts in the raw data from the impact of these adjustments.
} 
firm-level performance data and detailed industry information from the population of private pass-through firms, combined with market-based valuation multiples and an empirically appropriate liquidity discount.

Ultimately, we view the SCF as a complementary resource to our data for learning about the wealth distribution. Among respondents, the SCF collects valuable information on debt, non-taxed items, and the joint distribution between stocks and flows, which we use to evaluate the fit of our empirical model.

\subsubsection{Forbes 400}

Augmenting the SCF to include the Forbes 400 series adds $\$ 2.4 \mathrm{~T}$ in 2016, increases the top $0.1 \%$ share by 2.3 percentage points, and increases the growth in the top $0.1 \%$ since 1989 from 4.2 to 5.1 percentage points (Figure 1A). Our series estimates less wealth among the top 400 wealthiest individuals. ${ }^{50}$ Several top Forbes individuals have their wealth concentrated in public firms, some of which do not pay dividends (e.g., Warren Buffett and Berkshire Hathaway, Mark Zuckerberg and Facebook, and Jeff Bezos and Amazon). Others do (e.g., Bill Gates and Microsoft, the Waltons and Walmart). Our approach relies on observable fiscal capital income, so would miss these differences in the very right tail.

Quantifying the aggregate importance of these differences is difficult for a few reasons. First, when Raub, Johnson and Newcomb (2010) link the Forbes 400 data to the estate tax data, they only find about half of that wealth in the administrative data. It's hard to determine how much of this gap is due to tax avoidance and evasion, which are also likely quite substantial. Second, given the publicity associated with placing onto the Forbes list, it is possible that individuals exaggerate their wealth (Kopczuk, 2015). Third, many of the Forbes 400, those in the Bloomberg billionaires list, or top 400 units in the SCF have substantial shares of wealth in private firms, which are difficult to value. ${ }^{51}$ Ultimately, there is a lot of uncertainty regarding the accuracy of the Forbes data. Other approaches to verify statistics for this population, such as fitting a Pareto distribution to estimate the number of billionaires and their collective wealth, are sensitive to parameter values.

Nonetheless, we can compare aggregate estimates from different approaches to the Forbes data. Saez and Zucman (2019c) fit a Pareto distribution to estimate the number of billionaires and their collective wealth using Forbes data (see footnote 3 ). They estimate that there are 911 billionaires with $\$ 3 \mathrm{~T}(=400 \times 6.1+0.27 \times(400 \times 6.1))$ in $2018 .{ }^{52}$ These estimates fall

\footnotetext{
${ }^{50}$ Disclosure rules prevent us from being able to disclose the wealth of the top 400 wealthiest.

${ }^{51}$ Indeed the Bloomberg list has an accuracy rating system that reflects these difficulties: https://www . bloomberg.com/billionaires/methodology/

${ }^{52}$ Applying the same steps using 2016 data from Forbes 400 gives an estimate of $669\left(=400 \times(1.45 / 1)^{1.4}\right)$ billionaires and $\$ 2.4 \mathrm{~T}(=400 \times 5.1+0.16 \times(400 \times 5.1))$ of collective wealth (since mean wealth of $\$ 5.1 \mathrm{~B}(=$
} 
in between the equal returns estimates of 1,250 billionaires with collective wealth of $\$ 3.7 \mathrm{~T}$, and our estimates from our preferred specification of 644 billionaires and $\$ 1.7 \mathrm{~T}$ in 2016 .

In terms of top wealth shares, the Forbes-based Pareto parameter of 1.4 in 2016 implies top $0.1 \%$, top $1 \%$, and top $10 \%$ shares in 2016 of $13.9 \%, 26.8 \%$, and $51.8 \%$, respectively. ${ }^{53}$ Comparing these shares to those in Table 1 reveals that top shares from our preferred series $(14.3 \%, 29.6 \%, 65.6 \%)$ line up more closely with these Forbes-400-implied top shares than do those from the equal-returns approach $(20.2 \%, 38.1 \%, 72.3 \%)$.

In terms of composition, our results are consistent with the Forbes 400 in that equity plays a central role and fixed income does not. Moreover, in terms of private business valuations, our approach may be better than Forbes, which relies on a combination of self-reported values and limited public data on private firms.

Overall, Forbes-based estimates of the total wealth and number of billionaires fall in between the equal-returns and preferred estimates, and the Forbes data are more consistent with our preferred top wealth shares and composition. While it is possible that the Forbes estimates are overstated for the reasons above, estimates from our preferred specification may need to be scaled up to match the true unobserved wealth of the wealthiest 400 .

\subsubsection{Distributional Financial Accounts}

The Distributional Financial Accounts (DFA) map the categories of the SCF onto the aggregates of the Financial Accounts. The goal of this exercise is to enable higher frequency estimates of the wealth distribution consistent with valuation methods used in the Accounts. Key aggregate adjustments include reducing the value of private business wealth, both in corporate and non-corporate firms, and reducing the value of real estate relative to SCF aggregates. In addition, because the Financial Accounts include defined benefit pensions, the DFA aggregates exceed SCF aggregates for combined pension wealth. While the DFAs are available at high frequency, they cannot be used to study the geography of wealth inequality and, as of this writing, are not available for higher-wealth groups within the top $1 \%$.

Totals for private business wealth in the US Financial Accounts are likely low because of data limitations and differences in valuation method (see footnote 23). Bhandari, Birinci, McGrattan and See (2019) raise additional concerns with the quality of measurement for private business wealth in the SCF. We hope our new data and alternative market-based

$6.0 \times .85)$ and a minimum threshold of $\$ 1.45 \mathrm{~B}(=1.7 \times .85)$ imply a Pareto parameter of $\left.1.4=\frac{5.1}{1.45} /\left(\frac{5.1}{1.45}-1\right)\right)$. Without the $15 \%$ behavioral adjustment to mean wealth and the threshold, the raw estimates for 2016 are $839\left(=400 \times(1.7 / 1)^{1.4}\right)$ with collective wealth of $\$ 3 \mathrm{~T}(=400 \times 6.0+0.24 \times(400 \times 6.1)$.

${ }^{53}$ Given the 2016 estimate of the Pareto parameter of $a=1.4$ and the assumption that top wealth is Pareto distributed, the top $p$ percentile's share of wealth in 2016 is $\left(\frac{p}{100}\right)^{\frac{1.4-1}{1.4}}$. 
method of valuing private business can help shed light on these measurement considerations and help improve the Financial Accounts.

Applying these DFA adjustments helps reconcile the differences between our series and the SCF. Top 1\% shares track our series closely over time. As in the SCF, equity wealth and especially private business wealth are largely responsible for the level and growth of top shares, while fixed income remains a small driver.

\subsubsection{Estate Tax}

Comparing estimates using estate tax data requires scaling up observed wealth by an estimate of the underlying sampling rate, which is the decedent's unobserved mortality rate. Only those with sufficiently high wealth face the estate tax, and mortality rates are likely correlated with wealth. To address this problem, Kopczuk and Saez (2004b) (KS) begin with population mortality rates produced by the Social Security Administration. Lacking time-varying mortality rates by wealth, KS apply time-fixed mortality differentials for white college graduates by age and gender from Brown, Liebman and Pollet (2002). Saez and Zucman (2019a) (SZ) argue that mortality differentials are understated in the KS series, and that mortality differentials have increased over time. SZ update and apply the KS series through 2012, and then apply new mortality rate differentials for the top 1 percent by household income. Specifically, SZ construct mortality differentials by age and gender using 2012-2014 mortality rates by household income percentile from Chetty, Stepner, Abraham, Lin, Scuderi, Turner, Bergeron and Cutler (2016) (CSALSTBC). SZ then linearly extrapolate between the KS differential in 1980 and the top income differential in 2012.

These differentials have several weaknesses. First, individuals are ranked based on household income at age 61 or lower, which necessitates an age threshold of 76 in the CSALSTBC data. Because these data do not include mortality rates for those over 76, SZ impute via extrapolation the mortality differentials for this group - which comprises the majority of estate tax filers. Second, SZ calculate the mortality differential using only three years of mortality data, 2012 to 2014, so mortality rate trends and thus trends in estimated wealth concentration depend on an assumed underlying trend. To address these concerns, and to examine the sensitivity of estate tax-based wealth estimates, we estimate new mortality rates for the top 1\% using two measures of household income, using 1- and 2-year lagged income, and employing two smoothing techniques, for ages 30 to 90 and for years 1998 to $2017 .{ }^{54}$

\footnotetext{
${ }^{54}$ Appendix Figure A.18 presents these new mortality rate statistics, which may be useful to others. The new mortality rates for years 2001-2014 are generally similar to those of Chetty, Stepner, Abraham, Lin, Scuderi, Turner, Bergeron and Cutler (2016). Mortality rates constructed using household capital income (AGI plus tax exempt interest less wages) are slightly higher on average for both genders than mortality rates constructed using income including wages.
} 
Appendix Figure A.19 compares the original KS approach, which we have updated to 2016, to the SZ approach, and to the approach using our mortality statistics. ${ }^{55}$ Consistent with SZ, our estate tax series shows a higher level of wealth concentration relative to the KS approach. However, we find that the mortality differential across the income distribution was already substantial in 1998 and has increased only slightly over subsequent years. As a result, our estate tax series shows only modest growth in wealth concentration, compared to the SZ series which relies on linearly increasing mortality differentials through 2012 . The level of top $0.1 \%$ wealth concentration estimated in the new estate tax series is $13.7 \%$ in 2016.

Little is known about mortality rate trends by wealth group. Moreover, because mortality rates for younger people are fairly low and there are many high wealth individuals in their 50s, small differences in assumed mortality rates can lead to significant differences in estimated wealth. ${ }^{56}$ Thus, considerable uncertainty remains inherent to this approach.

There are several additional limitations to the estate tax series for understanding levels and trends of wealth inequality. First, widespread use of estate tax planning services, avoidance behavior, and the possibility of evasion imply that the amount of wealth observed is likely too low relative to the truth. Second, the threshold for filing estate tax returns has increased substantially over time from less than $\$ 1 \mathrm{M}$ in 2000 to more than $\$ 5 \mathrm{M}$ in 2016 , so estimating wealth shares for groups below these thresholds is impossible. A third weakness for estate tax data involves adding defined benefit pensions. Annuitized pension wealth is not included in the estate tax base, therefore we can only estimate top wealth shares excluding this category.

As with the SCF, a key use of the estate tax data in this study is for cross-validating the flow-stock relationship among sampled individuals. For example, the SCF- and estatetax-implied rates of return for fixed income assets offer independent support for our threetier approach. In addition, the estate tax data provide useful information about portfolio composition for these individuals. Equity wealth is the most important category for top wealth shares in the estate tax. Private business wealth plays a significant role despite wellknown issues associated with valuation of such assets in estates. Fixed income portfolio

\footnotetext{
${ }^{55}$ For comparison, we focus on mortality rates constructed using income definitions which most closely match the CSALSTBC estimates. Specifically, we rank individuals by household adjusted gross income plus tax-exempt interest measured two years prior. CSALSTBC use the same definition of income, measured two years prior, or at age 61, whichever is earlier. To more closely approximate the smooth relationship between mortality rates and age in the baseline mortality rates produced by the Social Security Administration, we use five-year moving averages across age. For example, the estimated mortality rate at age 90 is an average of point estimates for those aged 88 to 92 .

${ }^{56}$ Appendix Figure A.18 shows the sensitivity of wealth share estimates to small differences in assumed mortality rates by age. Wealth share estimates are 8.8 times more sensitive to a 0.1 percentage point increase in mortality rates for those aged 51 to 55 compared to those aged 71 to 75
} 
shares in estate tax data closely resemble those in our preferred series.

\section{Conclusion}

This paper combines administrative tax data with a range of new data to provide estimates of wealth concentration and composition in the United States. We find the top 0.1\% share of wealth has increased from $7 \%$ to $14 \%$ from 1978 to 2016 . While this increase is lower than some prior estimates, we emphasize that wealth is very concentrated - the top $1 \%$ has nearly as much wealth as the bottom $90 \%$. We find that private business and public equity wealth are the primary sources of wealth at the top, and pension and housing wealth account for almost all wealth for the bottom $90 \%$.

Our estimates have implications for inequality and capital tax policy. Accounting for heterogeneity materially reduces top capital income and thus affects measures of income inequality that add up to national income. Relative to an equal-returns approach, our approach reduces the top $1 \%$ share in distributional national income by 2 percentage points and the capital share of the top $1 \%$ by 13 percentage points. A larger role for pass-through business wealth, lower concentration of financial wealth, and a less rapid rise in recent years in top financial wealth and capital shares all point to a larger role for human capital and a smaller role for non-human capital in top income growth. In terms of capital tax policy, these estimates provide an input for estimates of unrealized capital gains, the estate tax base, wealth taxes, and other proposals that seek to harmonize labor and capital taxes. Though the capitalization approach has advantages over other methods, uncertainty remains inherent to the approach as estimates can be sensitive to different assumptions.

We highlight a few avenues for future research. First, there are many ways to improve these wealth estimates and incorporate further refinements, such as the impact of tax avoidance and evasion (Guyton, Langetieg, Reck, Risch and Zucman, 2020), better measures of pension wealth and the accuracy of the Forbes 400, and social insurance programs such as Medicare and Social Security. Second, we hope our estimates for wealth and income inequal-

ity can improve our understanding of the drivers of inequality (Hubmer, Krusell and Smith, 2020). For example, our estimates provide inputs to investigating how much of wealth is inherited and the relative importance of family firms versus self-made entrepreneurs (Gomez, 2019; Atkeson and Irie, 2020). Third, these estimates can be linked with estate tax data to estimate behavioral responses to capital taxation and inform policy design and enforcement. Fourth, these regional estimates can help improve our understanding of economic growth and the roles that capital flows, demographics, and regional policy play in shaping regional disparities in prosperity and opportunity in the United States. 


\section{References}

Arrow, Kenneth J. 1987. "The demand for information and the distribution of income." Probability in the Engineering and Informational Sciences, 1(1): 3-13.

Atkeson, Andrew, and Magnus Irie. 2020. "Understanding 100 years of the evolution of top wealth shares in the U.S.: What is the Role of Family Firms?"

Atkinson, Anthony Barnes, and Joseph E. Stiglitz. 1976. "The design of tax structure: direct versus indirect taxation." Journal of Public Economics, 6(1-2): 55-75.

Auerbach, Alan. 2006. "Who Bears the Corporate Tax? A Review of What We Know." Tax Policy and the Economy, 20: 1-40.

Auerbach, Alan J. 1983. "Stockholder tax rates and firm attributes." Journal of Public Economics, 21(2): 107-127.

Auerbach, Alan J., and Mervyn A. King. 1983. "Taxation, portfolio choice, and debtequity ratios: A general equilibrium model." Quarterly Journal of Economics, 98(4): 587609.

Auten, Gerald, and David Splinter. 2016. "Using Tax Data to Measure Long-Term Trends in U.S. Income Inequality." Treasury Office of Tax Analysis Working Paper.

Auten, Gerald, and David Splinter. 2017. "Income Inequality in the United States: Using Tax Data to Measure Long-Term Trends."

Auten, Gerald, Geoffrey Gee, and Nicholas Turner. 2013. "Income Inequality, Mobility, and Turnover at the Top in the US, 1987-2010." American Economic Review, 103(3): 168-72.

Bach, Laurent, Laurent E. Calvet, and Paolo Sodini. 2016. "Rich pickings? Risk, return, and skill in the portfolios of the wealthy."

Batty, Michael M. Batty, Jesse Bricker, Joseph S. Briggs, Elizabeth Holmquist, Susan Hume McIntosh, Kevin B. Moore, Eric R. Nielsen, Sarah Reber, Molly Shatto, Kamila Sommer, Tom Sweeney, and Alice Henriques Volz. 2019. "Introducing the Distributional Financial Accounts of the United States."

Bhandari, Anmol, Serdar Birinci, Ellen McGrattan, and Kurt See. 2019. "What Do Survey Data Tell Us about US Businesses?" National Bureau of Economic Research.

Bricker, Jesse, Alice Henriques, and Peter Hansen. 2018. "How much has wealth concentration grown in the United States? A re-examination of data from 2001-2013."

Bricker, Jesse, Alice Henriques, Jacob Krimmel, and John Sabelhaus. 2016. "Measuring income and wealth at the top using administrative and survey data." Brookings Papers on Economic Activity, 2016(1): 261-331. 
Bricker, Jesse, Peter Hansen, and Alice Henriques Volz. 2019. "Wealth concentration in the US after augmenting the upper tail of the survey of consumer finances." Economics Letters, 184: 108659.

Brown, Jeffrey, Jeffrey Liebman, and Joshua Pollet. 2002. "Estimating Life Tables That Reflect Socioeconomic Differences in Mortality." In The Distributional Aspects of Social Security and Social Security Reform., ed. Martin Feldstein and Jeffrey Liebman. Chicago and London:University of Chicago Press.

Catherine, Sylvain, Max Miller, and Natasha Sarin. 2020. "Social Security and Trends in Inequality." Working Paper.

Chetty, Raj, and Nathaniel Hendren. 2018a. "The impacts of neighborhoods on intergenerational mobility I: Childhood exposure effects." Quarterly Journal of Economics, 133(3): 1107-1162.

Chetty, Raj, and Nathaniel Hendren. 2018b. "The impacts of neighborhoods on intergenerational mobility II: County-level estimates." Quarterly Journal of Economics, 133(3): 1163-1228.

Chetty, Raj, Michael Stepner, Sarah Abraham, Shelby Lin, Benjamin Scuderi, Nicholas Turner, Augustin Bergeron, and David Cutler. 2016. "The Association Between Income and Life Expectancy in the United States, 2001-2014." JAMA, 315(16): 1750-1766.

Chetty, Raj, Nathaniel Hendren, Patrick Kline, and Emmanuel Saez. 2014. "Where is the land of opportunity? The geography of intergenerational mobility in the United States." Quarterly Journal of Economics, 129(4): 1553-1623.

Cochrane, John. 2020. "Wealth and Taxes." Cato Institute, Tax and Budget Bulletin, 86.

Cooper, Michael, John McClelland, James Pearce, Richard Prisinzano, Joseph Sullivan, Danny Yagan, Owen Zidar, and Eric Zwick. 2016. "Business in the United States: Who Owns It, and How Much Tax Do They Pay?" Tax Policy and the Economy, 30(1): $91-128$.

Drechsler, Itamar, Alexi Savov, and Philipp Schnabl. 2017. "The Deposits Channel of Monetary Policy." Quarterly Journal of Economics, 132(4): 1819-1876.

Fagereng, Andreas, Luigi Guiso, Davide Malacrino, and Luigi Pistaferri. 2016. "Heterogeneity in returns to wealth and the measurement of wealth inequality." American Economic Review Papers \& Proceedings, 106(5): 651-55.

Fagereng, Andreas, Luigi Guiso, Davide Malacrino, and Luigi Pistaferri. 2020. "Heterogeneity and Persistence in Returns to Wealth." Econometrica, 88(1): 115-170.

Fajgelbaum, Pablo D., Eduardo Morales, Juan Carlos Suárez Serrato, and Owen Zidar. 2019. "State taxes and spatial misallocation." Review of Economic Studies, 86(1): 333-376. 
Feldstein, Martin. 1974. "Social security, induced retirement, and aggregate capital accumulation." Journal of Political Economy, 82(5): 905-926.

Gabaix, Xavier, Jean-Michel Lasry, Pierre-Louis Lions, and Benjamin Moll. 2016. "The Dynamics of Inequality." Econometrica, 84(6): 2071-2111.

Garbinti, Bertrand, Jonathan Goupille-Lebret, and Thomas Piketty. 2018. "Income inequality in France, 1900-2014: Evidence from Distributional National Accounts (DINA)." Journal of Public Economics, 162: 63-77.

Giffen, Sir Robert. 1913. Statistics. Macmillan.

Gomez, Matthieu. 2019. "Displacement and the Rise in Top Wealth Inequality."

Guvenen, Fatih, Gueorgui Kambourov, Burhan Kuruscu, Sergio Ocampo, and Daphne Chen. 2017. "Use it or lose it: Efficiency gains from wealth taxation."

Guyton, John, Patrick Langetieg, Daniel Reck, Max Risch, and Gabriel Zucman. 2020. "Tax Evasion by the Wealthy: Measurement and Implications." Measuring and Understanding the Distribution and Intra/Inter-Generational Mobility of Income and Wealth. University of Chicago Press.

Hubmer, Joachim, Per Krusell, and Anthony Smith. 2020. "Sources of Wealth Inequality: Past, Present, and Future."

IRS. 2001-2017. "Estate Tax Statistics."

Kawano, Laura. 2014. "The Dividend Clientele Hypothesis: Evidence from the 2003 Tax Act." American Economic Journal: Economic Policy, 6(1): 114-36.

Kline, Patrick, and Enrico Moretti. 2014. "People, places, and public policy: Some simple welfare economics of local economic development programs." Annual Review of Economics, 6(1): 629-662.

Koeplin, John, Atulya Sarin, and Alan C. Shapiro. 2000. "The private company discount." Journal of Applied Corporate Finance, 12(4): 94-101.

Kopczuk, Wojciech. 2015. "What do we know about the evolution of top wealth shares in the United States?" Journal of Economic Perspectives, 29(1): 47-66.

Kopczuk, Wojciech, and Emmanuel Saez. 2004a. "Top wealth shares in the united states: 1916-2000: Evidence from estate tax returns." National Tax Journal, 57(2, part 2): $445-488$.

Kopczuk, Wojciech, and Emmanuel Saez. 2004b. "Top wealth shares in the united states: 1916-2000: Evidence from estate tax returns." National Bureau of Economic Research. 
Kopczuk, Wojciech, Emmanuel Saez, and Jae Song. 2010. "Earnings inequality and mobility in the United States: evidence from social security data since 1937." Quarterly Journal of Economics, 125(1): 91-128.

Mallet, Bernard. 1908. "A method of estimating capital wealth from the estate duty statistics." Journal of the Royal Statistical Society, 71(1): 65-101.

Miller, Merton H. 1977. "Debt and taxes." Journal of Finance, 32(2): 261-275.

Miller, Merton H., and Franco Modigliani. 1961. "Dividend policy, growth, and the valuation of shares." Journal of Business, 34(4): 411-433.

Piketty, Thomas. 2014. Capital in the 21st Century. Cambridge, MA:Harvard University Press.

Piketty, Thomas, Emmanuel Saez, and Gabriel Zucman. 2018. "Distributional national accounts: methods and estimates for the United States." Quarterly Journal of Economics, 133(2): 553-609.

Poterba, James M. 2002. "Taxation, risk-taking, and household portfolio behavior." In Handbook of public economics. Vol. 3, 1109-1171. Elsevier.

Raub, Brian, Barry Johnson, and Joseph Newcomb. 2010. "A comparison of wealth estimates for America's wealthiest decedents using tax data and data from the Forbes 400." 128-135.

Sabelhaus, John, and Alice M. Henriques Volz. 2019. "Are Disappearing Employer Pensions Contributing to Rising Wealth Inequality?" Board of Governors of the Federal Reserve System (US).

Saez, Emmanuel. 2002. "The desirability of commodity taxation under non-linear income taxation and heterogeneous tastes." Journal of Public Economics, 83(2): 217-230.

Saez, Emmanuel, and Gabriel Zucman. 2016. "Wealth inequality in the United States since 1913: Evidence from capitalized income tax data." Quarterly Journal of Economics, 131(2): 519-578.

Saez, Emmanuel, and Gabriel Zucman. 2019a. "Progressive Wealth Taxation." Brookings Papers on Economic Activity.

Saez, Emmanuel, and Gabriel Zucman. 2019b. "Scoring of the Sanders Wealth Tax Proposal." mimeo.

Saez, Emmanuel, and Gabriel Zucman. 2019c. "Scoring of the Warren Wealth Tax Proposal." mimeo.

Saez, Emmanuel, and Gabriel Zucman. 2019d. The Triumph of Injustice: How the Rich Dodge Taxes and How to Make Them Pay. WW Norton \& Company. 
Saez, Emmanuel, and Gabriel Zucman. 2020. "Comments on Smith, Zidar, and Zwick (2019)." mimeo.

Scholz, John Karl. 1992. "A direct examination of the dividend clientele hypothesis." Journal of Public Economics, 49(3): 261-285.

Smith, Matthew, Danny Yagan, Owen M Zidar, and Eric Zwick. 2020. "The Rise of Pass-Throughs and The Decline in the Labor Share." Working paper.

Smith, Matthew, Danny Yagan, Owen Zidar, and Eric Zwick. 2019. "Capitalists in the Twenty-first Century." Quarterly Journal of Economics, 134(4): 1675-1745.

Stewart, Charles. 1939. "Income Capitalization as a Method of Estimating the Distribution of Wealth By Size Groups." In Studies in Income and Wealth, Volume 3. 95-146. NBER.

Wolff, Edward N. 1998. "Recent trends in the size distribution of household wealth." Journal of Economic Perspectives, 12(3): 131-150.

Yagan, Danny. 2015. "Capital tax reform and the real economy: The effects of the 2003 dividend tax cut." American Economic Review, 105(12): 3531-63.

Zucman, Gabriel. 2013. "The missing wealth of nations: Are Europe and the US net debtors or net creditors?" Quarterly Journal of Economics, 128(3): 1321-1364.

Zwick, Eric. 2019. "Economic Measurement and the Distributional Accounts." Testimony before Joint Economic Committee.

Zwick, Eric, and James Mahon. 2017. "Tax policy and heterogeneous investment behavior." American Economic Review, 107(1): 217-48. 
Figure 1: Wealth Concentration in the United States

A. Top $0.1 \%$ Share of Total Wealth

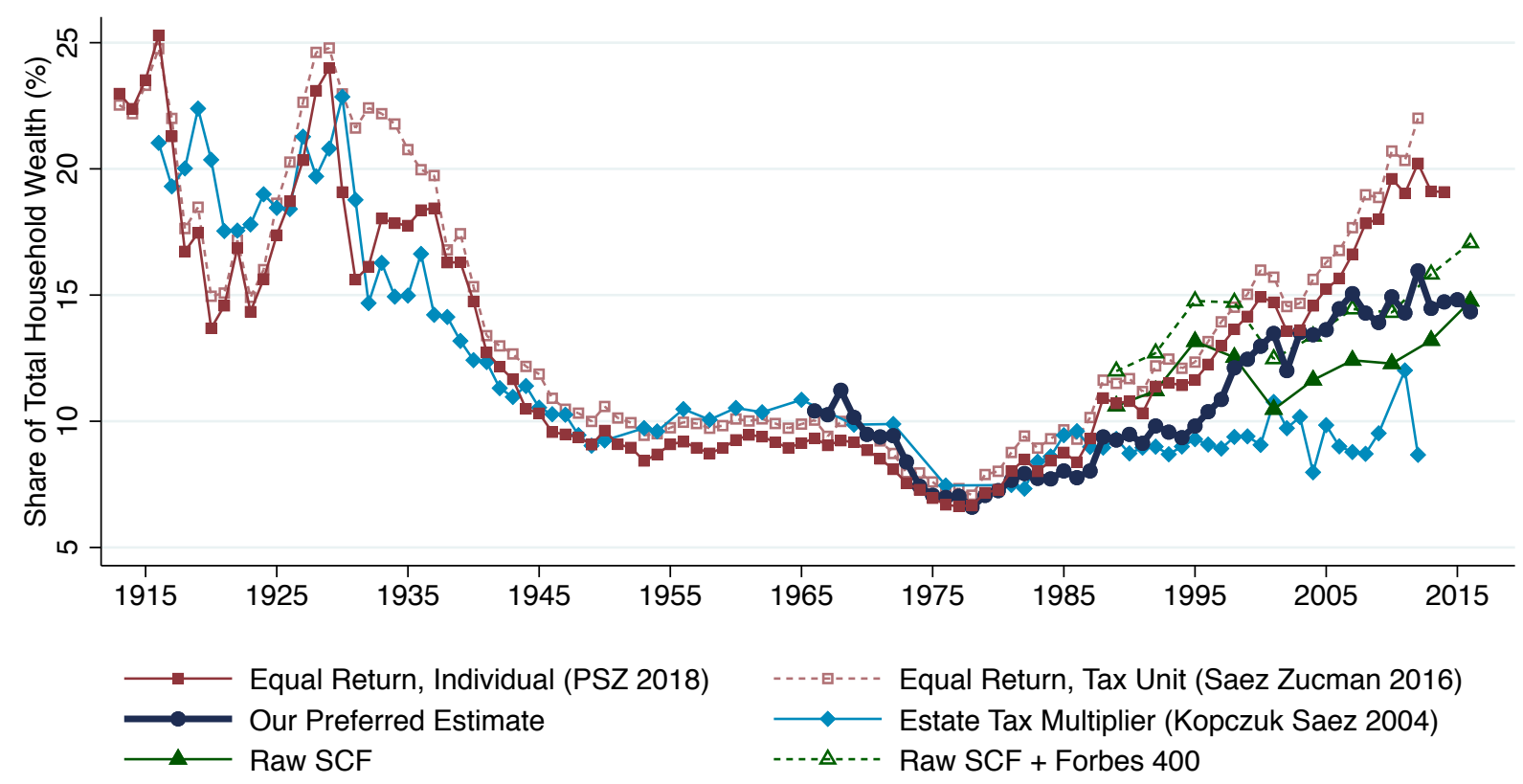

B. Wealth Composition for Key Components within Top Decile (2016)

Taxable Fixed Income

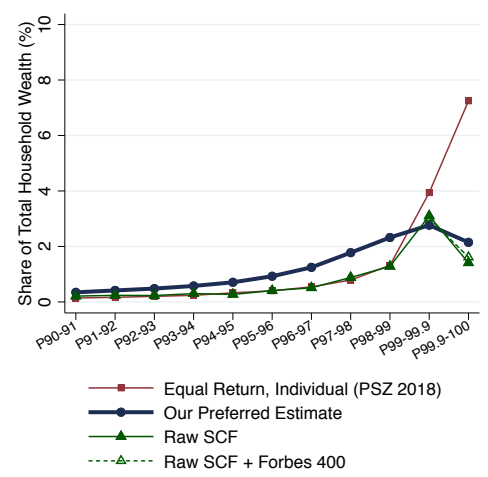

Private Business

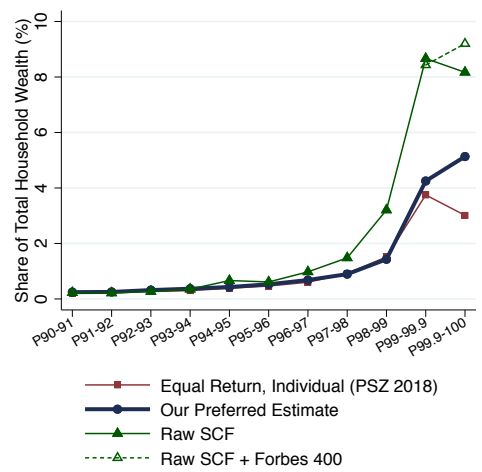

Public Equity

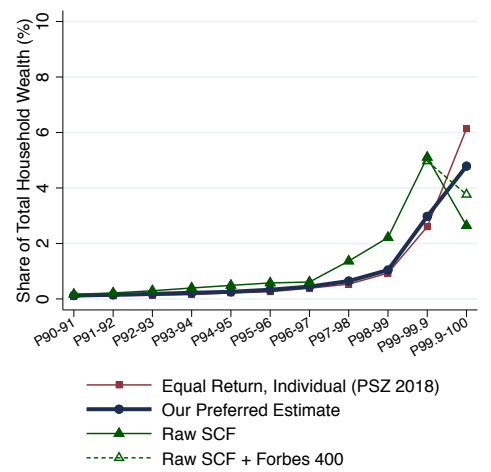

Notes: This figure plots the share of total household wealth for different wealth groups. Panel A graphs our preferred specification for the top $0.1 \%$ share of net household wealth, along with analogous series from Piketty, Saez and Zucman (2018), Saez and Zucman (2016), Kopczuk and Saez (2004a) (retrieved from and updated in the appendix of Saez and Zucman (2016)), and the SCF. Panel B plots the share of aggregate household wealth in 2016 for different groups within the top decile that comes from taxable fixed income wealth, private business wealth, and public equity wealth. For example, private business wealth of the top $0.1 \%$ amounts to $8 \%$ of aggregate household wealth in the raw SCF series. 
Figure 2: Aggregate Household Wealth and Fiscal Income Components

A. Components of Aggregate Household Wealth

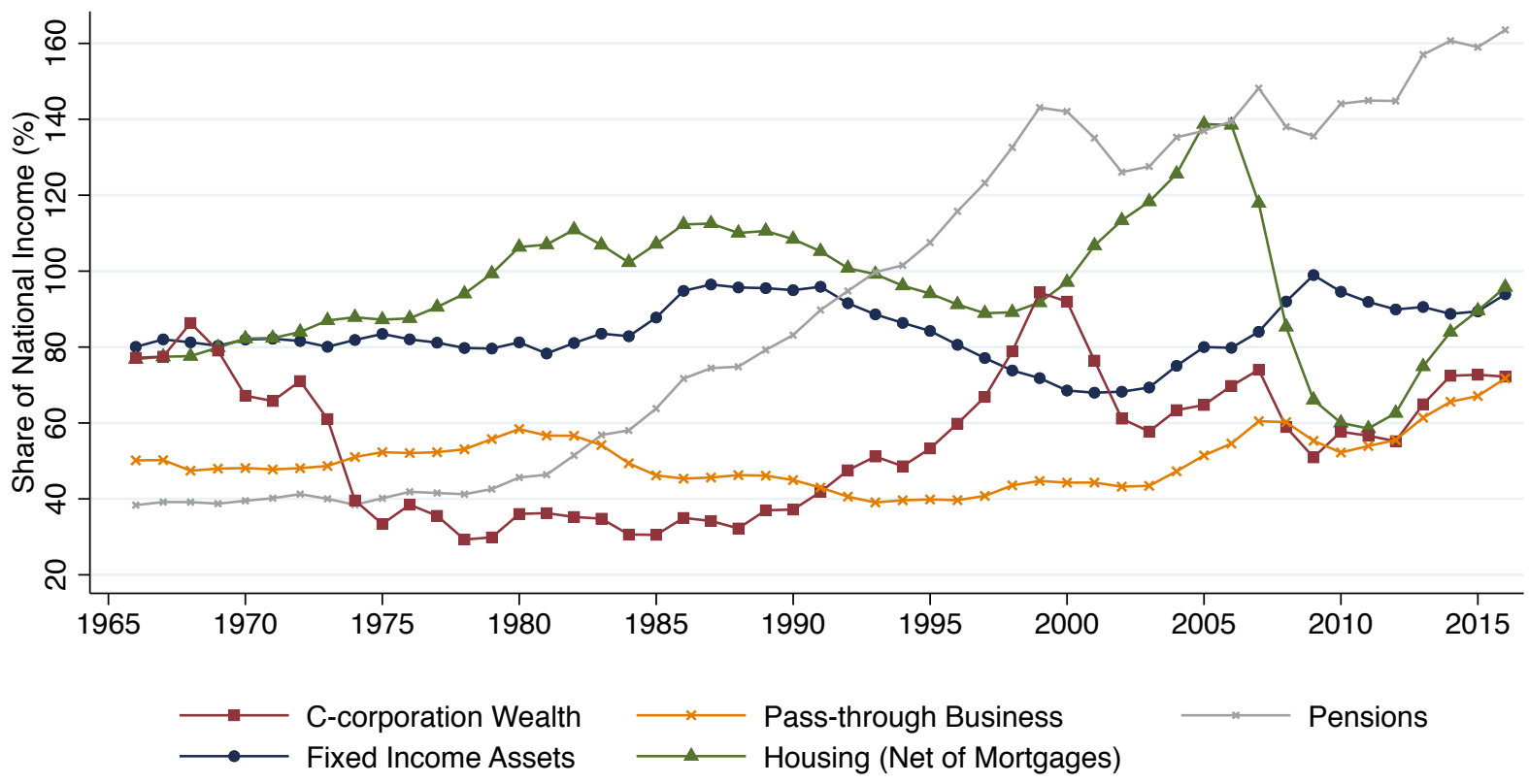

B. Components of Aggregate Fiscal Capital Income

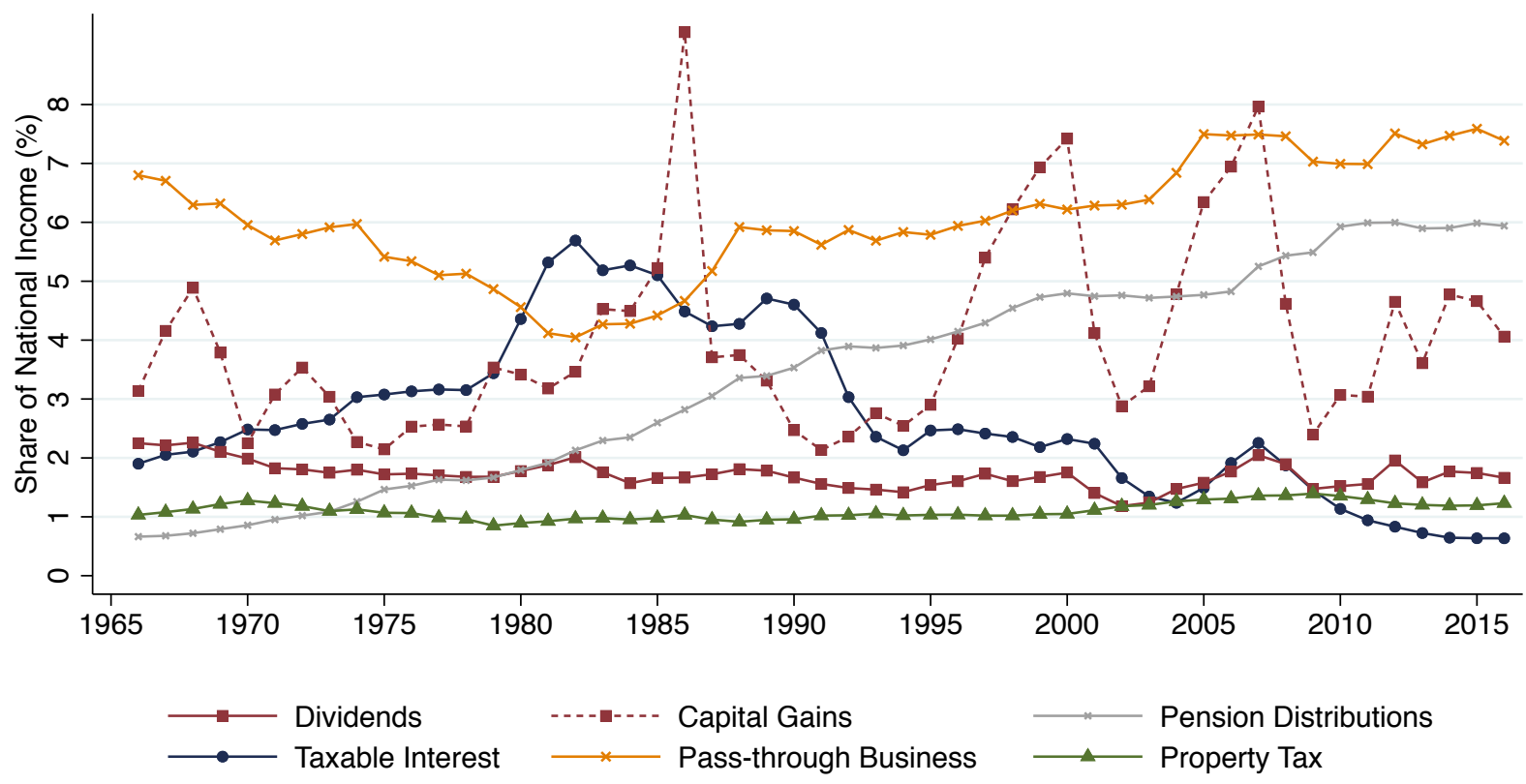

Notes: This figure plots the main components of aggregate national household wealth and fiscal capital income. Panel A plots net household wealth components relative to national income. Fixed income assets include taxable bonds, municipal bonds, currencies, and deposits, and exclude non-mortgage debt. Ccorporation wealth includes public and private C-corporations. Pass-through business includes S-corporation equity and non-corporate equities, including sole proprietorships and partnerships. Housing denotes housing wealth net of mortgages. Panel B graphs the ratio of components of fiscal income relative to national income. 
Figure 3: Concentration of Fiscal Income Components (Ranked by Component)

A. Taxable Interest

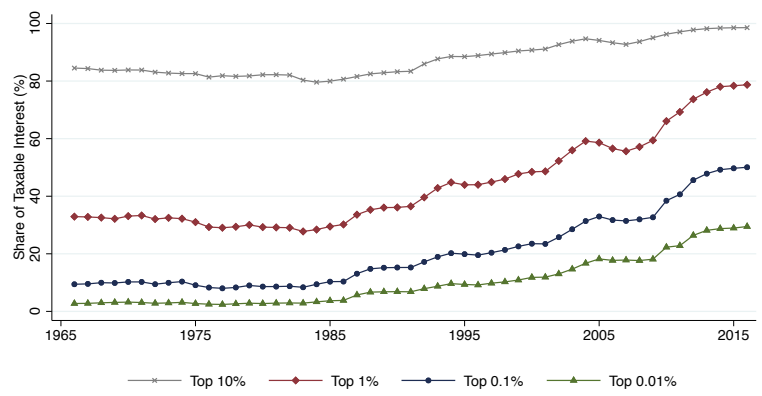

C. Dividends

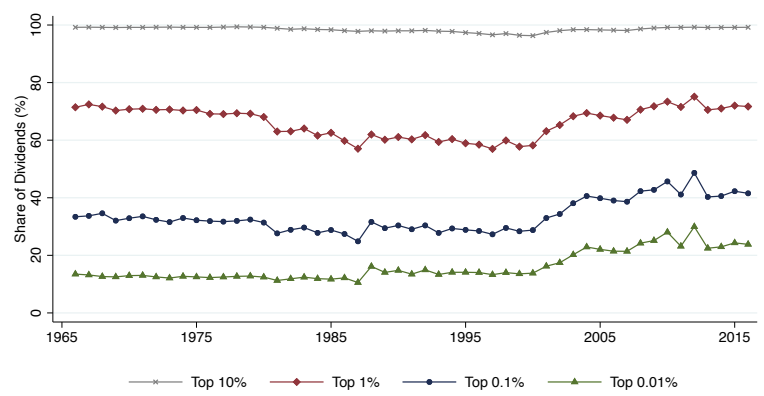

E. S-corporation + Partnership

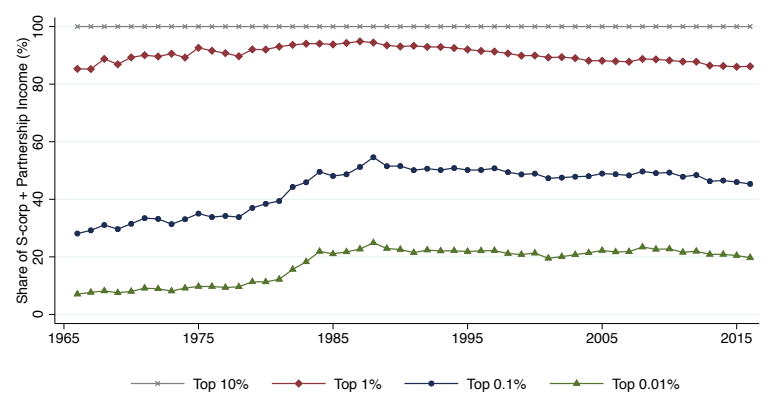

G. Wage

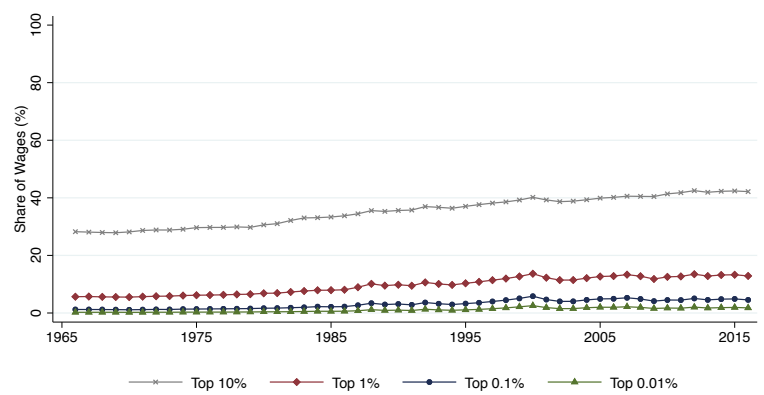

B. Property Tax

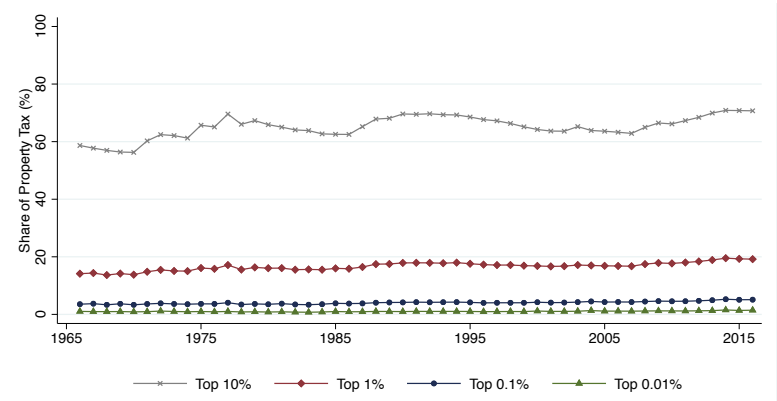

D. Capital Gains

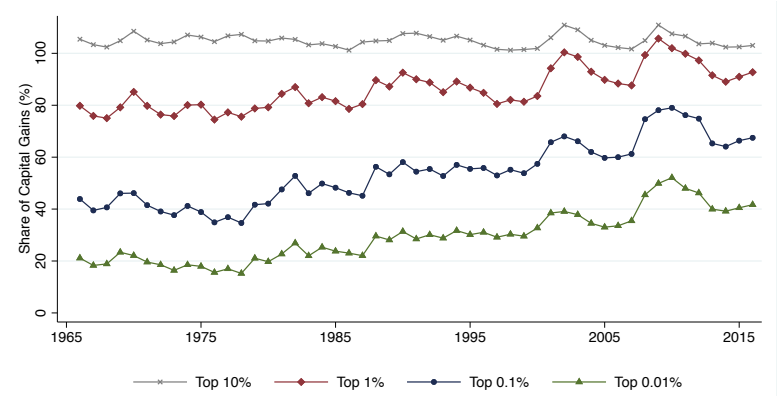

F. Sole Proprietorship

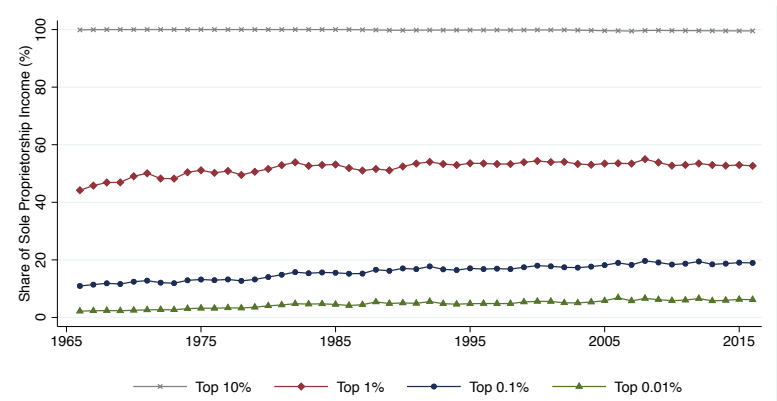

H. Pension Income

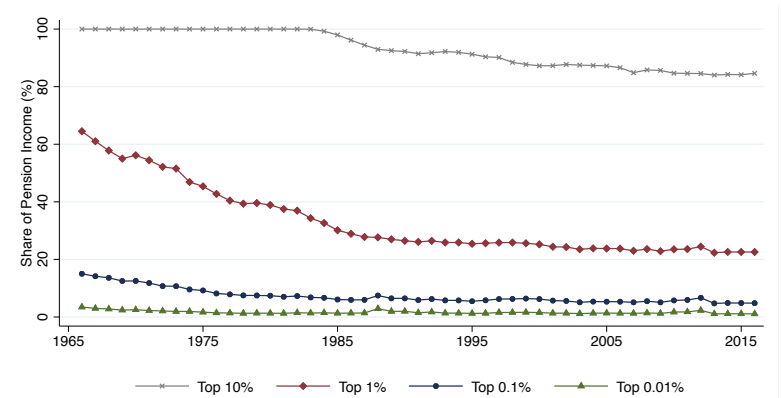

Notes: This figure describes the top share of fiscal income of different types. Panel A plots the evolution of top shares of interest income. Panel B, C, D, E, F, G, and H provide analogous series for property taxes, dividends, realized capital gains, S-corporation plus partnership income, sole proprietorship income, wages, and pension income, respectively. Ranks are for each component. For example, Panel A Top 10\% plots the share of taxable interest income that goes to those in the top $10 \%$ of the taxable interest income distribution each year. 
Figure 4: Fixed Income Rates of Return Vary across Wealth and Interest Income Groups

\section{A. SCF Fixed Income Portfolio Shares (Net Worth Ranks)}

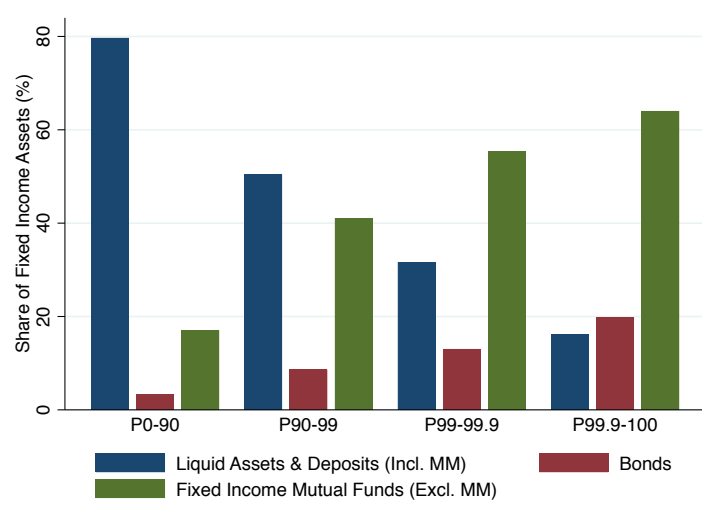

C. Interest Rate, $\bar{r}_{f i x}$

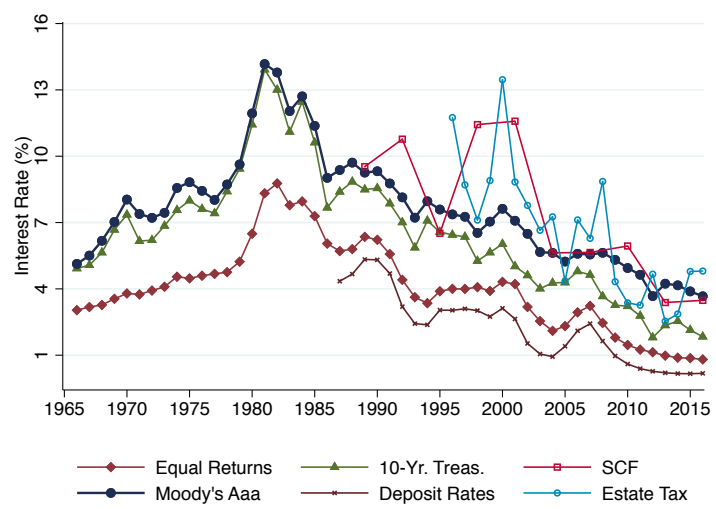

B. Average Rates of Return

(Taxable Interest Ranks)

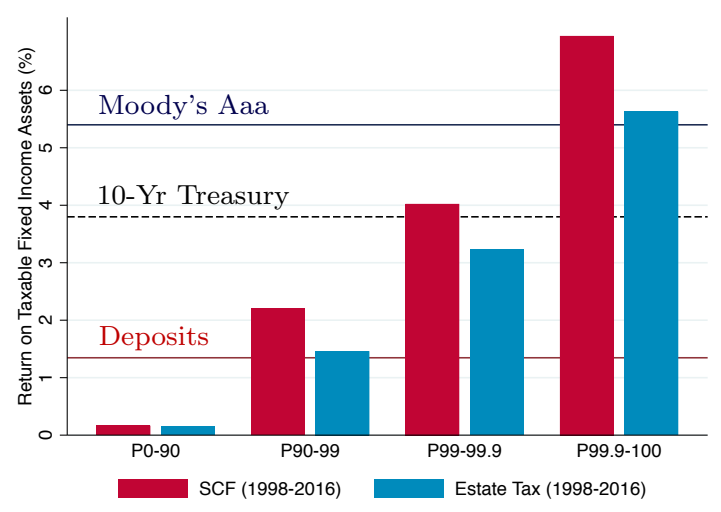

D. Capitalization Factor, $1 / \bar{r}_{f i x}$

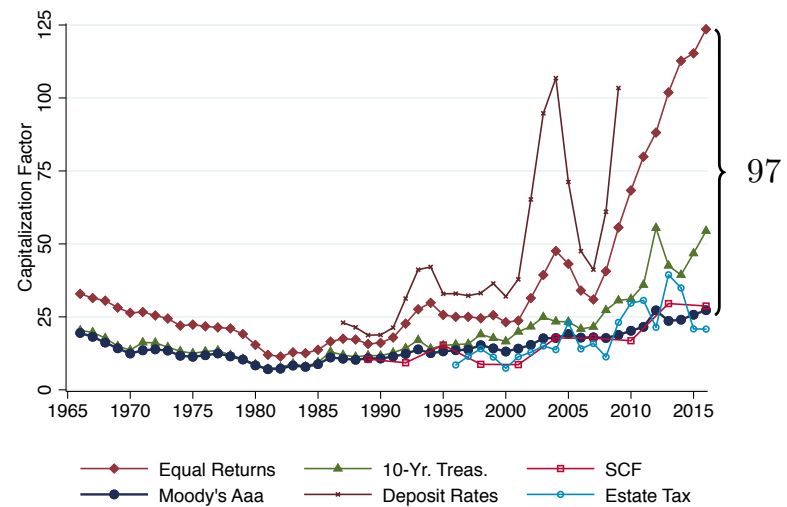

Notes: This figure provides evidence of heterogeneous fixed income portfolios and returns and then compares interest rates and capitalization factors under alternative assumptions of average returns to fixed income wealth. Panel A decomposes fixed income wealth into asset subclasses to show portfolio shares by wealth group in 2016. Panel B plots the returns to fixed income assets by percentile of taxable interest income. Panel C plots different rate-of-return series by year. Equal returns plots $\bar{r}_{f i x}$ following the capitalization in Saez and Zucman (2016). 10-Yr. Treas. and Moody's Aaa refer to ten-year Treasury yields and Moody's Aaa yields. Deposits are the bank deposit rate from Drechsler, Savov and Schnabl (2017). SCF plots returns to fixed income assets held by the top $0.1 \%$ of the SCF interest income distribution. Similarly, the estate tax series plots the ratio of taxable interest income to fixed income assets from the estate tax for those whose interest income exceeded the top $0.1 \%$ of taxable interest income in the full population that year. Panel D plots capitalization factors, i.e., the reciprocal of the interest rates from Panel C. 
Figure 5: Dividends are More Informative than Realized Gains for Inferring Stock Wealth

A. Realized Gains Composition

(SOI Aggregates, 1997-2012)

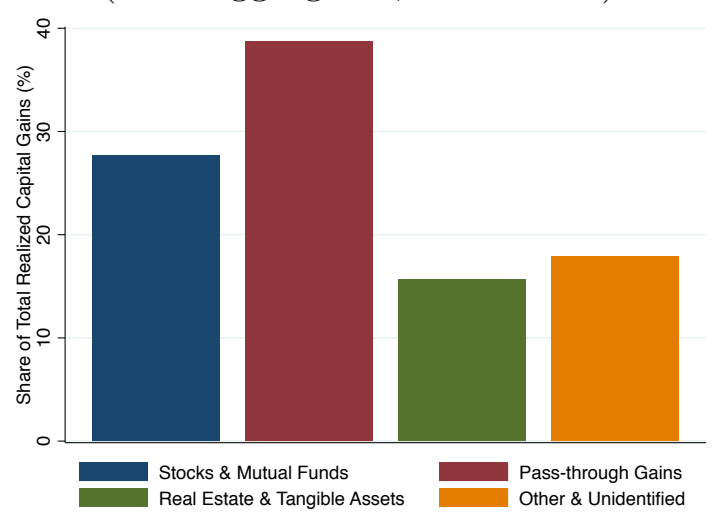

C. Best Fit Weight on Dividends

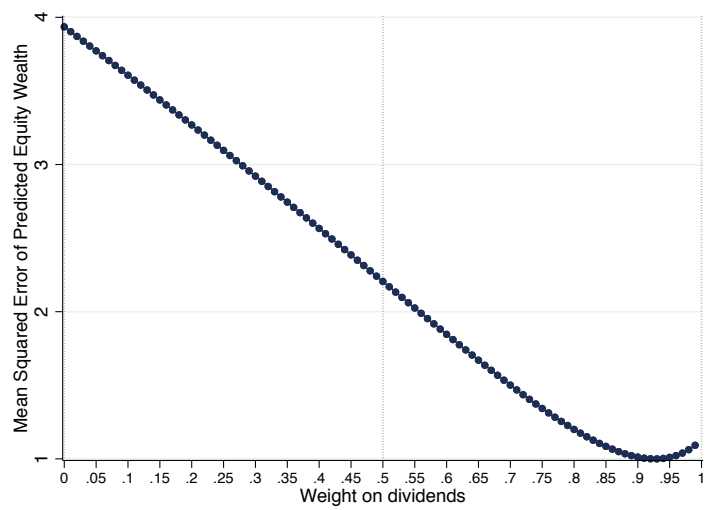

B. Average Rates of Return

(Respective Flow Ranks)

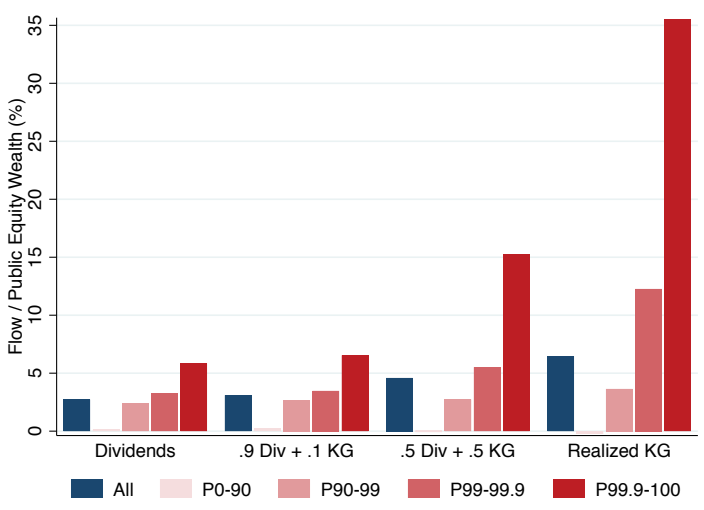

D. Capitalization Factors

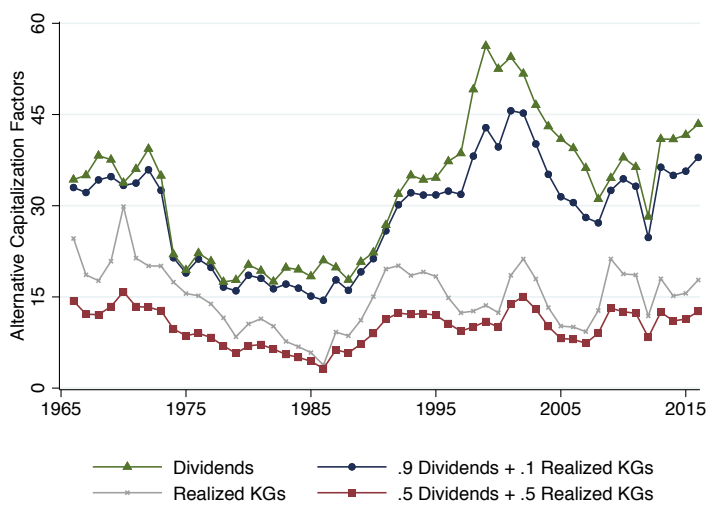

Notes: Panel A decomposes realized capital gains by component using IRS statistics of income aggregates from 1997-2012. Panel B plots average yields, which are the ratio of income flows to stocks, for different income flows and different groups using data from the SCF from 1989-2016. Four different income flows are shown: (1) dividend income, (2) a convex combination of dividend income and realized capital gains with a 0.9 weight on dividend income and a 0.1 weight on realized capital gains, (3) an average of dividend income and realized capital gains, and (4) realized capital gains. The denominator for each is public equity wealth in the SCF, which is the "equity" variable defined in Appendix E. These yields are plotted for four groups ranked by flows. For example, the first part of the graph shows the dividend yield for the full population, those in the bottom $90 \%$ of the dividend income distribution, those in the P90-P99, P99-99.9, and top 0.1\% of the dividend income distribution, respectively. Panel $\mathrm{C}$ plots the mean squared error of predicted equity wealth in the SCF for different weights on dividends when forming income flows for capitalization. For example, the rightmost point of this graph shows the mean-squared error from capitalizing $(0 \times$ capital gains $+1 \times$ dividends) to estimate equity wealth. The $y$-axis value is normalized so that the smallest error equals 1. Panel D shows how the capitalization factors for different combinations of dividends and realized capital gains evolve overtime. 
Figure 6: The Value of Private Business Equity and Unequal Returns across Industries

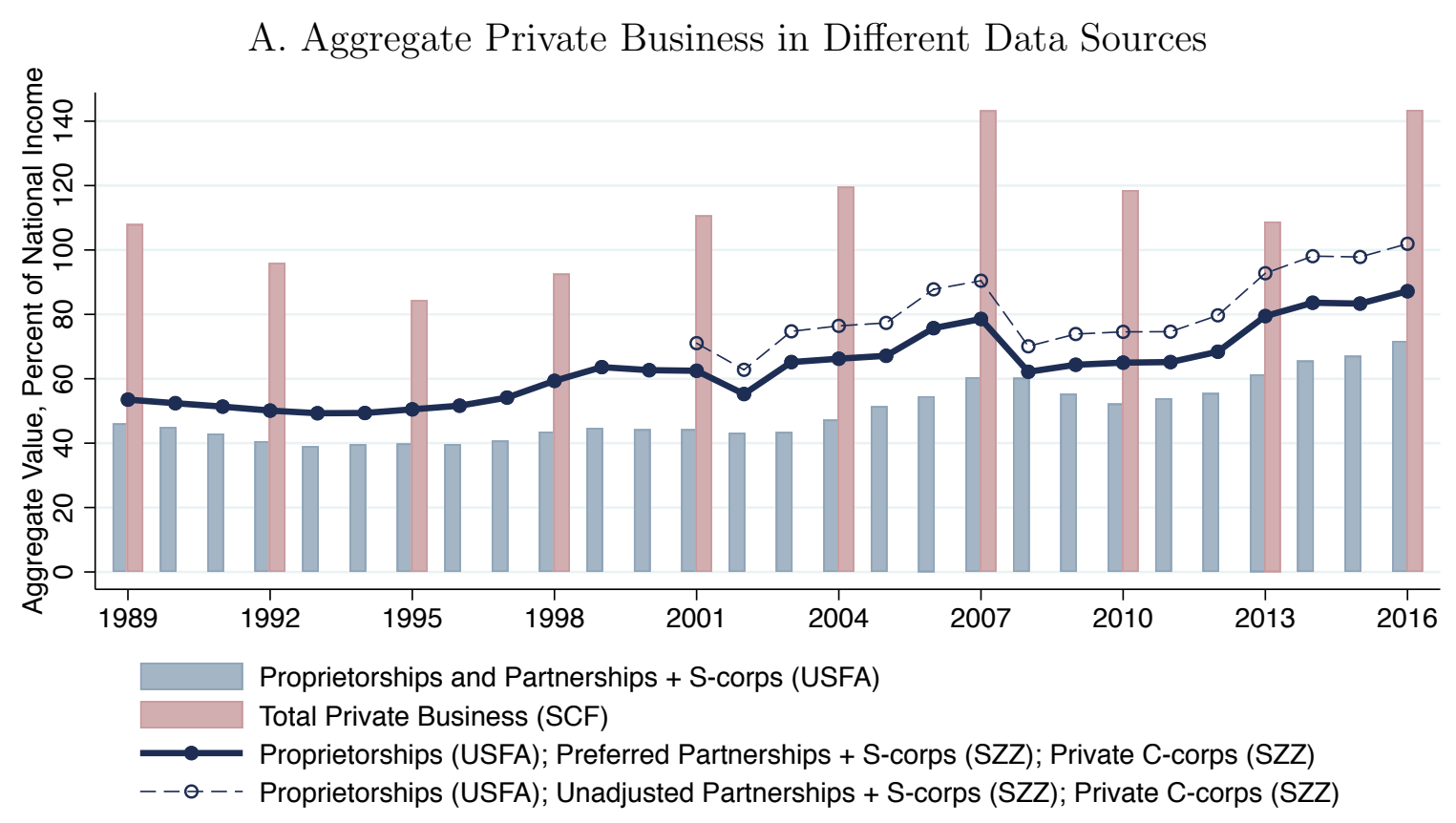

B. Industry Return Heterogeneity (2001-2016)

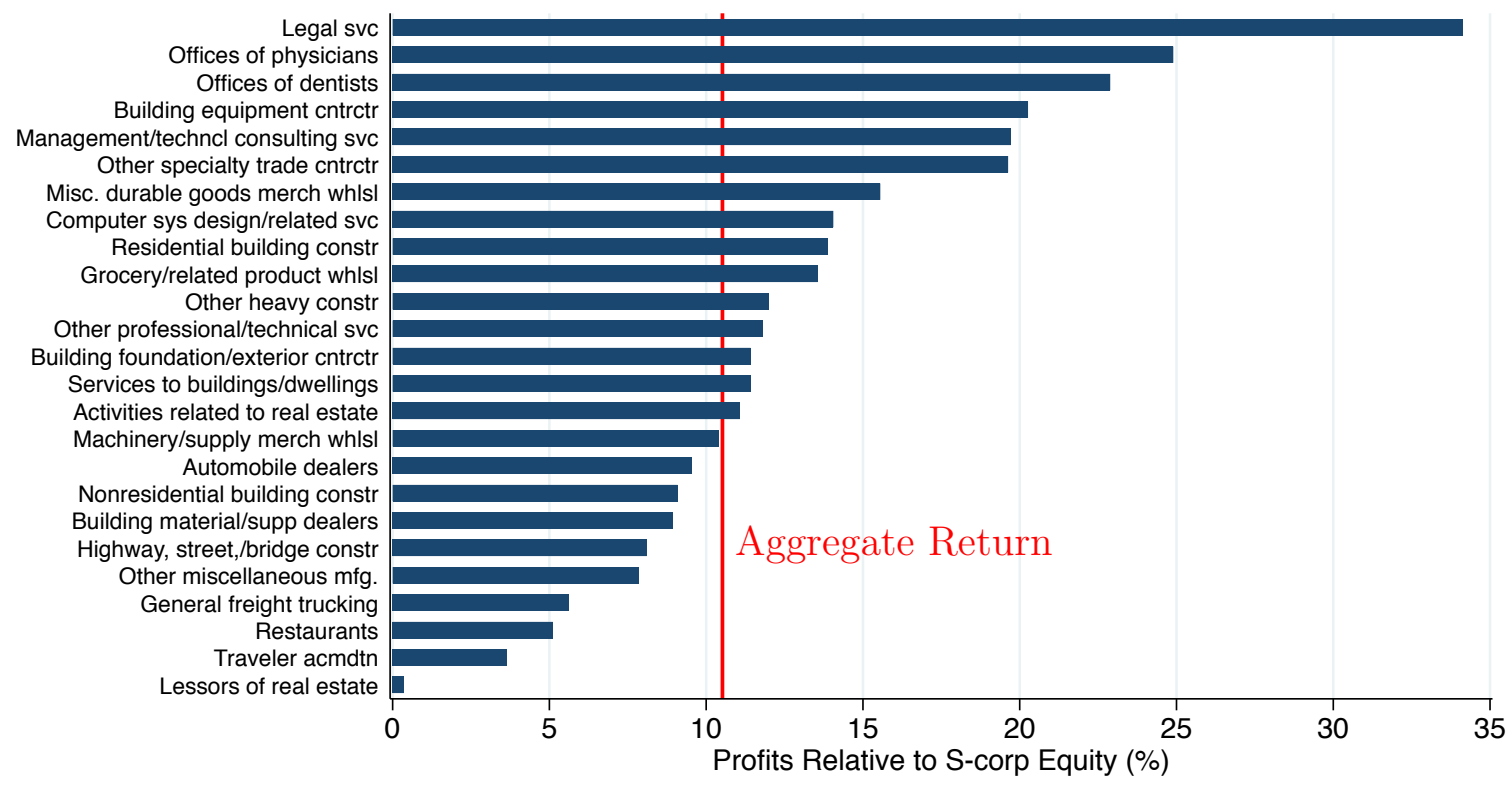

Notes: This figure documents differences in the aggregate value of private businesses across data sources and heterogeneity in effective returns on equity across industries. Panel A compares the aggregate private business values from the Survey of Consumer Finances (SCF) to an analogous concept from the capitalization approach based on the US Financial Accounts, which combines non-corporate business wealth with S-corporation equity wealth. The panel also plots estimates of private business wealth using our valuations for private Ccorporations, S-corporations, and partnerships. Two versions are displayed. One plots our preferred series, which makes adjustments for liquidity discounts and labor income characterized as profits, and the other shows the series without these two adjustments. Panel B plots the implied return on equity by industry from 2001-2016 for the thirty largest industries in terms of aggregate S-corporation value, ordered by return on equity. The red line corresponds to the aggregate implied return on equity within the S-corporation sector. 
Figure 7: Using Wages and Pension Distributions to Infer Pension Wealth

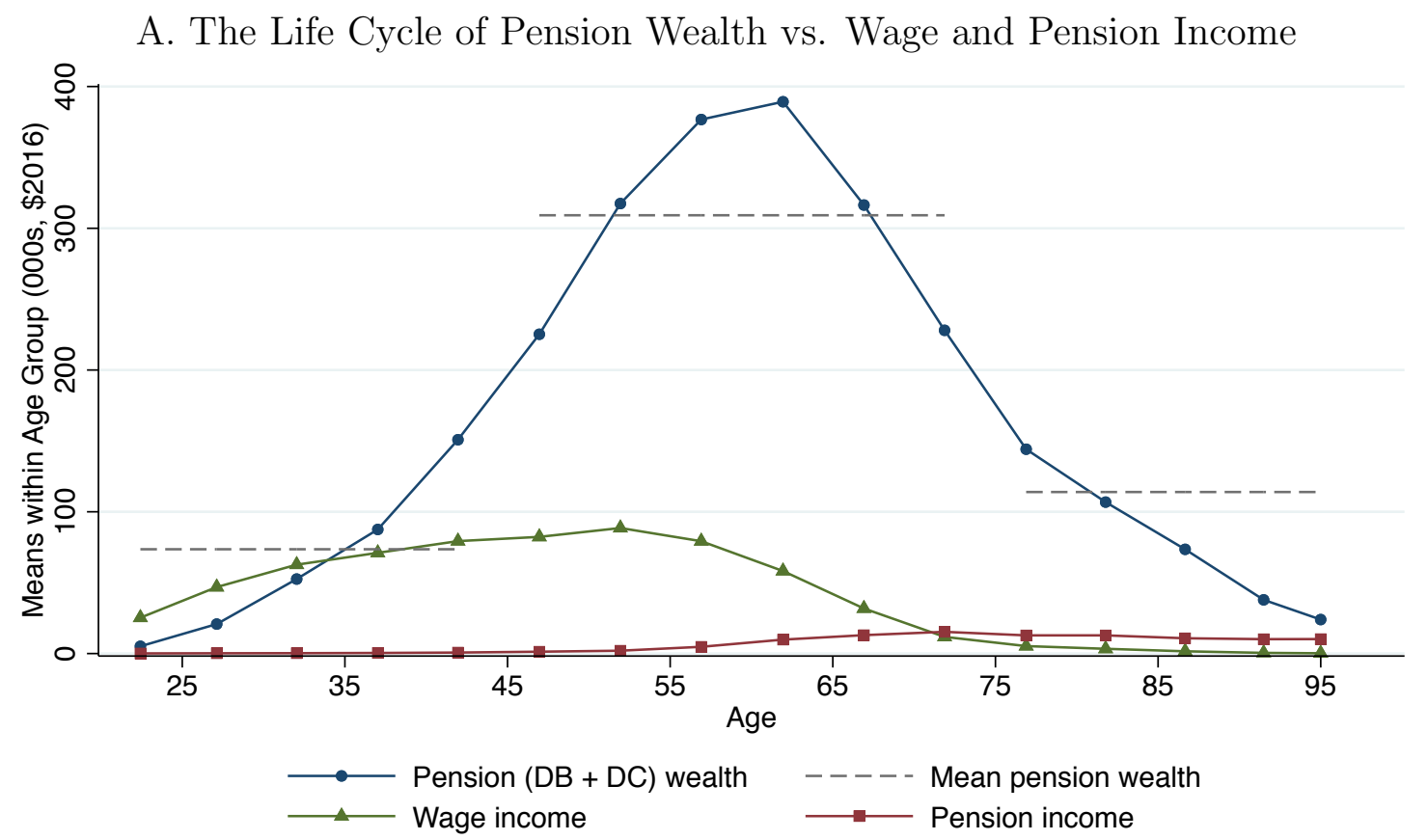

B. Flow-Stock Relationships for Pension Wealth Vary with Age

Wage Income

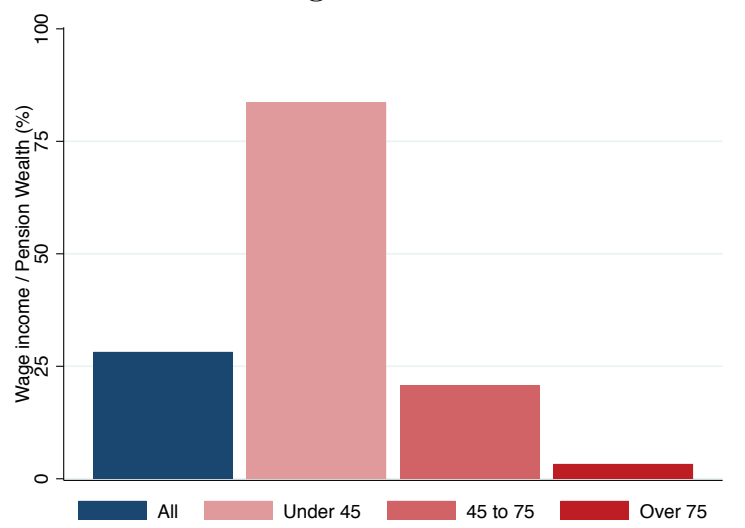

Pension Income

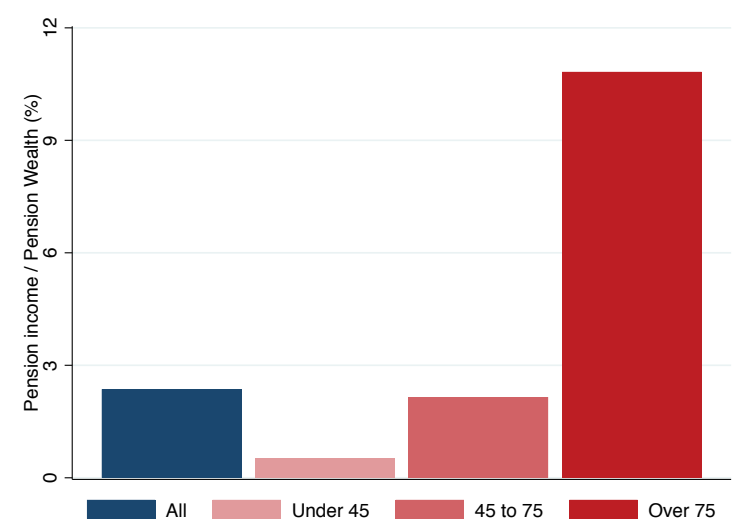

Notes: Panel A plots 1989-2016 data from the Survey of Consumer Finance on the life cycle of pension wealth, wage income, and pension income. Pension wealth is the defined-benefit-augmented SCF from Sabelhaus and Henriques Volz (2019). The dashed lines plot average pension wealth for that age group. Panel B plots the ratio of wage income to pension wealth for the full population, those under age 45, those aged 45-75, and those who are over 75. Panel $\mathrm{C}$ is similar but plots the ratio of pension distributions to pension wealth by age group. 
Figure 8: Regional Variation in the Returns to Housing Assets

A. Geographic Variation in Property Tax Rates

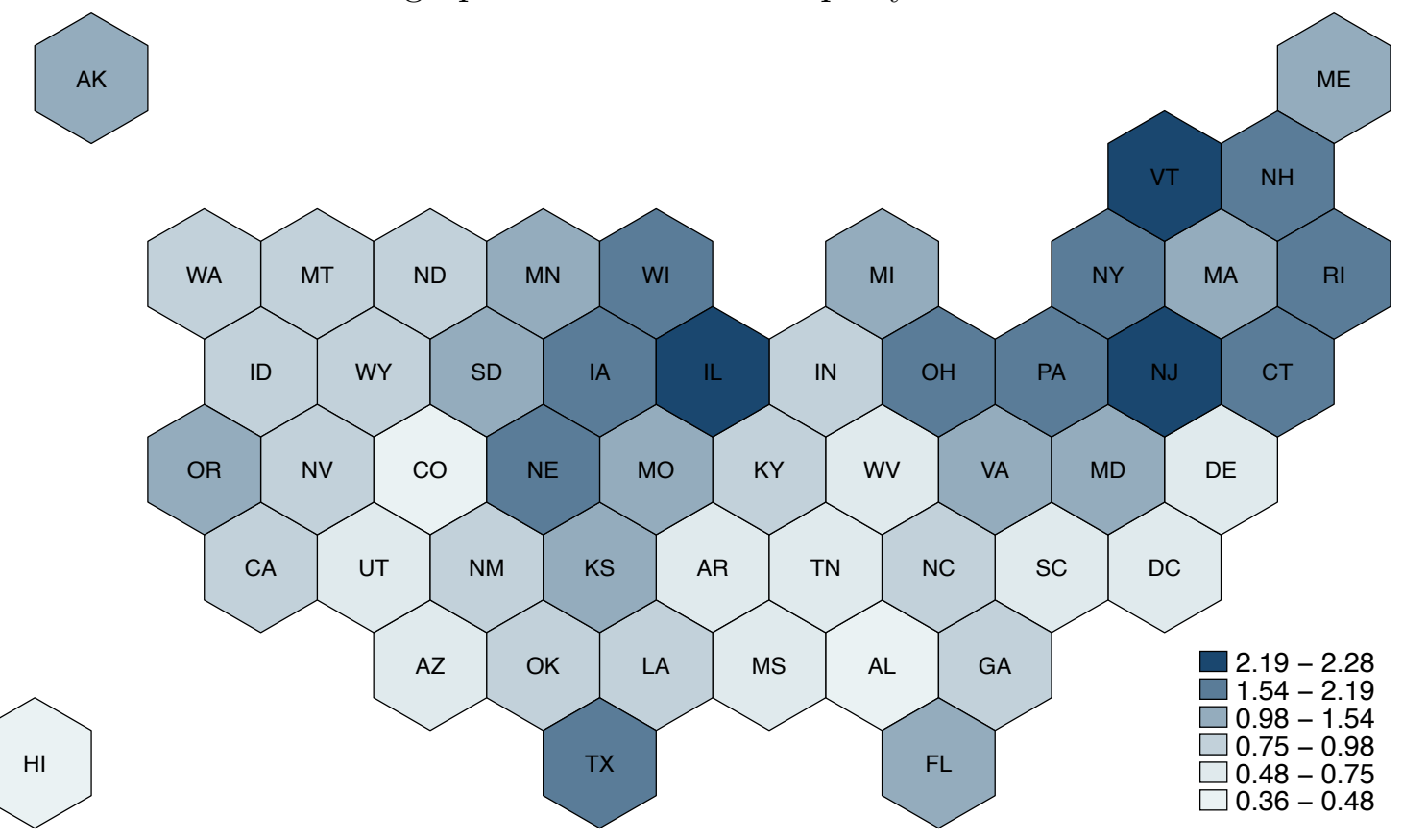

B. Evolution of Housing Capitalization Factors in California

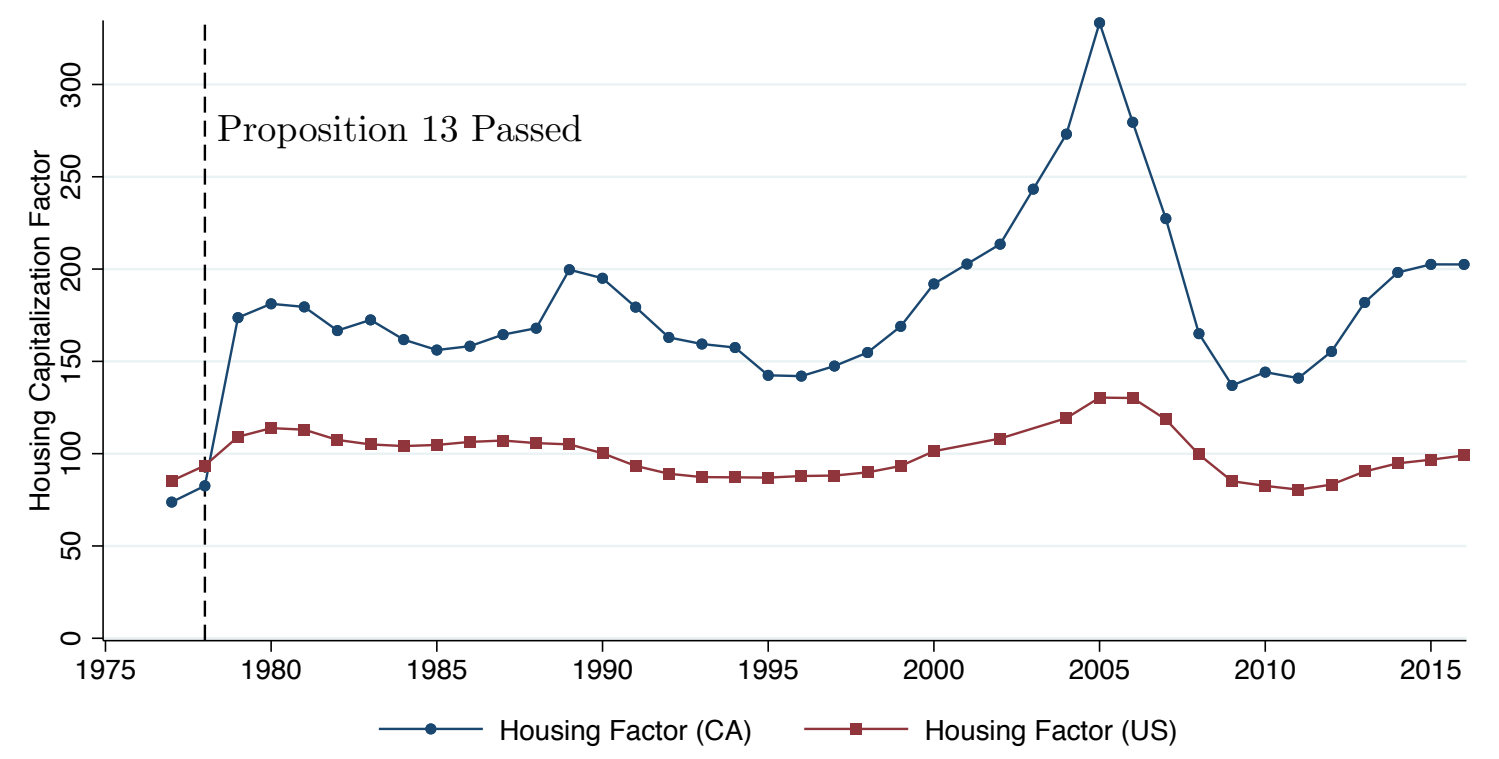

Notes: Panel A provides a map of state property tax rates from ATTOM. Panel B shows how the housing asset capitalization factor, equal to the reciprocal of the state property tax rate, has evolved in California versus an equal returns benchmark pooling all states. 
Figure 9: Coastal States Drive Growth in Wealth and Wealth per Capita

A. Change in Wealth-to-GDP Ratio (1980-2016)

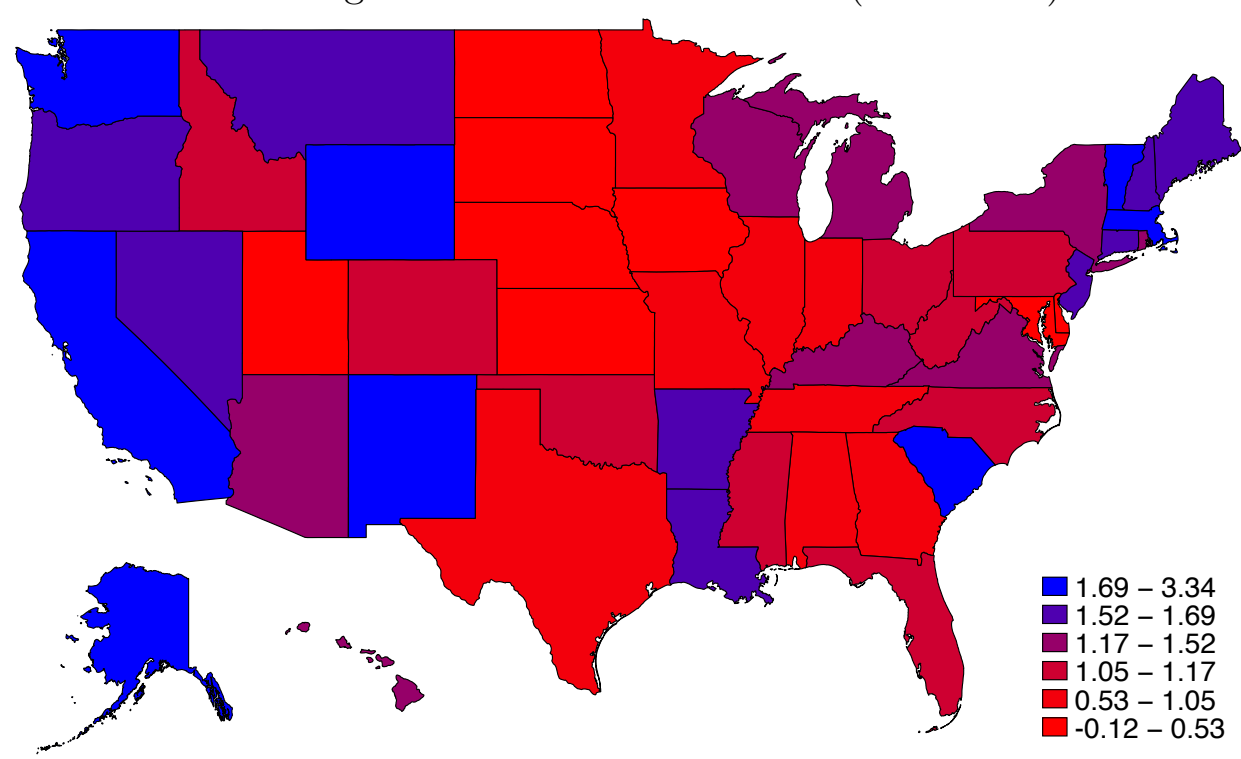

B. Change in Wealth per Capita (1980-2016)

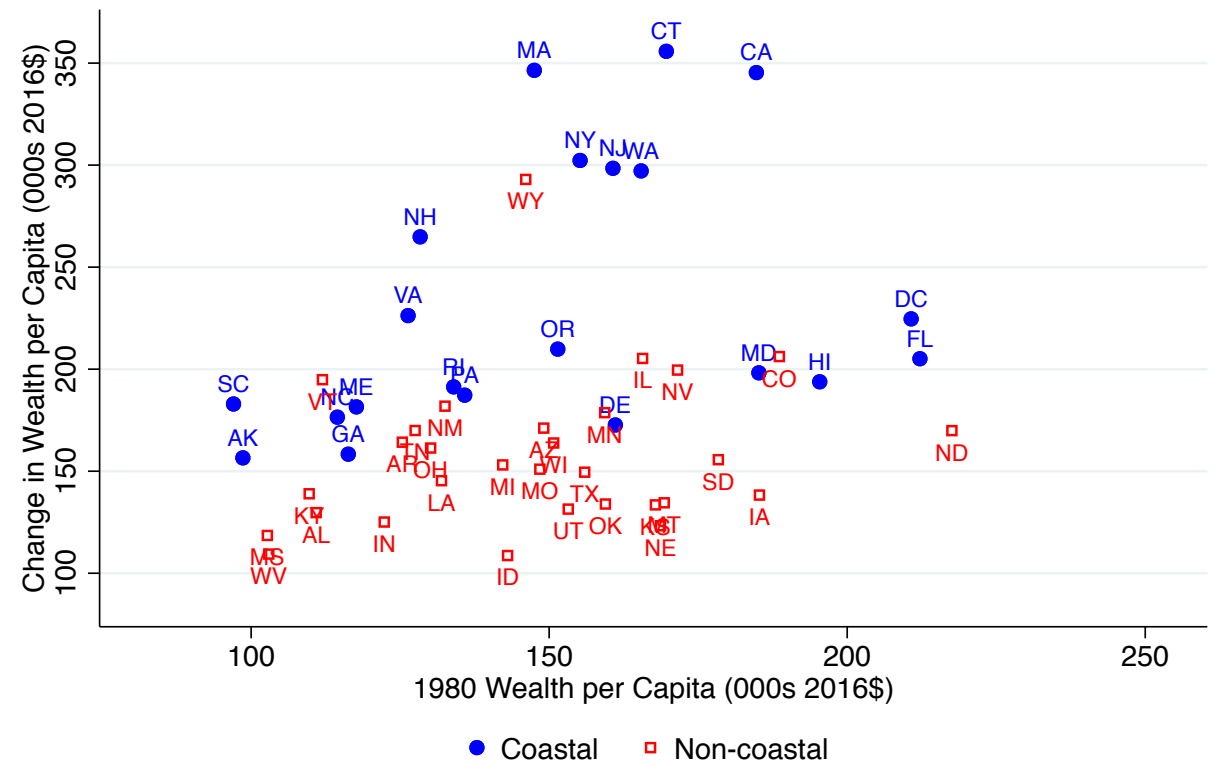

Notes: Panel A shows the change in wealth-to-GDP ratio from 1980 to 2016 across states. Panel B compares the level of wealth per capita by state in 1980 to the change in wealth per capita from 1980 to 2016. State GDP data are from the BEA and the wealth data use our preferred series. 
Figure 10: Wealth Concentration by Group under Different Approaches

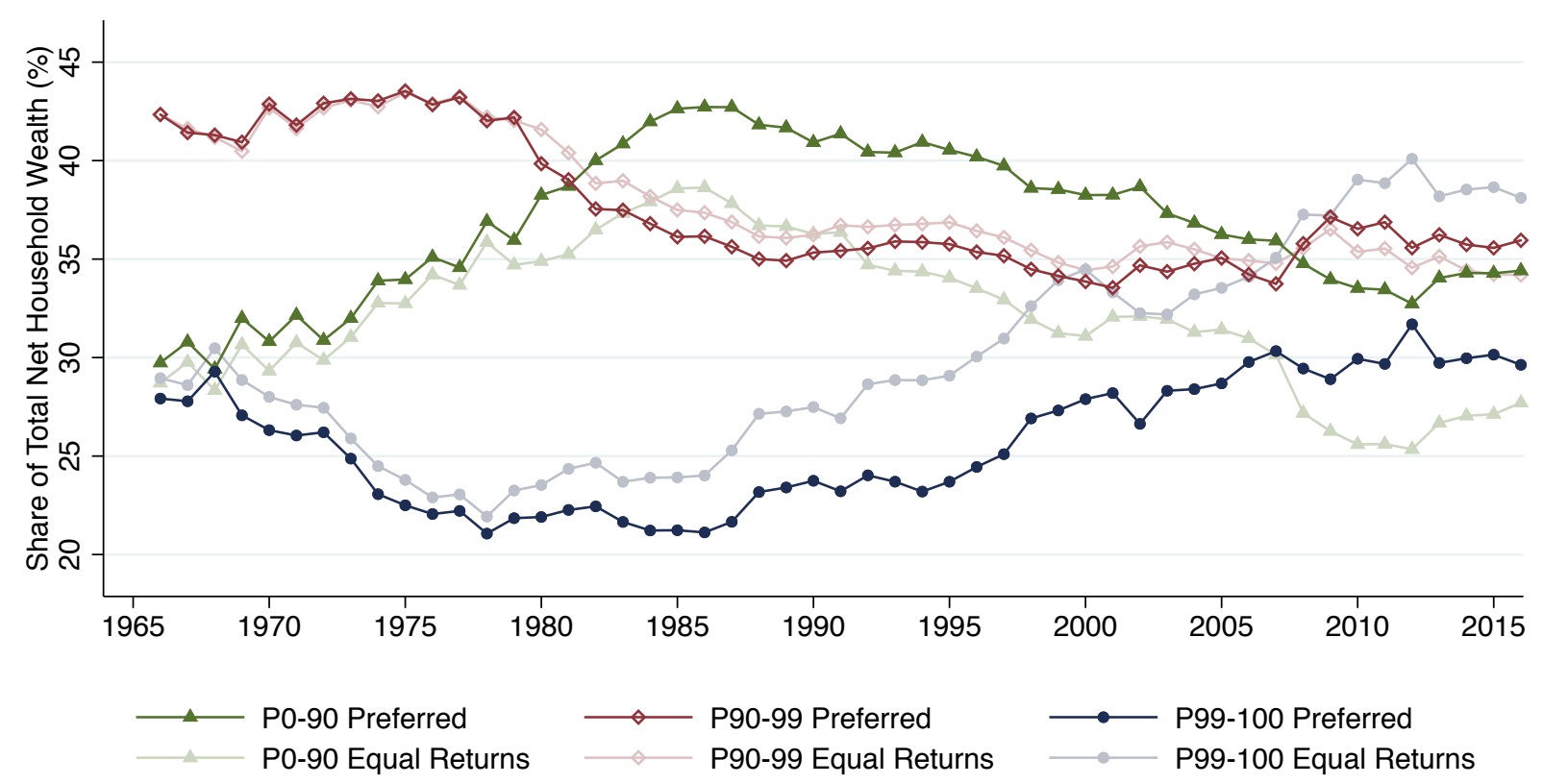

Notes: This figure plots the share of total household wealth for different wealth groups, including the bottom 90\%, P90-99, and the top 1\% under our preferred approach and the equal-returns approach. Each series defines rankings using that approach's respective wealth estimates. 
Figure 11: Implications for Imputed National Income

A. Top $1 \%$ Fixed income

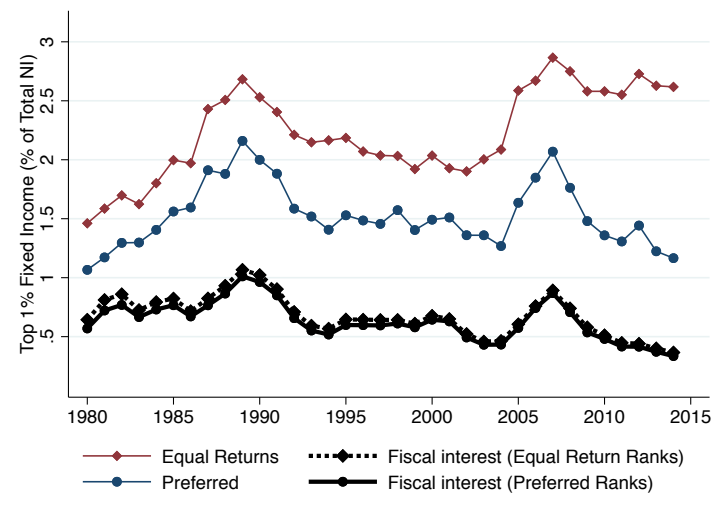

C. Top $1 \%$ Income Share

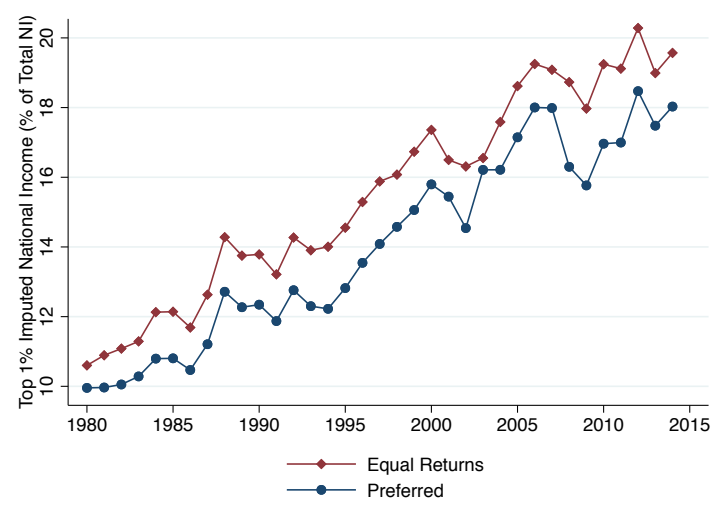

B. Top $1 \%$ Capital income

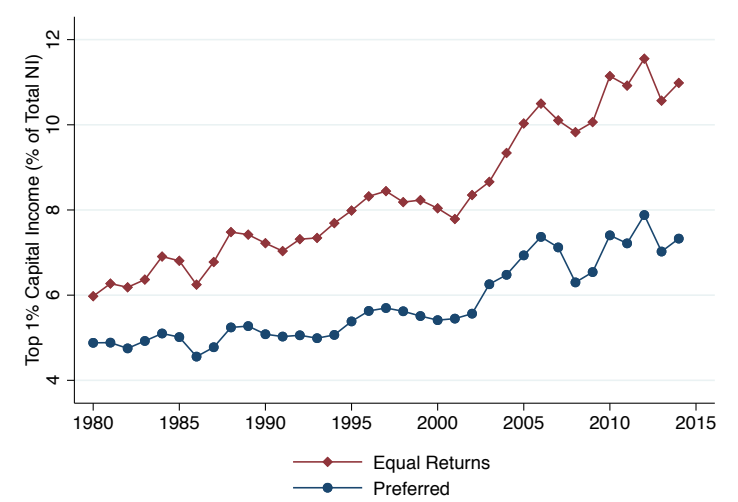

D. Top 1\% Capital Income Share

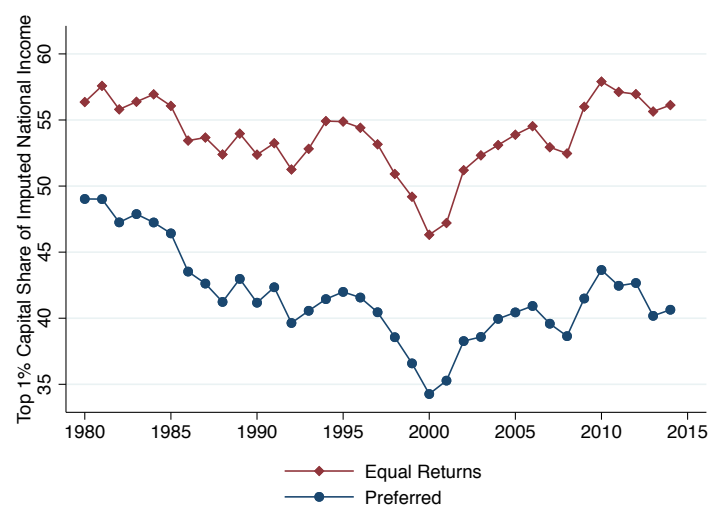

Notes: This figure shows the effect of alternative wealth assumptions for the allocation of capital income to top earners. Panel A and B plot top 1\% fixed income and total capital income as a share of total national income, respectively. Panel $\mathrm{C}$ plots the top $1 \%$ share of national income under alternative assumptions regarding allocation of wealth. Panel D compares the capital share of top $1 \%$ income under alternative assumptions regarding allocation of wealth. 
Figure 12: Top Capital and Labor Income in Imputed National Income under Different Approaches

A. Top $1 \%$ Equal Returns

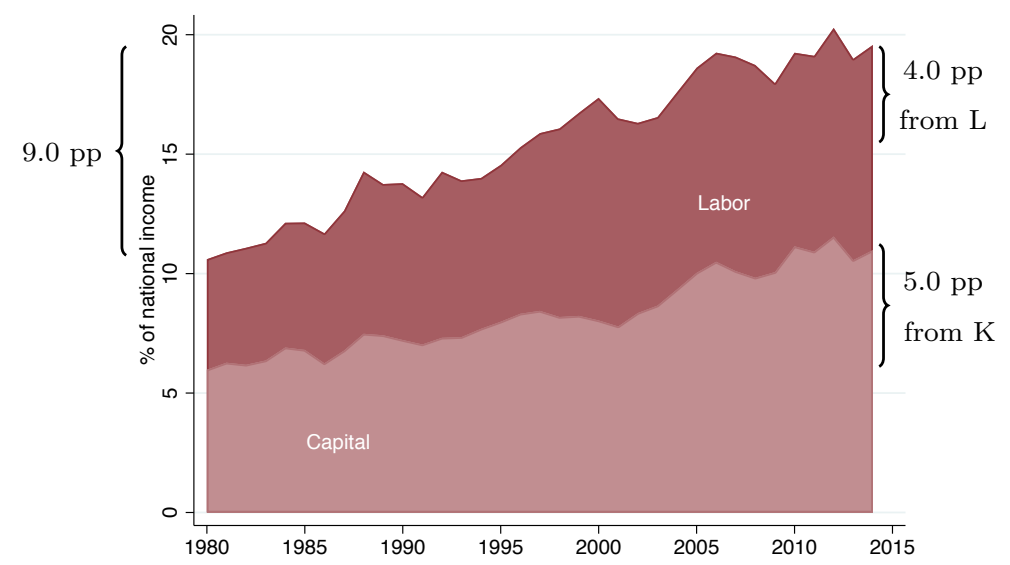

$\stackrel{1}{\perp}$

C. Top 0.1\% Equal Returns

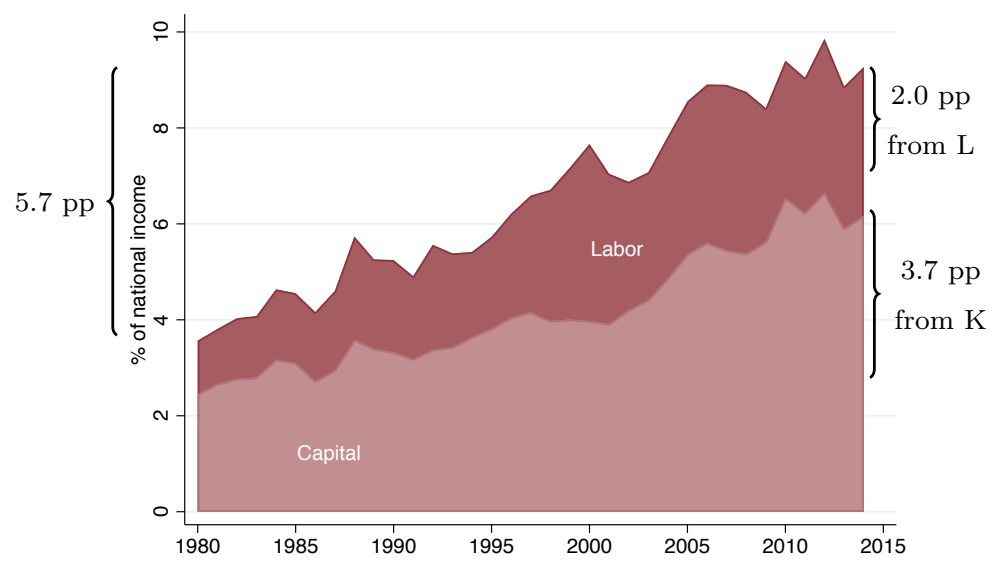

B. Top $1 \%$ Preferred

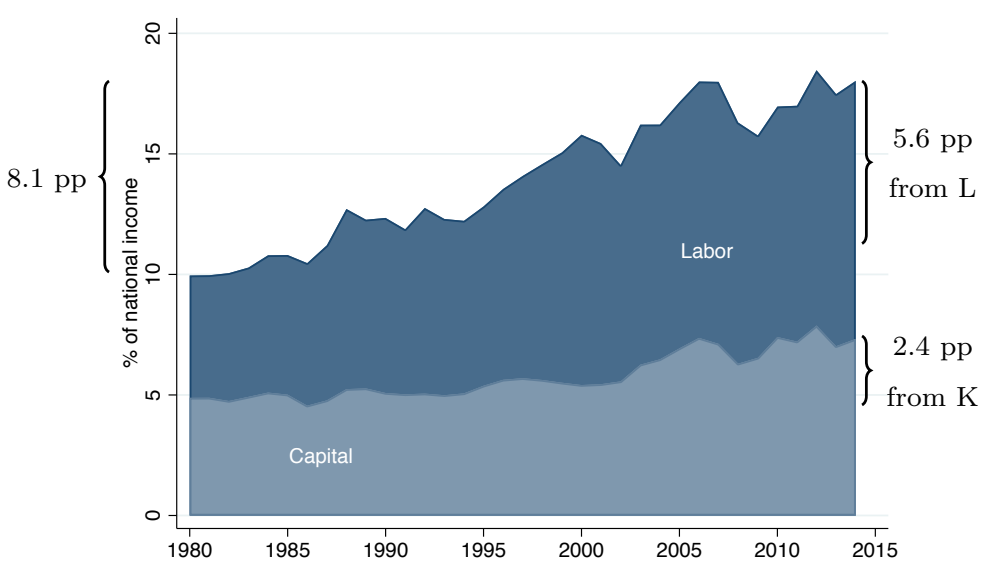

D. Top $0.1 \%$ Preferred

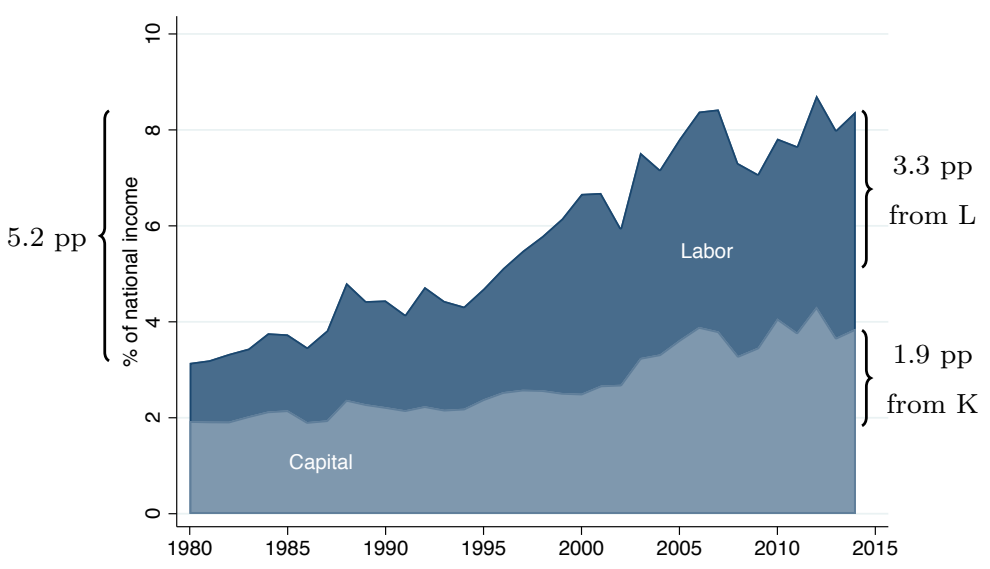

Notes: These series show the composition of imputed national income for top income groups. 
Figure 13: Comparing Approaches for Fixed Income and C-corporation Equity

A. Top $0.1 \%$ Taxable Fixed Income Wealth Estimates

Level in 2016
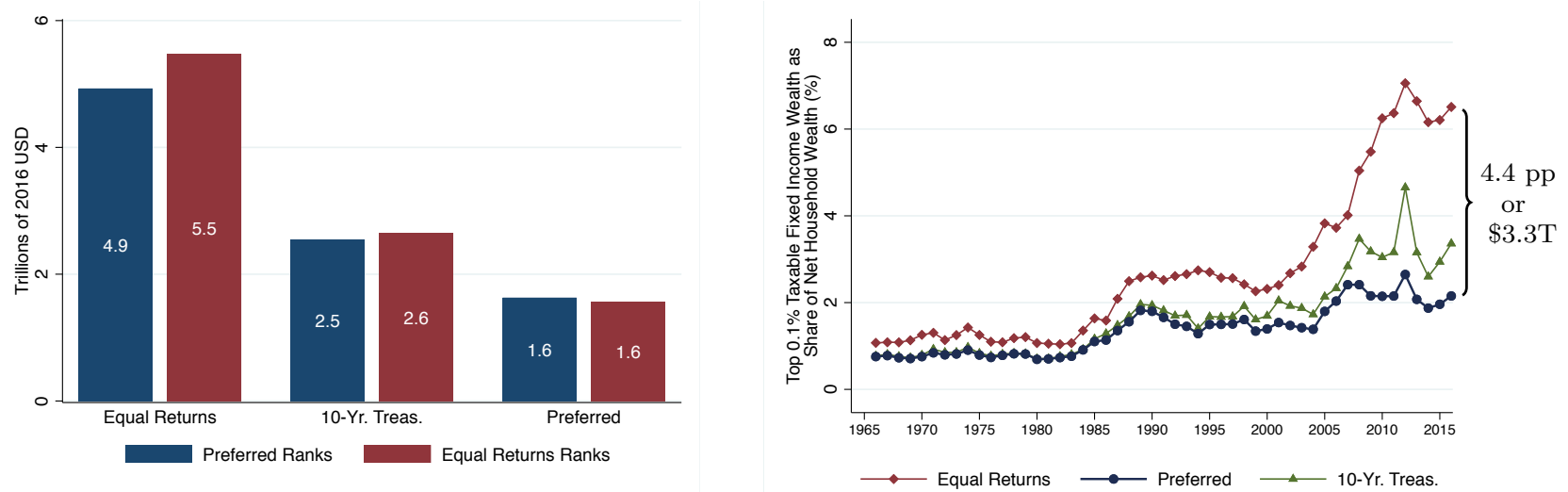

B. Top 0.1\% C-corporation Equity Wealth Estimates Level in 2016
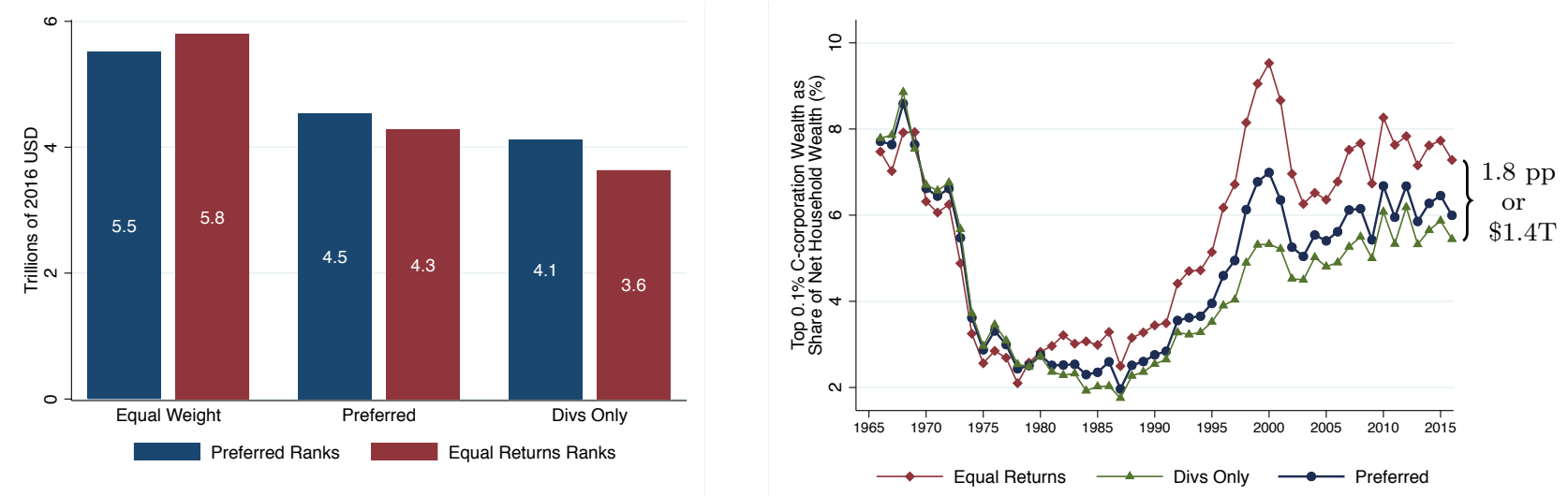

C. Model Performance: Actual vs. Predicted Assets in SCF Taxable Fixed Income

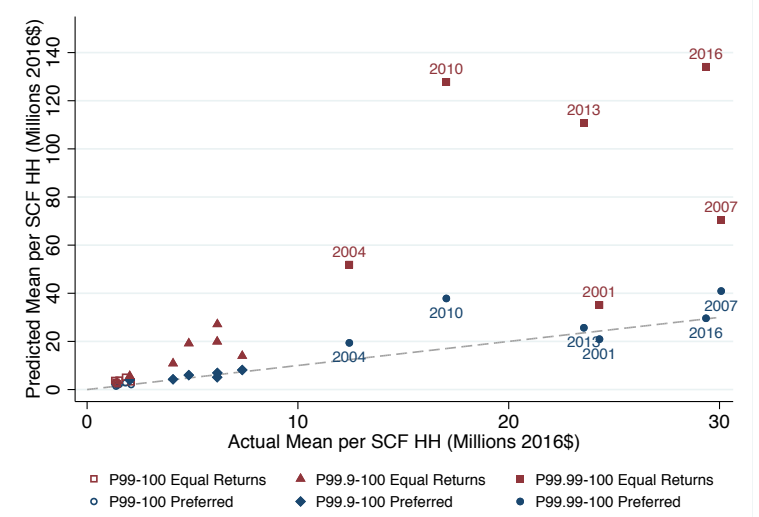

Public Equity

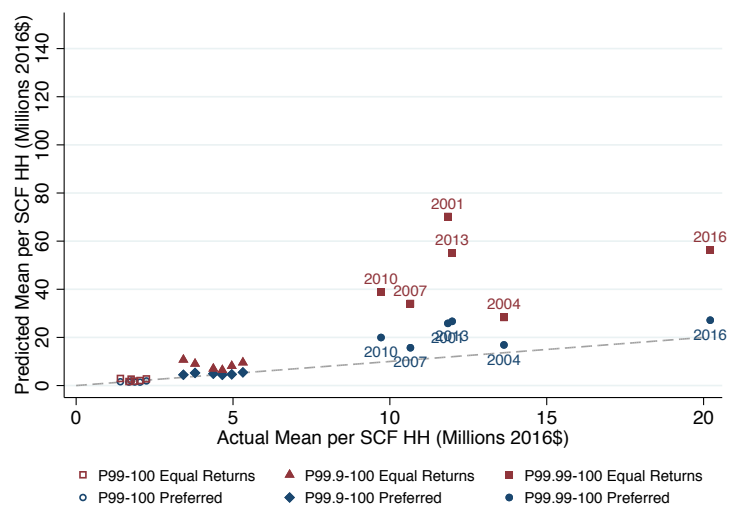


Notes for Figure 13: This figure calculates top wealth by asset type under alternative capitalization assumptions. Panel A presents fixed income estimates, Panel B presents C-corporation equity wealth estimates, and Panel C presents both. The left graph in Panel A shows top $0.1 \%$ fixed income wealth when using different capitalization approaches for the top group under wealth ranks from our preferred definition and from the equal-return definition. The right graph in Panel A plots these estimates over time. Similarly, Panel B plots C-corporation equity estimates given different weights on dividends and realized capital gains. Panel C plots predicted versus actual SCF wealth using data on flows and stocks from the SCF. Predictions take flows as an input and produce estimates of fixed income wealth in the left graph and of equity wealth in the right graph. The dashed line plots the 45-degree line. Points on the graphs show predicted wealth for different income groups for a given year. In the right graph, equal returns points represent estimates using the equal-weight approach for equity wealth. 
Figure 14: Top Wealth Composition in 2016 under Alternative Specifications

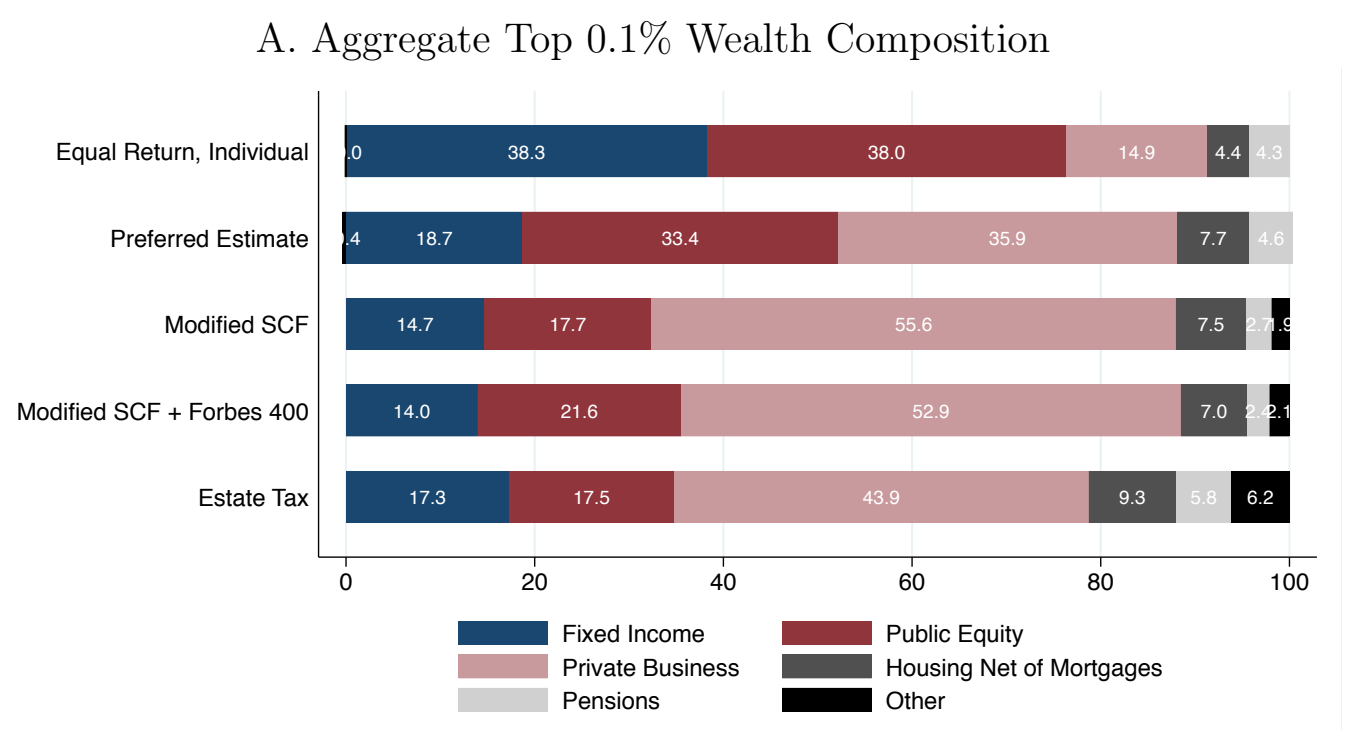

B. Top $0.1 \%$ Levels by Component

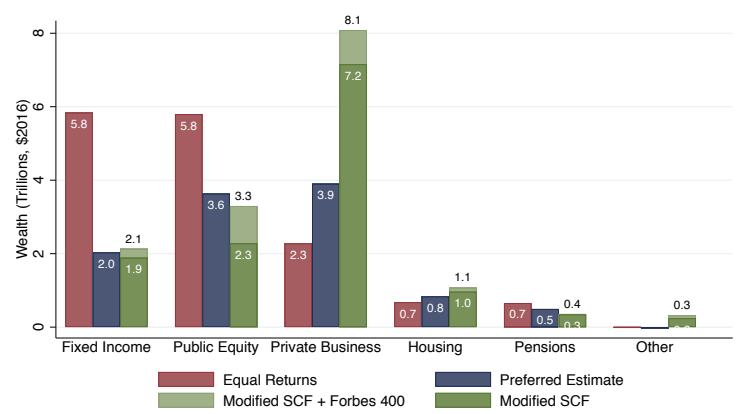

C. Top 1\% Levels by Component

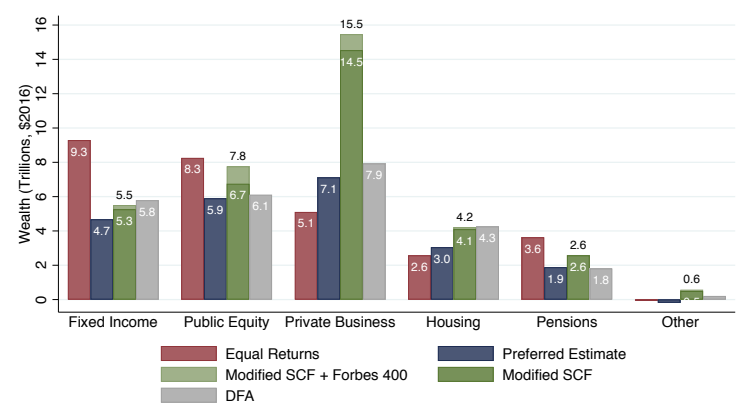

Notes: This figure presents top wealth levels and portfolio shares in 2016 estimated under equal returns assumptions and our preferred assumptions, and as calculated from the SCF, Distributional Financial Accounts, and estate tax returns. The Equal Return series allocates wealth following the capitalization approach in Saez and Zucman (2016). The Preferred Estimate series allocates fixed income asset wealth assuming a three-tiered correspondence of fixed income flows to rates of return (Aaa for top 0.1\%, UST10 for P99-99.9, residual for P0-99), C-corporation equity wealth using $90 \%$ dividends plus $10 \%$ of realized capital gains, housing values using state-specific capitalization factors, pass-through equity using industry-specific marketbased valuation models with liquidity and human-capital adjustments, and an age-specific pension model. See Appendix D for detailed definitions. For the preferred and DFA series, $20 \%$ of C-corporation wealth is reallocated to the private business category to account for private C-corporations. As described in Appendix G.1.1, the Modified SCF series plots the wealth allocation in the SCF after including the Sabelhaus and Henriques Volz (2019) defined benefit pension wealth and removing consumer durables, and Modified SCF + Forbes 400 adds Forbes 400 wealth to the modified SCF series. Estate Tax Returns uses data from the SOI Estate Tax Statistics (IRS, 2001-2017). The threshold for the top 0.1\% in 2016 is $\$ 14.1 \mathrm{M}$, so the estate tax cross-section only includes tax returns whose gross estate size is at least $\$ 10 \mathrm{M}$. 
Table 1: Thresholds and Average Wealth in Top Wealth Groups (2016)

\begin{tabular}{|c|c|c|c|c|c|c|}
\hline \multirow{2}{*}{ Wealth group } & \multirow[t]{2}{*}{ Count } & \multirow[t]{2}{*}{ Threshold } & \multicolumn{2}{|c|}{ Average wealth } & \multicolumn{2}{|c|}{ Wealth share } \\
\hline & & & Preferred & Equal Return & Preferred & Equal Retı \\
\hline \multicolumn{7}{|c|}{ Panel A. Top wealth groups (Preferred ranks) } \\
\hline Full population & $238,657,000$ & & $\$ 317,000$ & $\$ 317,000$ & $100.0 \%$ & $100.0 \%$ \\
\hline Top $10 \%$ & $23,865,700$ & $\$ 658,000$ & $\$ 2,081,000$ & $\$ 2,158,000$ & $65.6 \%$ & $68.1 \%$ \\
\hline Top $1 \%$ & $2,386,600$ & $\$ 3,130,000$ & $\$ 9,403,000$ & $\$ 10,910,000$ & $29.6 \%$ & $34.5 \%$ \\
\hline Top $0.1 \%$ & 238,700 & $\$ 14,100,000$ & $\$ 45,501,000$ & $\$ 58,688,000$ & $14.3 \%$ & $18.5 \%$ \\
\hline Top $0.01 \%$ & 23,800 & $\$ 72,200,000$ & $\$ 215,743,000$ & $\$ 304,015,000$ & $6.8 \%$ & $9.6 \%$ \\
\hline
\end{tabular}

Panel B. Intermediate wealth groups (Preferred ranks)

$\begin{array}{llllllc}\text { Bottom } 90 \% & 214,791,300 & & \$ 121,000 & \$ 112,000 & 34.4 \% & 31.9 \% \\ \text { Top 10-1\% } & 21,479,100 & \$ 658,000 & \$ 1,268,000 & \$ 1,185,000 & 36.0 \% & 33.7 \% \\ \text { Top 1-0.1\% } & 2,147,900 & \$ 3,130,000 & \$ 5,392,000 & \$ 5,600,000 & 15.3 \% & 15.9 \% \\ \text { Top 0.1-0.01\% } & 214,900 & \$ 14,100,000 & \$ 26,646,000 & \$ 31,518,000 & 7.6 \% & 9.0 \% \\ \text { Top 0.01\% } & 23,800 & \$ 72,200,000 & \$ 215,743,000 & \$ 304,015,000 & 6.8 \% & 9.6 \%\end{array}$

Panel C. Top wealth groups (Equal returns ranks)

$\begin{array}{lllllll}\text { Full population } & 238,657,000 & & \$ 317,000 & \$ 317,000 & 100.0 \% & 100.0 \% \\ \text { Top 10\% } & 23,865,800 & \$ 600,000 & \$ 1,976,000 & \$ 2,289,000 & 62.3 \% & 72.3 \% \\ \text { Top 1\% } & 2,386,600 & \$ 3,430,000 & \$ 8,496,000 & \$ 12,067,000 & 26.8 \% & 38.1 \% \\ \text { Top 0.1\% } & 238,700 & \$ 17,300,000 & \$ 40,768,000 & \$ 63,860,000 & 12.8 \% & 20.2 \% \\ \text { Top 0.01\% } & 23,800 & \$ 97,900,000 & \$ 192,686,000 & \$ 336,634,000 & 6.1 \% & 10.6 \%\end{array}$

Panel D. Intermediate wealth groups (Equal returns ranks)

\begin{tabular}{lllllcc} 
Bottom $90 \%$ & $214,791,200$ & & $\$ 133,000$ & $\$ 97,000$ & $37.7 \%$ & $27.7 \%$ \\
Top 10-1\% & $21,479,200$ & $\$ 600,000$ & $\$ 1,251,000$ & $\$ 1,203,000$ & $35.5 \%$ & $34.2 \%$ \\
Top 1-0.1\% & $2,147,900$ & $\$ 3,430,000$ & $\$ 4,910,000$ & $\$ 6,312,000$ & $13.9 \%$ & $17.9 \%$ \\
Top 0.1-0.01\% & 214,900 & $\$ 17,300,000$ & $\$ 23,943,000$ & $\$ 33,651,000$ & $6.8 \%$ & $9.6 \%$ \\
Top 0.01\% & 23,800 & $\$ 97,900,000$ & $\$ 192,686,000$ & $\$ 336,634,000$ & $6.1 \%$ & $10.6 \%$ \\
\hline
\end{tabular}

Notes: This table provides summary statistics on the distribution of wealth across individuals in 2016. Average wealth and wealth shares are calculated under our preferred specification and the equal-returns specification, which follows the capitalization approach in Saez and Zucman (2016). Our preferred capitalization allocates fixed income asset wealth assuming a three-tiered correspondence of fixed income flows to rates of return (Aaa for top 0.1\%, UST10 for P99-99.9, residual for P0-99), C-corporation equity wealth using $90 \%$ dividends plus $10 \%$ of realized capital gains, housing values using state-specific capitalization factors, pass-through equity using industry-specific market-based valuation models with liquidity and human-capital adjustments, and an age-specific pension model. See Appendix D for detailed definitions. 
Table 2: Portfolio Shares in Top Wealth Groups (2016)

\begin{tabular}{lcccccc}
\hline & \multicolumn{5}{c}{ Portfolio shares } \\
\cline { 2 - 6 } Wealth group & Fixed Income & Public Equity & Private Business & Housing & Pensions & Other \\
\hline & \multicolumn{7}{c}{ Panel A. Top wealth groups } \\
Full population & $19.9 \%$ & $12.2 \%$ & $18.5 \%$ & $20.3 \%$ & $37.1 \%$ & $-8.1 \%$ \\
Top 10\% & $24.4 \%$ & $17.1 \%$ & $22.2 \%$ & $18.5 \%$ & $20.2 \%$ & $-2.3 \%$ \\
Top 1\% & $20.8 \%$ & $26.3 \%$ & $31.7 \%$ & $13.6 \%$ & $8.4 \%$ & $-0.8 \%$ \\
Top 0.1\% & $18.7 \%$ & $33.4 \%$ & $35.9 \%$ & $7.7 \%$ & $4.6 \%$ & $-0.4 \%$ \\
Top 0.01\% & $17.9 \%$ & $41.0 \%$ & $35.6 \%$ & $3.1 \%$ & $2.6 \%$ & $-0.2 \%$ \\
& & & & & \\
& & Panel B. Intermediate wealth groups & & \\
Bottom 90\% & $11.4 \%$ & $3.1 \%$ & $11.5 \%$ & $23.8 \%$ & $69.3 \%$ & $-19.0 \%$ \\
Top 10-1\% & $27.3 \%$ & $9.5 \%$ & $14.3 \%$ & $22.5 \%$ & $30.0 \%$ & $-3.5 \%$ \\
Top 1-0.1\% & $22.8 \%$ & $19.6 \%$ & $27.8 \%$ & $19.1 \%$ & $12.0 \%$ & $-1.3 \%$ \\
Top 0.1-0.01\% & $19.4 \%$ & $26.7 \%$ & $36.2 \%$ & $11.8 \%$ & $6.3 \%$ & $-0.5 \%$ \\
Top 0.01\% & $17.9 \%$ & $41.0 \%$ & $35.6 \%$ & $3.1 \%$ & $2.6 \%$ & $-0.2 \%$ \\
\hline
\end{tabular}

Notes: This table shows 2016 portfolio shares of fixed income, public equity, private business, housing, pension wealth, and other wealth according to our preferred capitalization and preferred wealth ranks. See Appendix D for component definitions. 
Table 3: Prediction Error in SCF for Taxable Fixed Income Assets by Approach

\begin{tabular}{|c|c|c|c|c|c|c|c|}
\hline \multirow{3}{*}{ Group } & \multirow{2}{*}{$\begin{array}{r}\text { Actual } \\
\text { SCF }\end{array}$} & \multicolumn{3}{|c|}{ Predicted } & \multicolumn{3}{|c|}{ Fit } \\
\hline & & SZ & UST 10 & SZZ & $\mathrm{SE}_{\mathrm{SZ}}$ & $\mathrm{SE}_{\mathrm{UST}} 10$ & $\mathrm{SE}_{\mathrm{SZZ}}$ \\
\hline & (1) & (2) & (3) & (4) & $(5)$ & (6) & (7) \\
\hline \multicolumn{8}{|c|}{ Panel A. 2016 fixed income totals (\$ M) } \\
\hline Bot $90 \%$ Interest Income & 0.04 & 0.00 & 0.00 & 0.00 & 0.98 & 0.93 & 0.92 \\
\hline Top 10\% Interest Income & 0.59 & 1.10 & 1.10 & 1.11 & 0.75 & 0.76 & 0.80 \\
\hline Top 1\% Interest Income & 1.83 & 5.29 & 3.24 & 2.81 & 3.58 & 0.59 & 0.29 \\
\hline Top $0.1 \%$ Interest Income & 6.47 & 28.22 & 12.43 & 7.10 & 11.29 & 0.85 & 0.01 \\
\hline Top $0.01 \%$ Interest Income & 29.63 & 136.34 & 60.05 & 30.10 & 12.97 & 1.05 & 0.00 \\
\hline \multicolumn{5}{|c|}{ Panel mean squared error: } & 5.91 & 0.84 & 0.40 \\
\hline \multicolumn{8}{|c|}{ Panel B. 2016 fixed income portfolio shares (\%) } \\
\hline Bot $90 \%$ Interest Income & 7.64 & 0.09 & 0.28 & 0.33 & 0.98 & 0.93 & 0.92 \\
\hline Top $10 \%$ Interest Income & 24.28 & 37.44 & 37.47 & 37.79 & 0.29 & 0.30 & 0.31 \\
\hline Top $1 \%$ Interest Income & 22.33 & 45.41 & 33.74 & 30.64 & 1.07 & 0.26 & 0.14 \\
\hline Top $0.1 \%$ Interest Income & 19.48 & 51.33 & 31.72 & 20.97 & 2.67 & 0.39 & 0.01 \\
\hline Top $0.01 \%$ Interest Income & 18.54 & 51.15 & 31.57 & 18.78 & 3.09 & 0.49 & 0.00 \\
\hline \multicolumn{5}{|c|}{ Panel mean squared error: } & 1.62 & 0.47 & 0.27 \\
\hline \multicolumn{8}{|c|}{ Panel C. 2001-2016 change in fixed income totals $(\$ T)$} \\
\hline Bot $90 \%$ Interest Income & 1.87 & -0.23 & -0.18 & -0.19 & 1.27 & 1.20 & 1.21 \\
\hline Top 10\% Interest Income & 3.65 & 8.02 & 8.16 & 8.34 & 1.43 & 1.53 & 1.65 \\
\hline Top $1 \%$ Interest Income & 2.13 & 7.45 & 4.13 & 3.54 & 6.24 & 0.89 & 0.44 \\
\hline Top $0.1 \%$ Interest Income & 0.95 & 4.76 & 1.73 & 0.83 & 16.31 & 0.70 & 0.02 \\
\hline Top $0.01 \%$ Interest Income & 0.37 & 1.91 & 0.81 & 0.39 & 16.81 & 1.34 & 0.00 \\
\hline \multicolumn{5}{|c|}{ Panel mean squared error: } & 8.41 & 1.13 & 0.67 \\
\hline \multicolumn{8}{|c|}{ Panel D. 2001-2016 change in fixed income portfolio shares (\%) } \\
\hline Bot $90 \%$ Interest Income & 0.32 & -0.88 & -0.83 & -0.89 & 14.24 & 13.20 & 14.61 \\
\hline Top 10\% Interest Income & 3.51 & 11.48 & 12.33 & 12.87 & 5.14 & 6.29 & 7.08 \\
\hline Top 1\% Interest Income & -0.54 & 11.75 & 3.85 & 3.02 & 516.89 & 66.03 & 43.26 \\
\hline Top $0.1 \%$ Interest Income & -1.32 & 11.14 & -4.37 & -9.74 & 88.98 & 5.32 & 40.60 \\
\hline \multirow[t]{2}{*}{ Top $0.01 \%$ Interest Income } & 2.28 & 29.36 & 12.59 & 4.54 & 140.51 & 20.35 & 0.97 \\
\hline & \multicolumn{4}{|c|}{ Panel mean squared error: } & 153.15 & 22.24 & 21.30 \\
\hline
\end{tabular}

Notes: This table evaluates alternative capitalization assumptions using a cross-validation approach in the SCF. Column (1) shows actual SCF wealth moments for different taxable interest income groups. Columns (2)-(4) show predicted wealth moments using different capitalization approaches. Columns (5)(7) present a goodness-of-fit measure for each capitalization approach, defined as squared prediction error or $\left(\frac{\text { Capitalized estimate }}{\text { Estimand in SCF }}-1\right)^{2}$. Portfolio shares under each capitalization specification are computed as (Capitalized fixed income)/(networth + tot_pen_db - vehic - taxfixinc_scf + Capitalized fixed income), where networth and vehic are SCF bulletin concepts, tot_pen_db is Sabelhaus-Henriques Volz defined benefit pension wealth, and taxfixinc_scf is our definition of taxable fixed income assets in the SCF. Interest income thresholds are taken according to the distribution of interest income in tax data. 


\section{For Online Publication}

Sections A and B provide appendix figures and tables, respectively. Section C describes how we construct the panel of state-year capitalization factors for housing values. Sections D, $\mathrm{E}$, and $\mathrm{F}$ describe the construction of variables in the tax data, the SCF, and the DFA, respectively. Section G describes the Forbes 400 portfolio data construction. Section H gives sources for other data used in this paper. Section I describes how we estimate liquidity discounts for private business valuation. Section J provides a response to each of the four comments in "Comments on Smith, Zidar, and Zwick (2019)" by Saez and Zucman. 


\section{A Appendix Figures}

Figure A.1: Components of Aggregate Household Wealth (1912-2016)

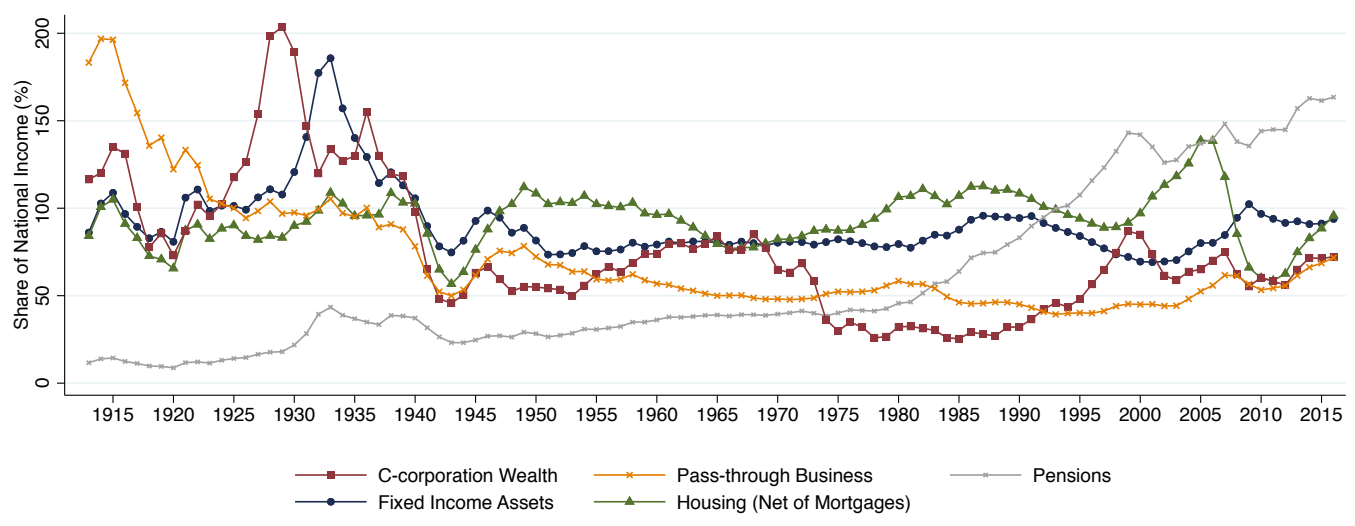

Notes: This figure extends the series shown in Figure 2A back to 1912. Wealth data is from Piketty, Saez and Zucman (2018), which draws from the US Financial Accounts (1945-2016) as well as Goldsmith, Brady, and Mendershausen (1956), Wolff (1989) and Kopzcuk and Saez (2004) prior to 1945. National income data is from the National Income and Product Accounts from 1929-onwards, and Kuznets (1941) and King (1930) before that. 
Figure A.2: Top Wealth Shares vs. Capitalized Income Shares in SCF

A. Replicating Figure IV.B. of Saez and Zucman (2016)

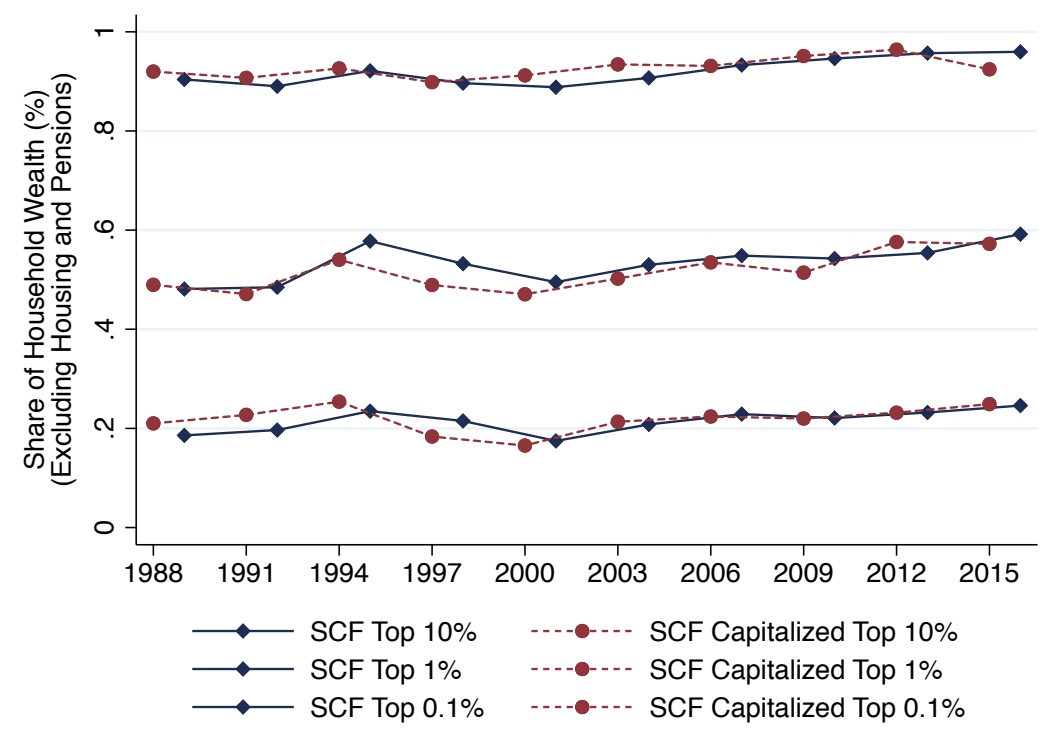

B. Actual vs. Capitalized Fixed Income

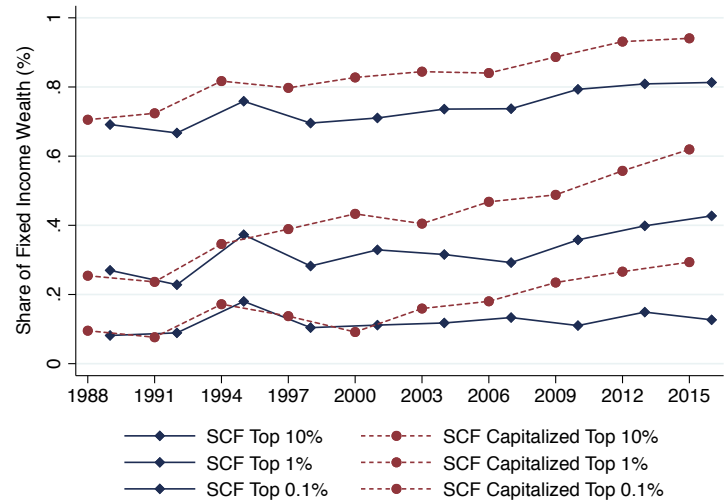

C. Actual vs. Capitalized Private Business Income

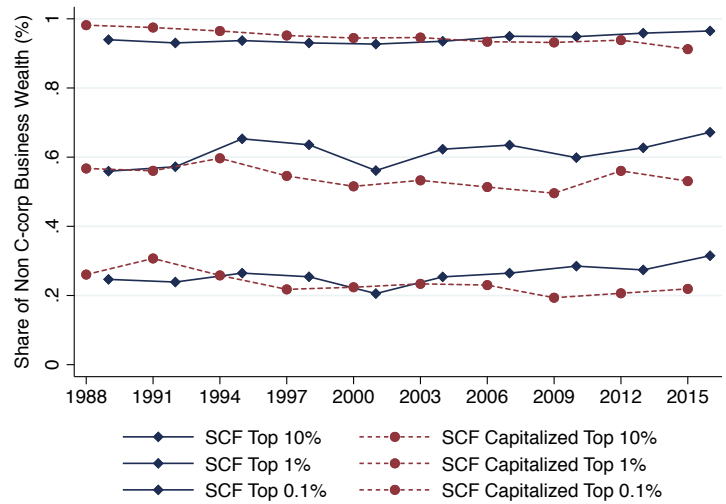

Notes: This figure plots the fraction of wealth (excluding housing and pensions) held by the top 10\%, $1 \%$, and $0.1 \%$ in the SCF using actual SCF wealth and capitalized income wealth. We exclude housing and pensions to exactly replicate Figure IV.B. of Saez and Zucman (2016). Panel A replicates Figure IV.B and plots two series. The solid line plots actual SCF wealth, while the dashed line plots SCF capitalized income. The composition of a given income group differs across the two measures as each group is defined using each series' own ranking. For example, the share of wealth held by households that are in the top 10\% of actual SCF wealth (excluding housing and pensions) are plotted in the solid blue series in Panel A, whereas the dashed series corresponds to a different group of top $10 \%$ households who have top $10 \%$ wealth based on ranking households using a wealth measure from capitalizing SCF income by category. Panel B and C show that the similarity in shares in Panel A masks substantial differences in actual versus capitalized wealth by category. Panel B shows that plotting the shares of fixed income wealth using the same overall wealth rankings as panel A reveals that the capitalized series overstates fixed income wealth concentration relative to the actual. In contrast, Panel $\mathrm{C}$ shows that capitalized private business income understates actual private business wealth concentration in the SCF. 
Figure A.3: Change in Top Wealth Shares by Component: 1989-2016
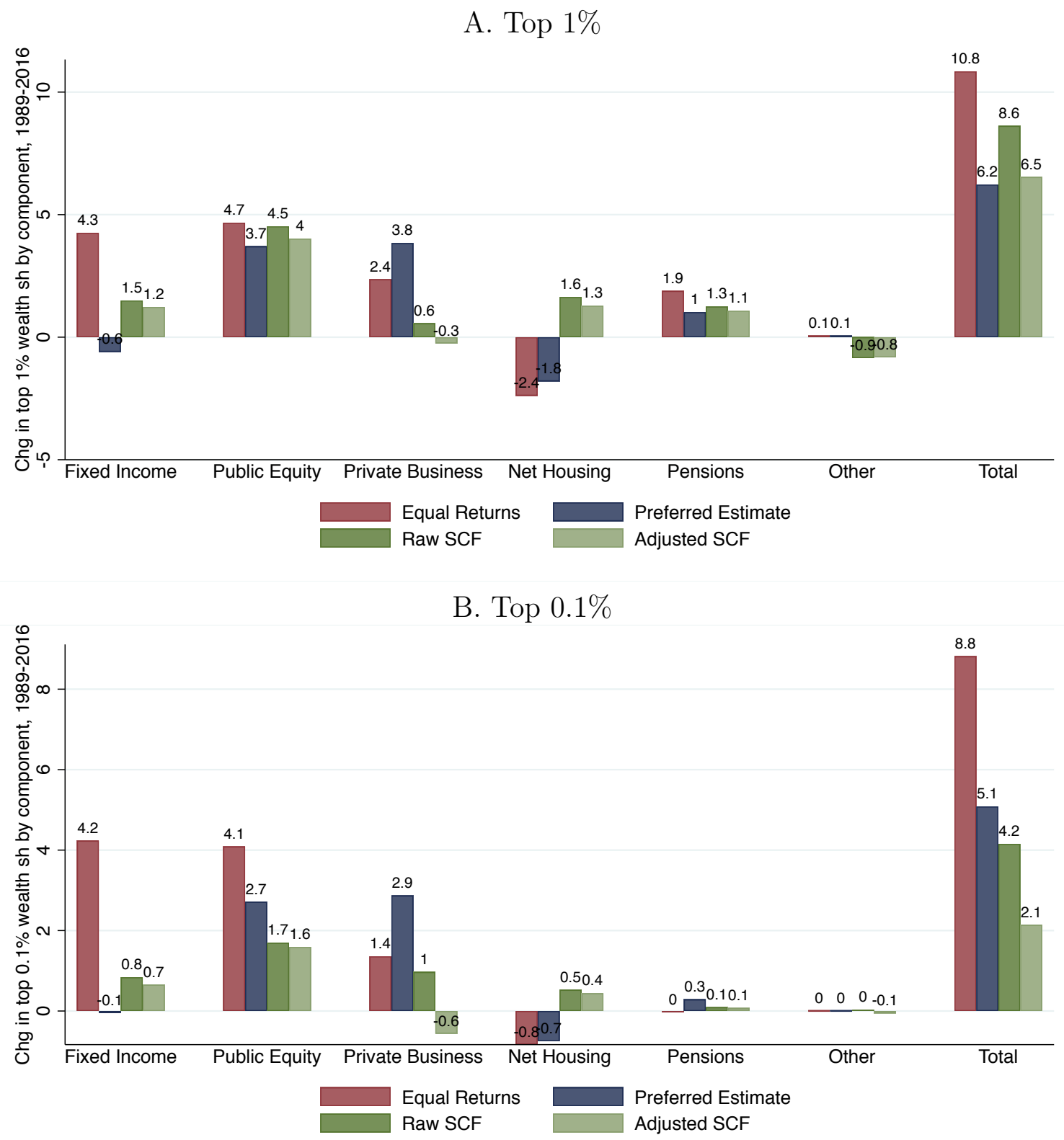

Notes: This figure decomposes the growth of the top $1 \%$ and $0.1 \%$ share of aggregate wealth by portfolio category under alternative scenarios. See the notes for Figure 14 for component definitions. 
Figure A.4: Change in Top Wealth Shares by Component over Different Time Periods

A. $1978-2016$

Top $1 \%$
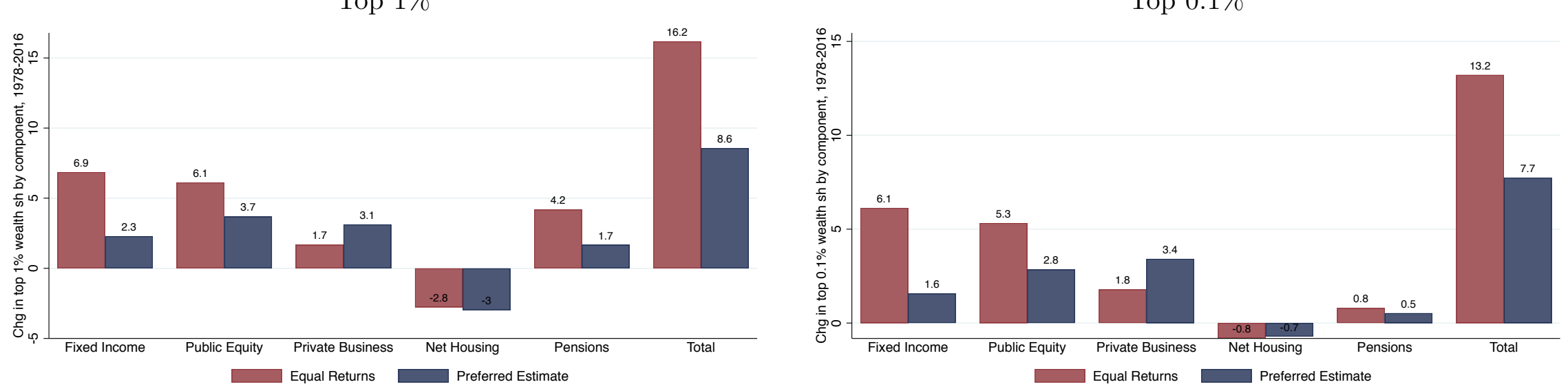

ले

Top $1 \%$
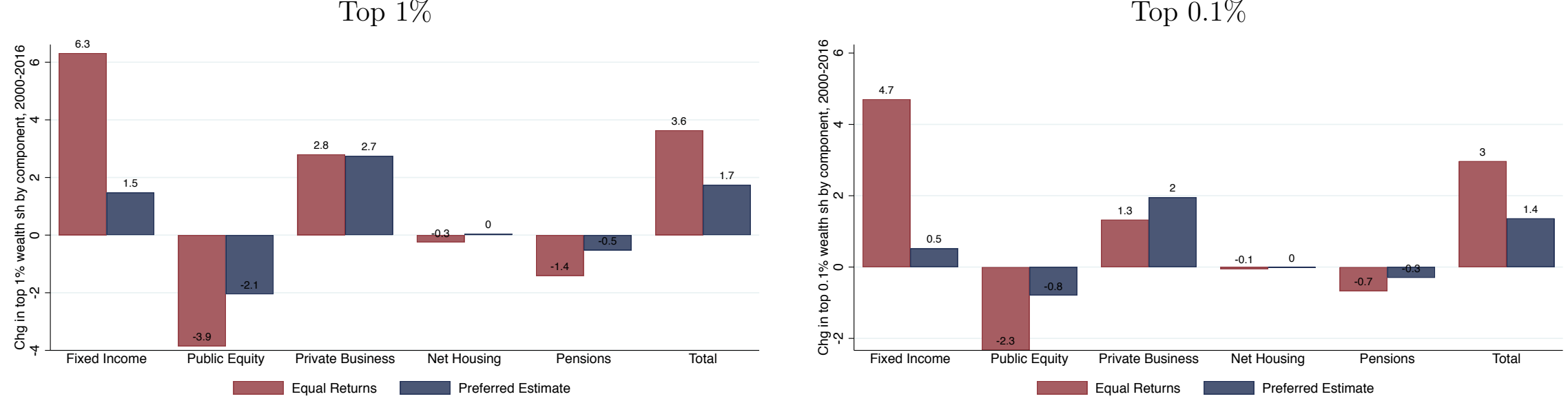

Notes: This figure decomposes the growth of the top $1 \%$ and $0.1 \%$ share of aggregate wealth by portfolio category under alternative scenarios. See the notes for Figure 14 for component definitions. 
Figure A.5: Fixed Income Rates of Return During Low Interest Rate Period

A. 2016

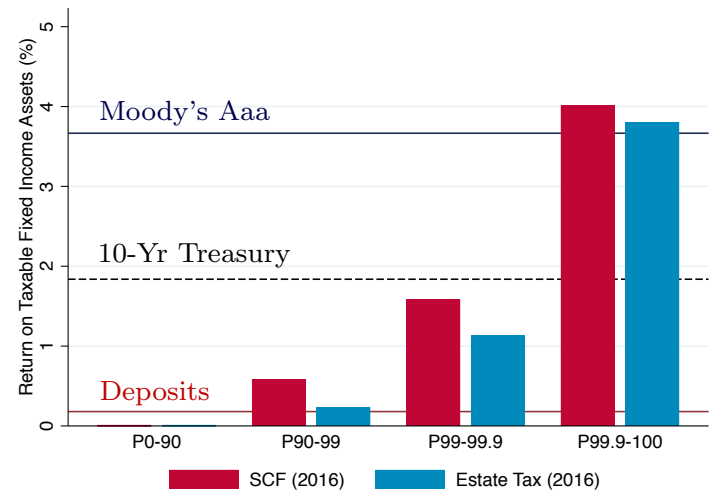

B. $2010-2016$

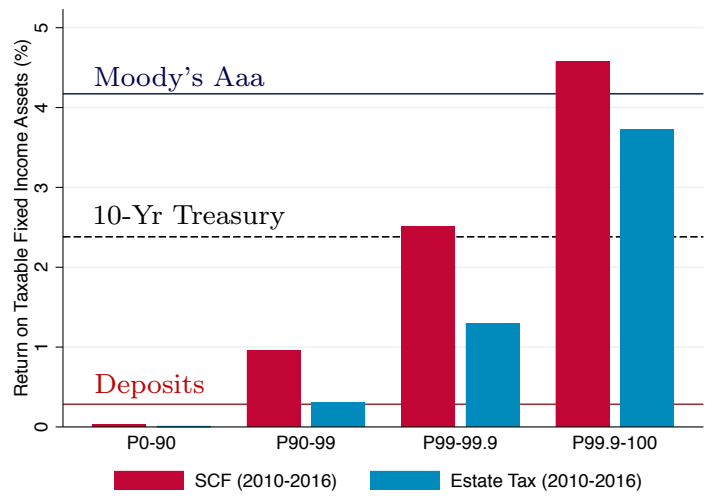

Notes: This figure plots the returns to fixed income assets by interest income group. It is a reproduction of Figure 4B but for the year 2016 and the average over the zero-lower-bound period from 2010 to 2016, respectively. 
Figure A.6: Public Company Share of Corporate Activity

\section{A. Public Share of C-corp Activity}

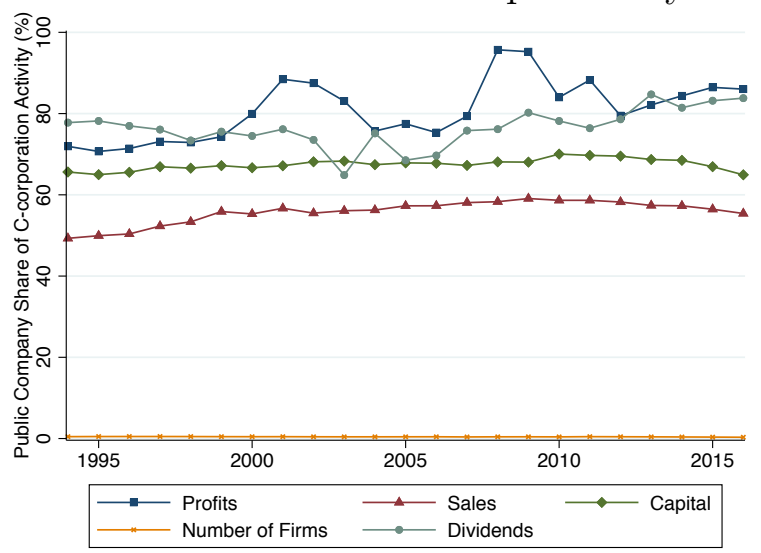

B. Public Share of C+S-corp Activity

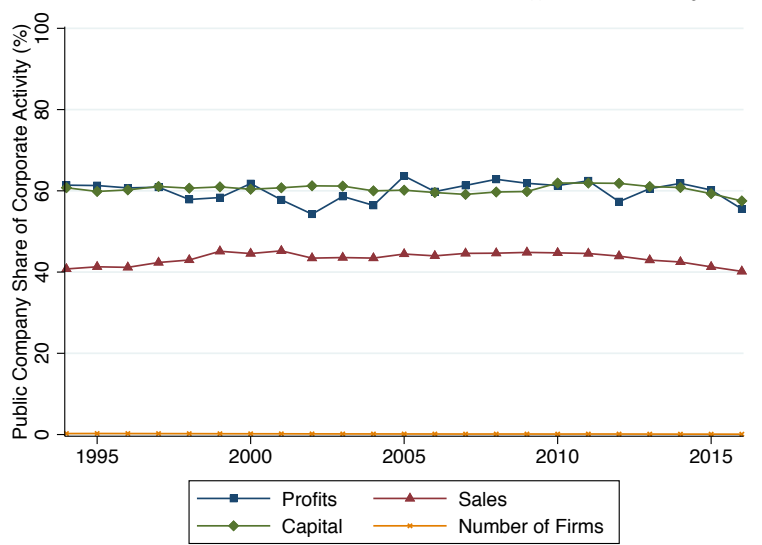

Notes: This figure uses the SOI corporate sample to divide corporate activity between non-public companies and public companies, defined as having shares listed on a public stock exchange such that the company's financial disclosures are available in the Compustat database. Panel A restricts to C-corporations. Panel $\mathrm{B}$ includes S-corporations. We use these data to assign a share of allocated C-corporate wealth to private companies. 
Figure A.7: Identifying Carried Interest Compensation among Realized Capital Gains

A. SOI's SOCA Totals Track the SOI Sample Capital Gains

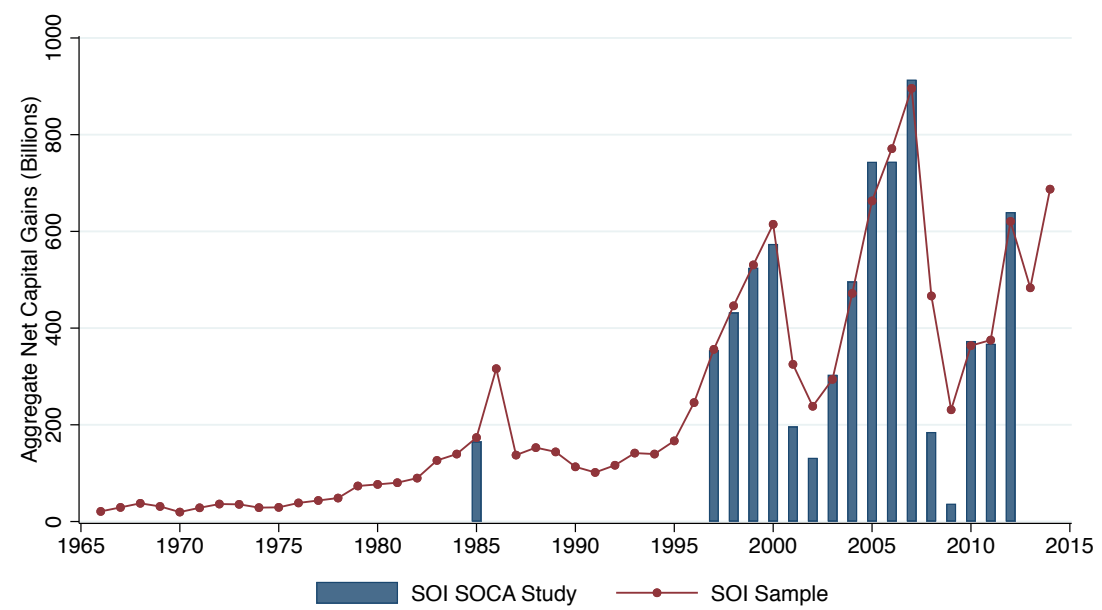

ఎ
B. Pass-Through Share of Gains Tracks 1065 K-1 Gains

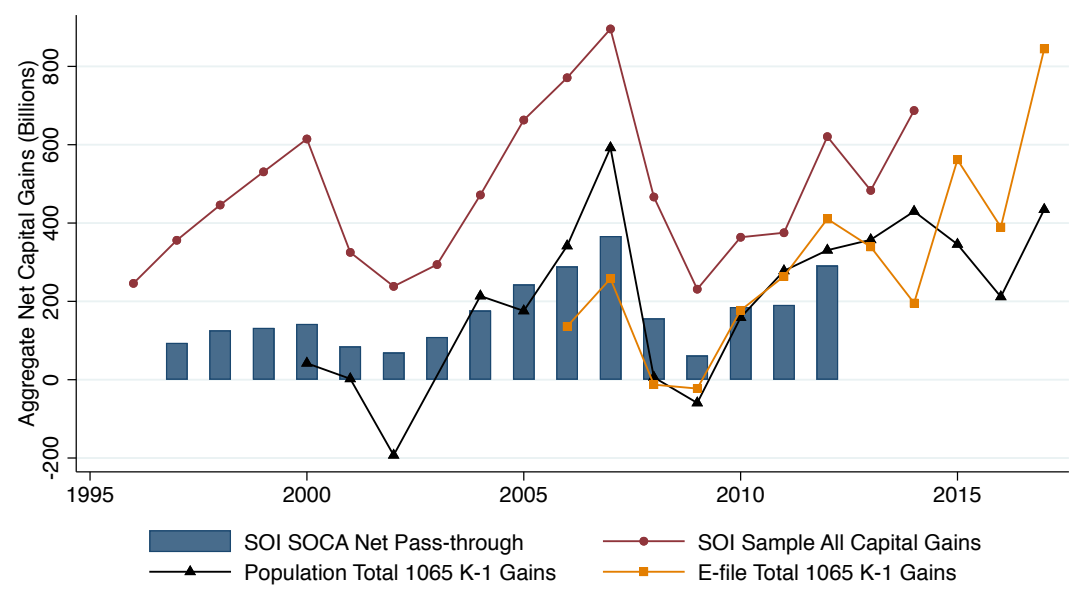

D. General Partner Gains versus Total and Top Capital Gains

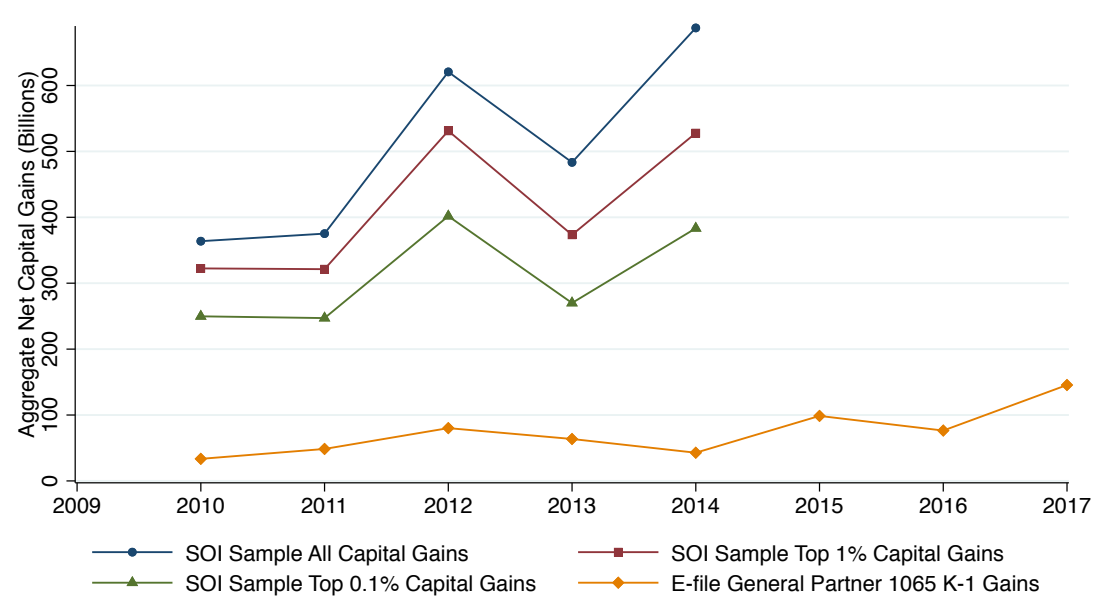

Notes: This figure presents evidence supporting our attempt to estimate the share of top realized capital gains that reflects carried interest compensation for financial services general partners (e.g., hedge fund, venture capital, private equity managers). We combine the realized capital gains flows used in our capitalized income estimates with data from SOI's Sale of Capital Assets (SOCA) study and information returns from different IRS databases. Fund managers are identified via the General Partner checkbox on information returns available in the e-file database. 
Figure A.8: Persistence of Realized Capital Gains and Other Income Flows

A. Top $1 \%$ Dividends

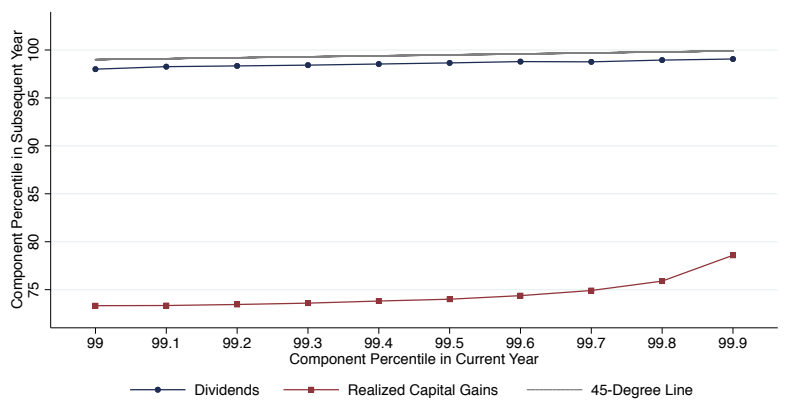

C. Top $1 \%$ Interest

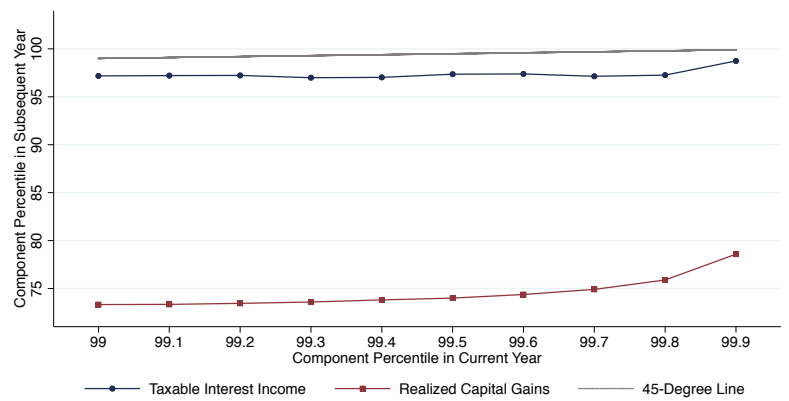

E. Top $1 \%$ Adjusted Gross Income

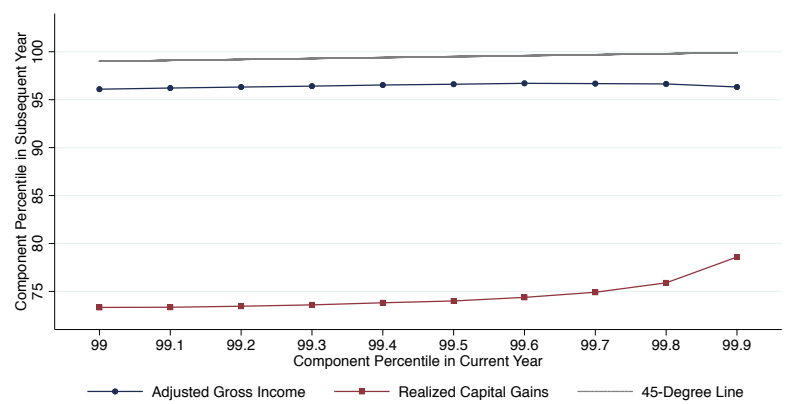

G. Top 1\% Wage Income

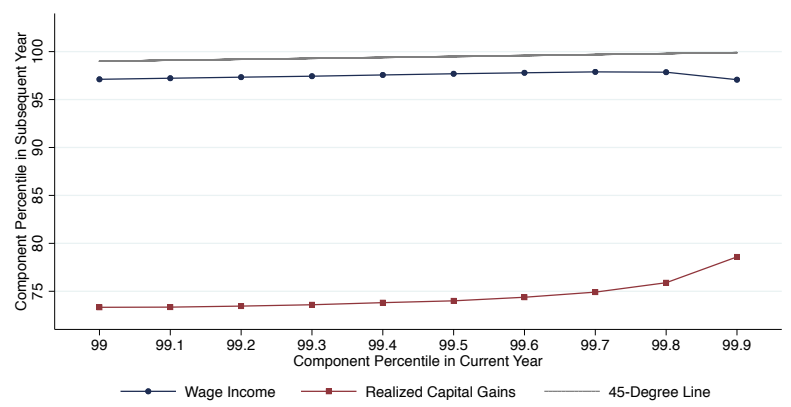

B. Top $10 \%$ Dividends

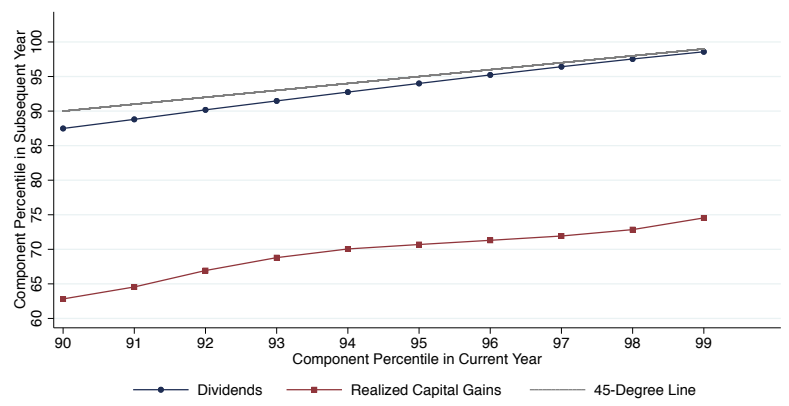

D. Top $10 \%$ Interest

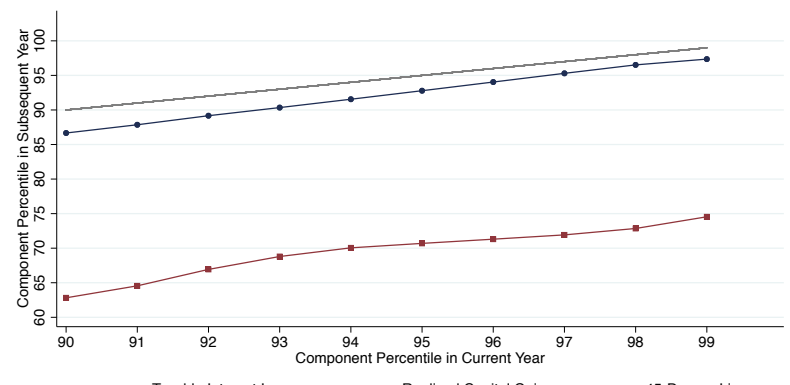

F. Top 10\% Adjusted Gross Income

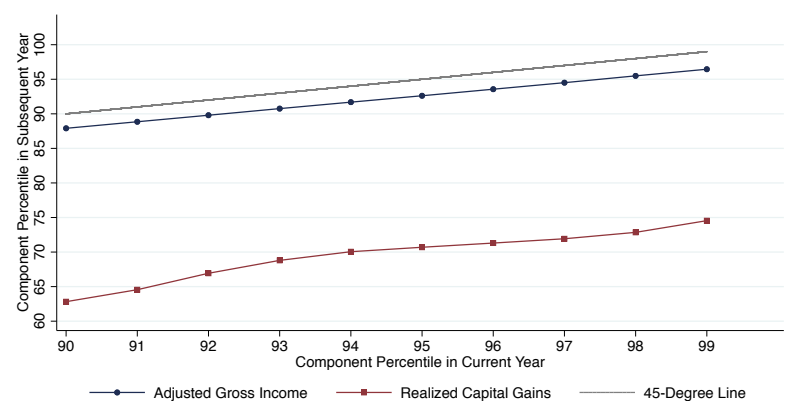

H. Top 10\% Wage Income

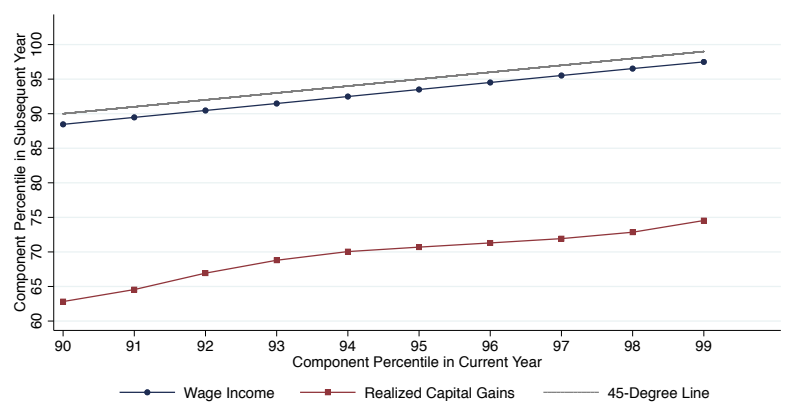

Notes: This figure uses the population of individual tax returns to evaluate year-over-year persistence of different income flows. For each year from 1996 to 2015, we construct the flow rank for an individual or joint filer in that year and the next year. We plot the average next-year ranks within percentiles for the top $10 \%$ and within 1000 -tiles for the top $1 \%$, pooled over all years in the data set. We compare the rank-rank correlation for realized capital gains to that for dividends, interest, adjusted gross income, and wages. 
Figure A.9: Change in Wealth per Capita (1980-2016), by Portfolio Category

A. Fixed Income

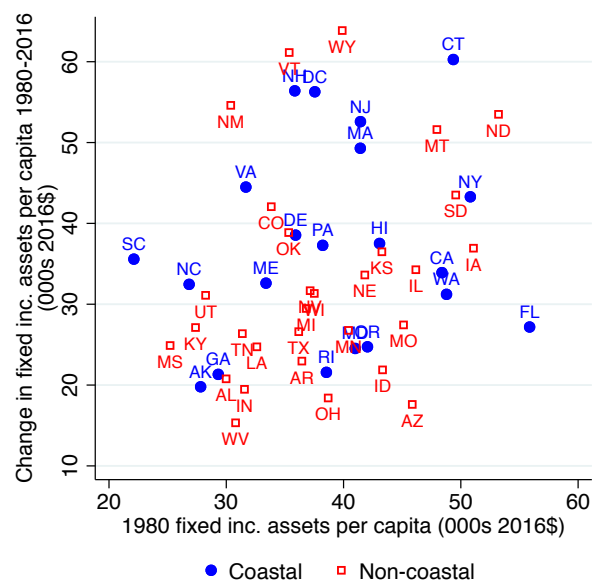

C. Private Business

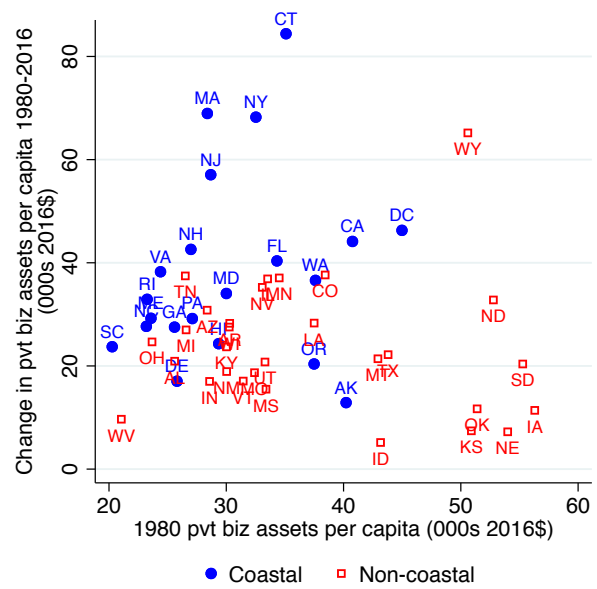

E. Pensions

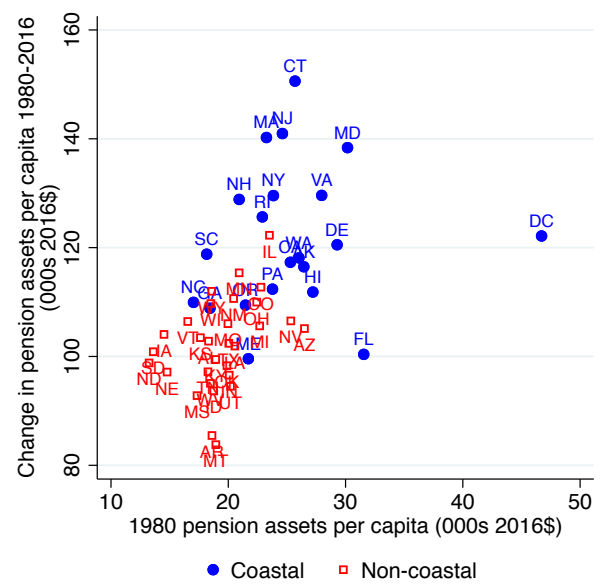

B. Public Equity

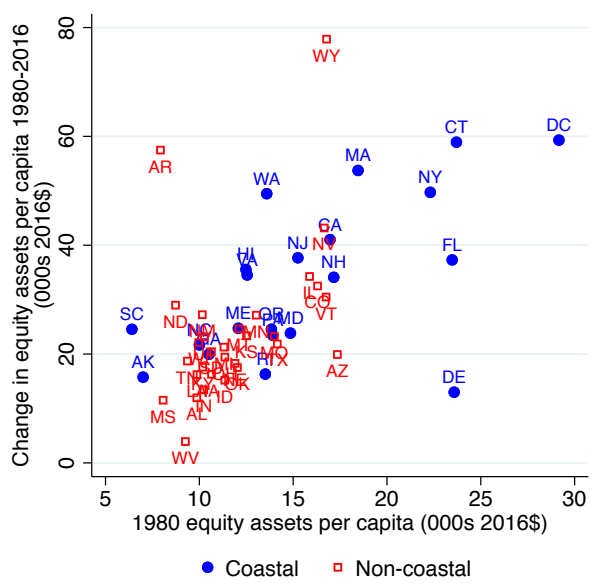

D. Housing

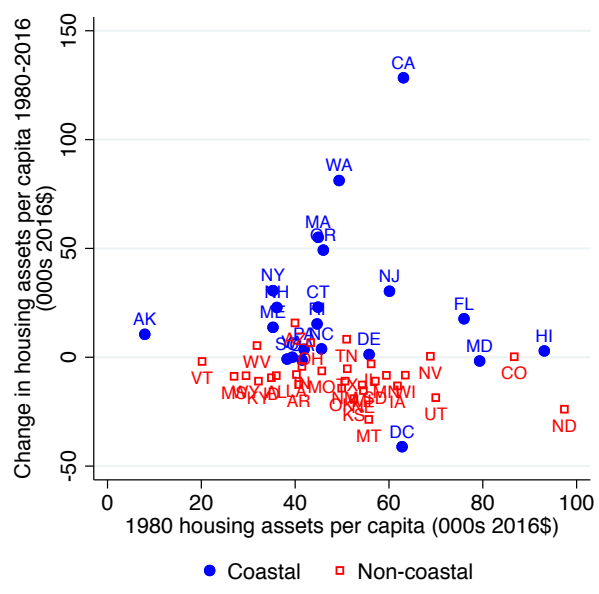

F. Other

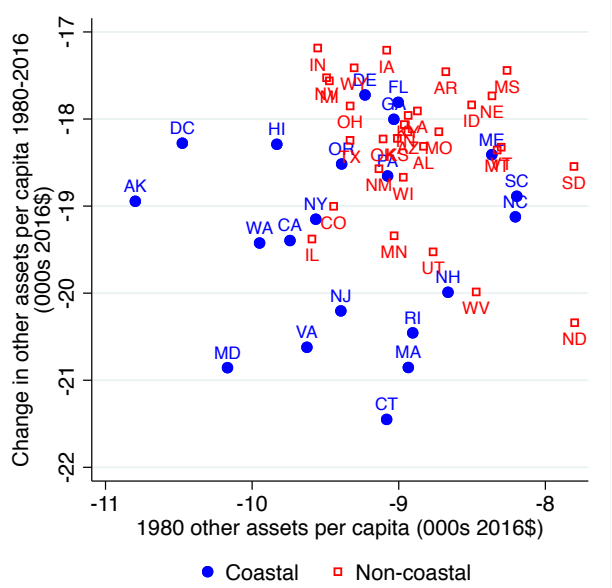

Notes: This figure decomposes state wealth changes from Figure 9B into portfolio components. For each major portfolio category, it compares the level of wealth per capita by state in 1980 to the change in wealth component per capita from 1980 to 2016. 
Figure A.10: Wealth per Capita across States by Portfolio Category, 1980-2016

A. Change in wealth per capita

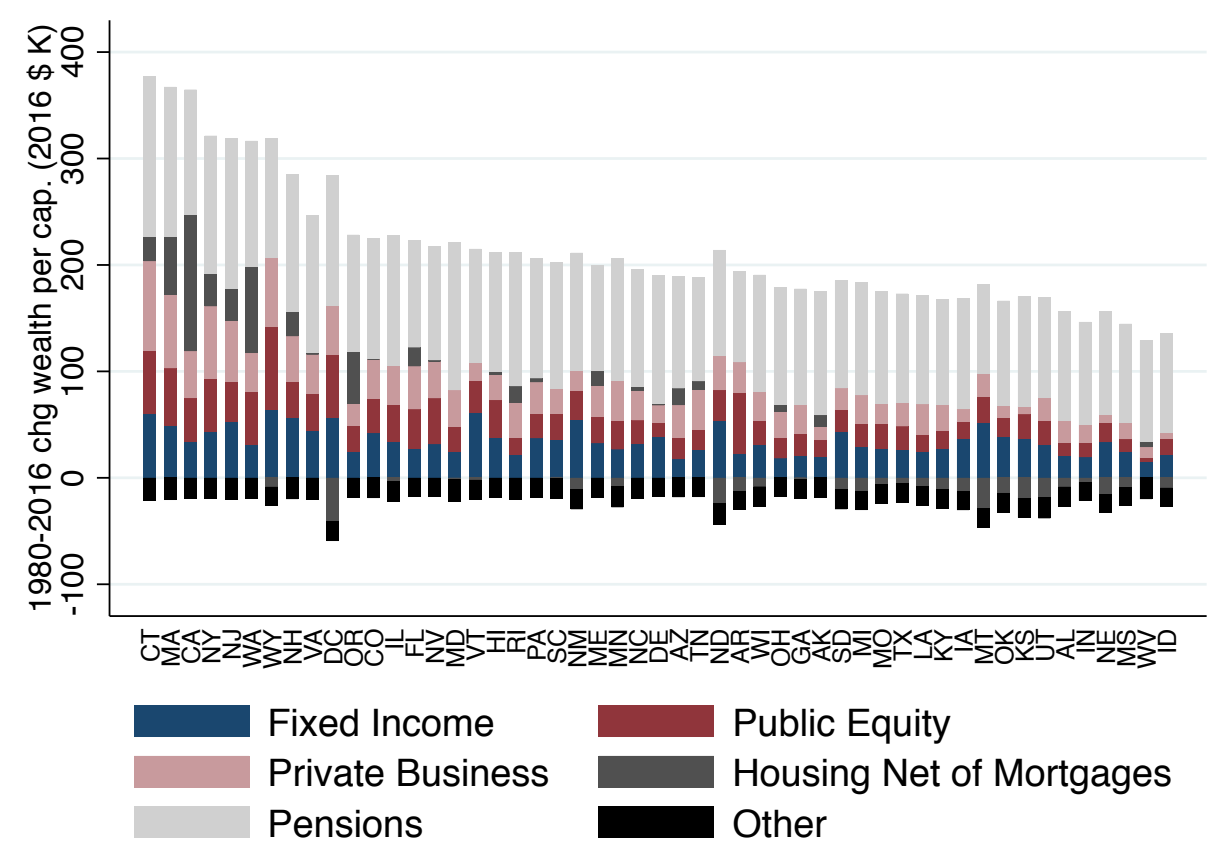

B. Cross sections

1980

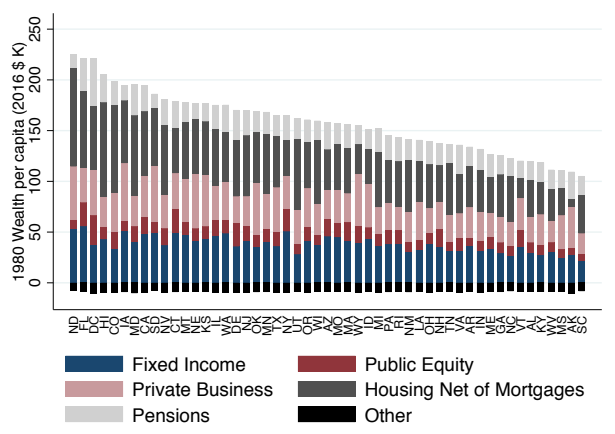

2016

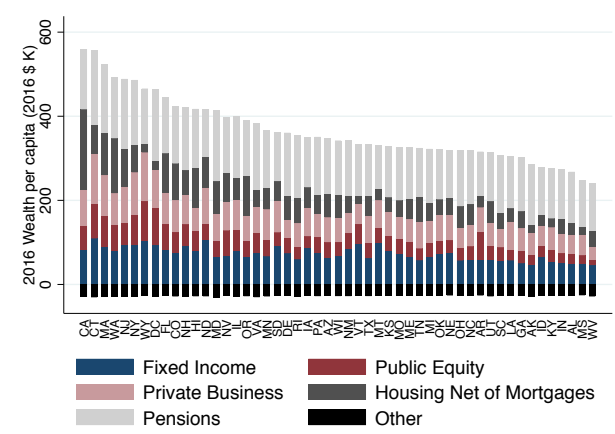

Notes: Panel A maps the change in wealth per capita in thousands of 2016 dollars from 1980 to 2016 across states, disaggregating by portfolio category. Bars are ordered left to right by change in total household wealth per capita. Panel B shows cross-sectional wealth per capita in thousands of 2016 dollars in 1980 and 2016 by portfolio category. Bars are ordered left to right by total household wealth per capita. 
Figure A.11: Implications for Imputed National Income, Top 0.1\%

A. Top $0.1 \%$ Fixed income

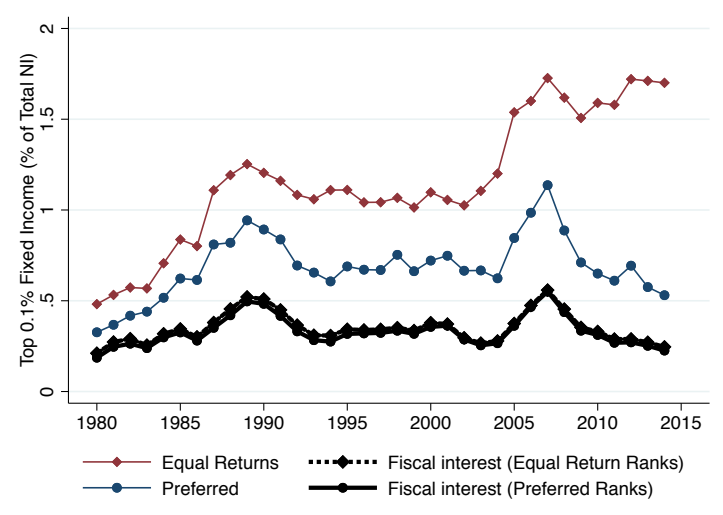

C. Top 0.1\% Income Share

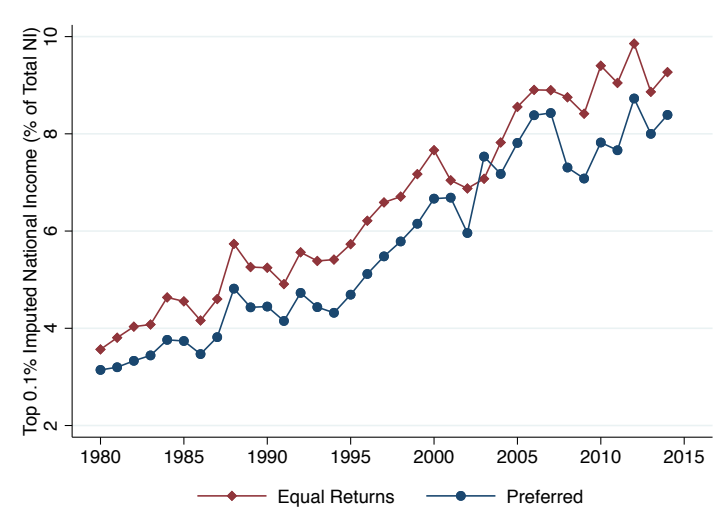

B. Top $0.1 \%$ Capital income

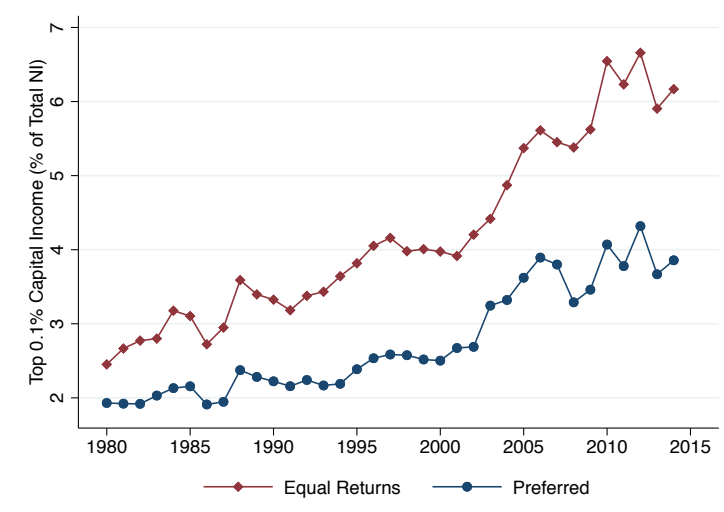

D. Top 0.1\% Capital Income Share

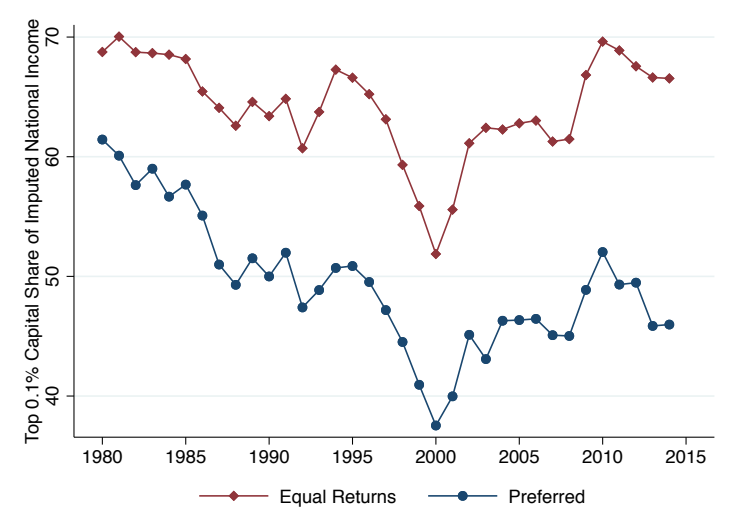

Notes: This figure is analogous to Figure 11, but for the top $0.1 \%$ in terms of imputed national income. 
Figure A.12: Income Concentration by Group under Different Approaches

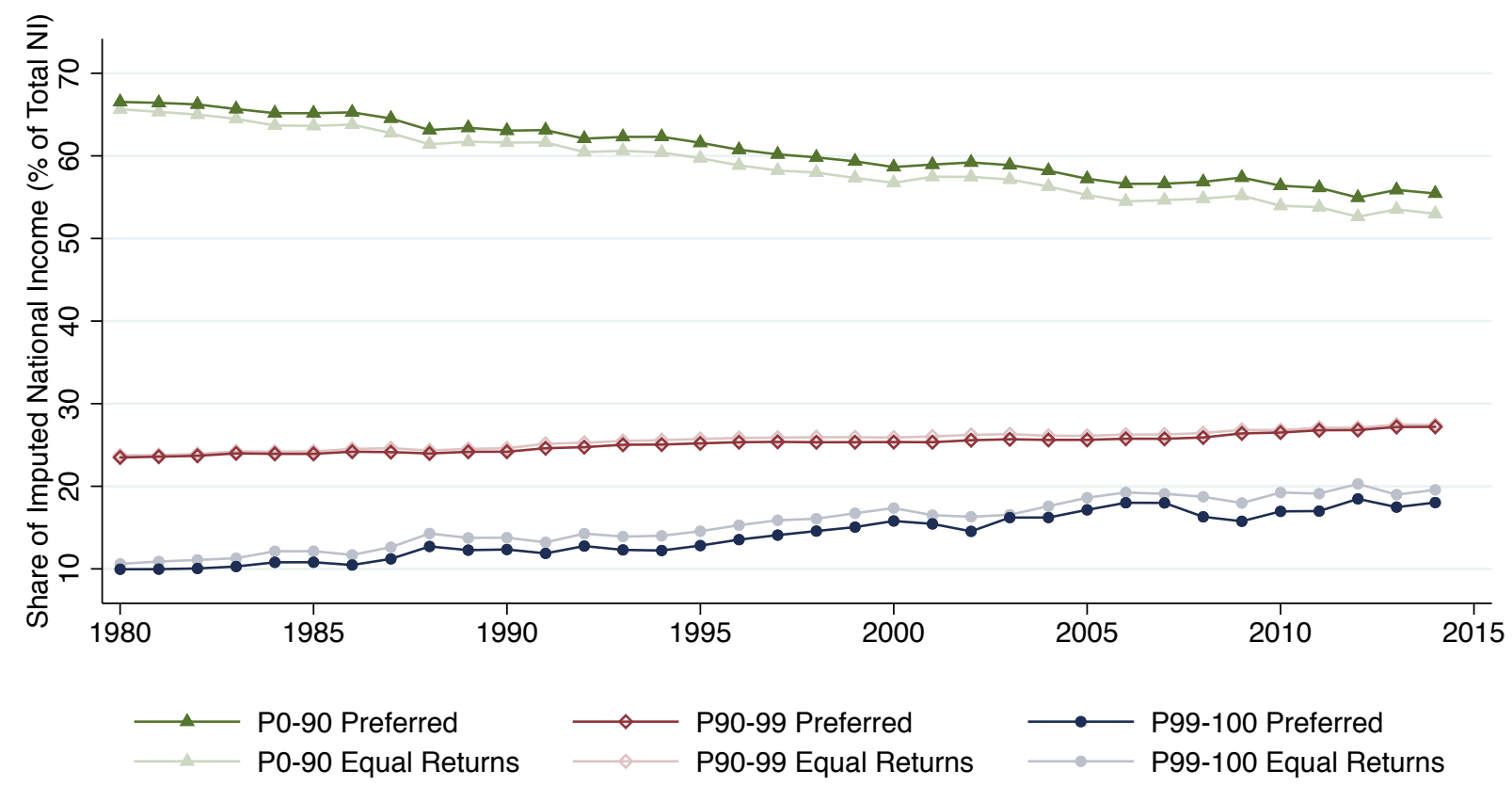

Notes: This figure plots the share of total household wealth for different imputed national income groups.

Figure A.13: Evolution of Savings Rates by Wealth Group

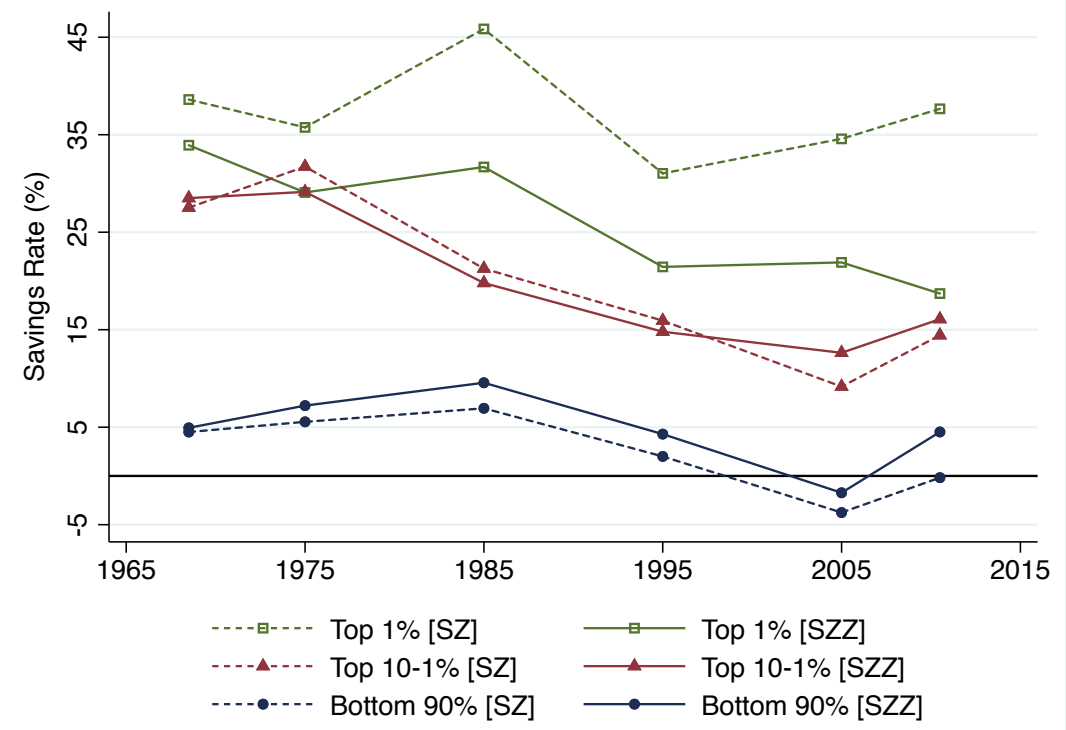

Notes: This figure plots the savings rates for different wealth groups for two different wealth estimates following the savings rate analysis of Saez and Zucman (2016). Savings in decade $t$ is defined as flows of wealth from $t$ to $t+1$ that are not due to price-adjusted returns to assets for the top $1 \%$, next $9 \%$, and bottom $90 \%$ of the wealth distribution. The dashed lines show the estimates from Saez and Zucman (2016), while the solid lines show the rates using wealth estimates from our preferred specification. 
Figure A.14: Social Security, Aggregate Wealth, and Wealth Concentration

A. Aggregates Relative to National Income

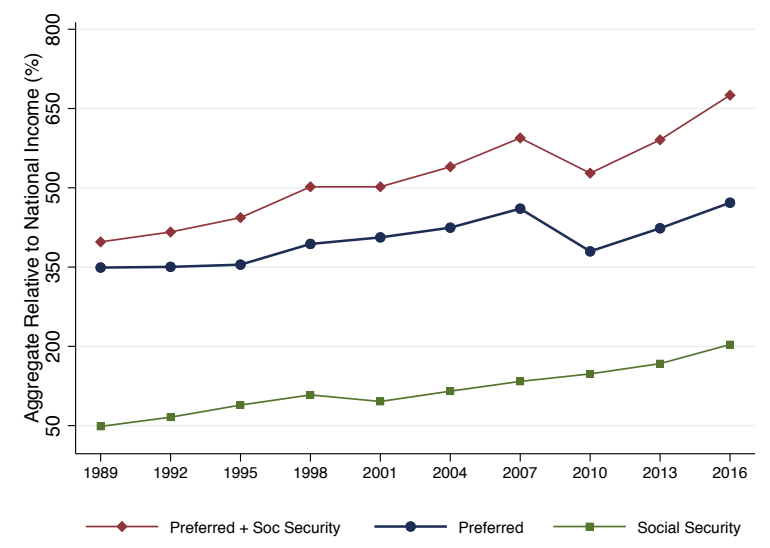

B. Top $0.1 \%$ Share with Social Security

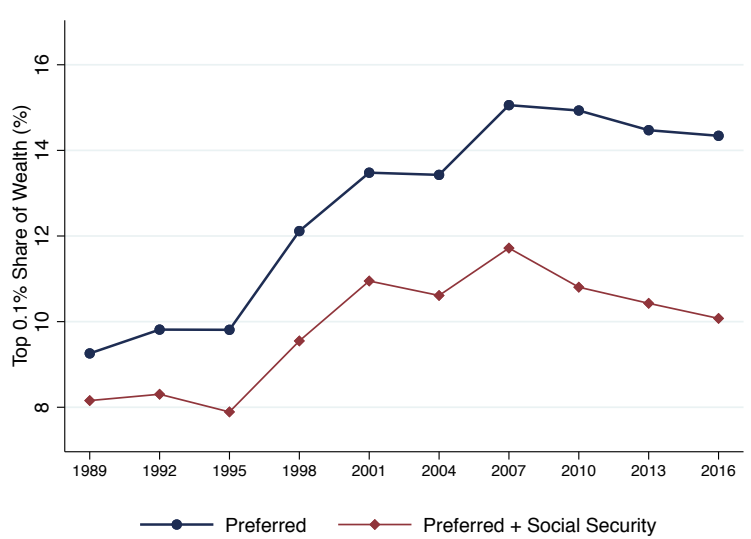

Notes: This figure uses data from Catherine, Miller and Sarin (2020) on estimated Social Security wealth from 1989 through 2016 for households in the SCF to show the effect of combining Social Security wealth with our preferred specification. Panel A plots aggregate Social Security wealth, our preferred aggregate wealth, and their sum, all relative to national income. Panel B plots our preferred top $0.1 \%$ wealth share and a modified series that includes total Social Security wealth in the denominator and top 0.1\% Social Security wealth in the numerator (the latter of which is close to zero relative to total wealth).

Figure A.15: Rates of Return on Fixed Income Claims

A. By wealth groups

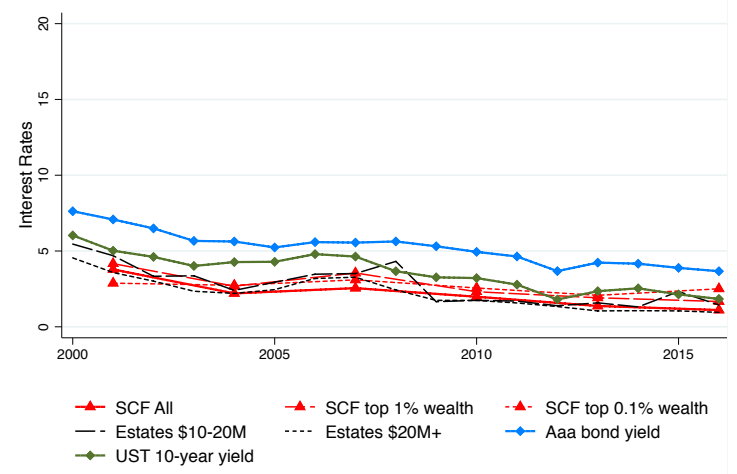

B. By interest income groups

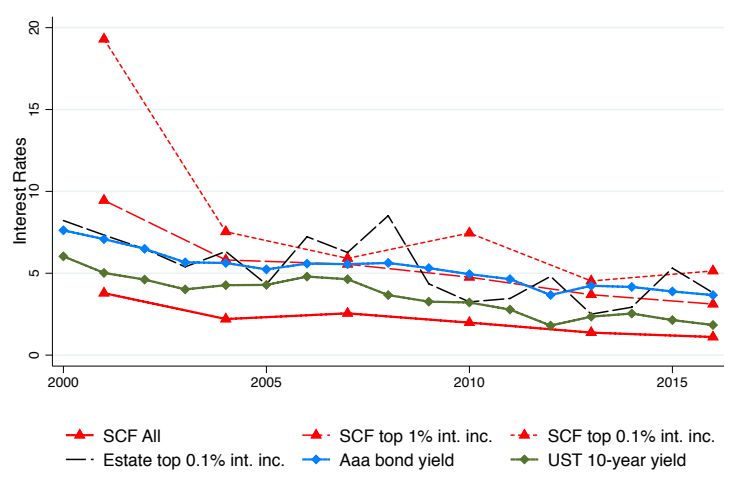

Notes: This figure shows rates of return on taxable fixed income assets across data sources. Panel A reproduces Figure 1 of Saez and Zucman's (2020) note "Comments on Smith, Zidar, and Zwick (2019)." We are able to exactly match their SCF rates of return and closely match their estate tax rates of return. Panel B shows the same series where groups are defined with taxable interest income rankings rather than wealth ranks. To match their graph, we depart from our preferred definition of taxable fixed income assets (described in Appendix E) and instead follow Saez and Zucman's fixed income wealth definition for the SCF, which takes a slightly different approach from us and Bricker, Henriques, Krimmel and Sabelhaus (2016) for splitting mutual funds whose underlying assets are a mix of equity and fixed income. 
Figure A.16: Top Shares of Wealth in the SCF Before and After Adjustments

A. Top $1 \%$

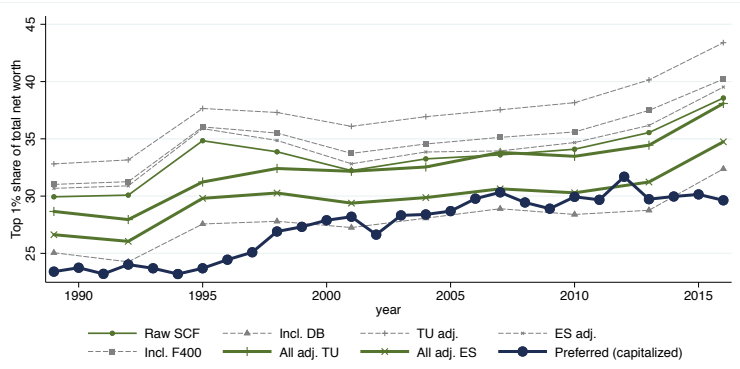

B. Top $0.1 \%$

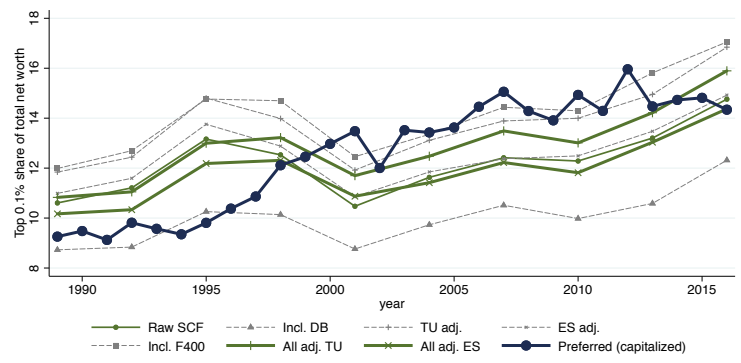

C. Progressive adjustments with tax unit ranks

Top 1\%, 2016

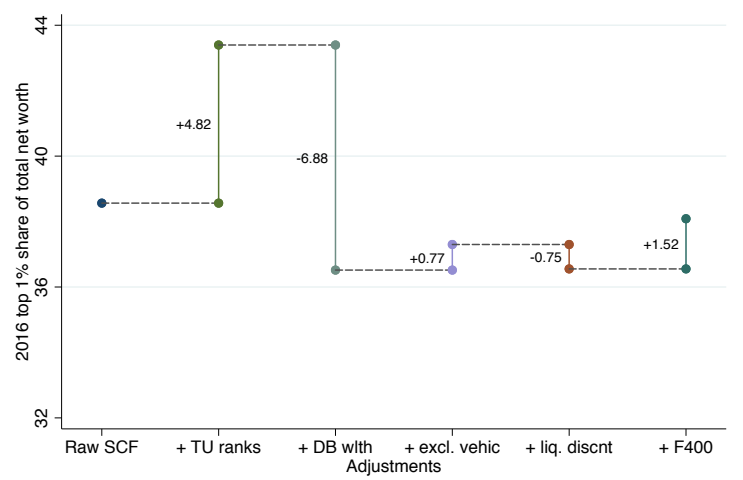

Top $0.1 \%, 2016$

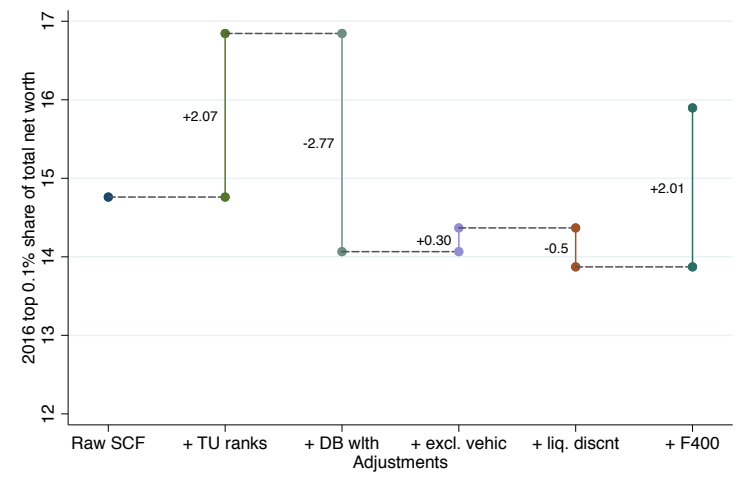

D. Progressive adjustments with equal split ranks

Top 1\%, 2016

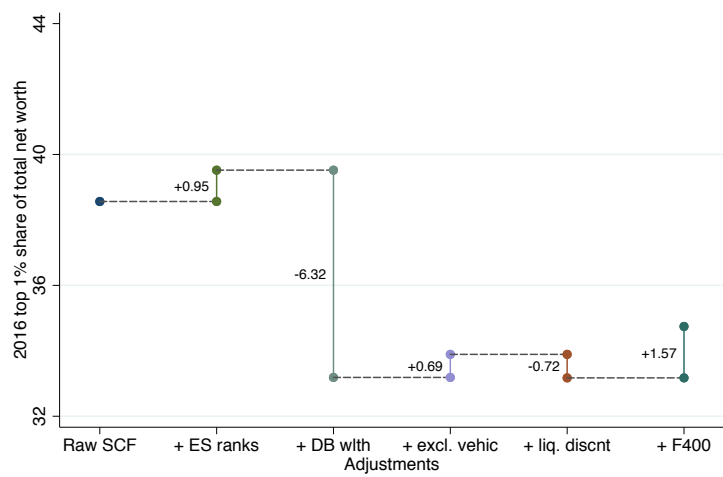

Top $0.1 \%, 2016$

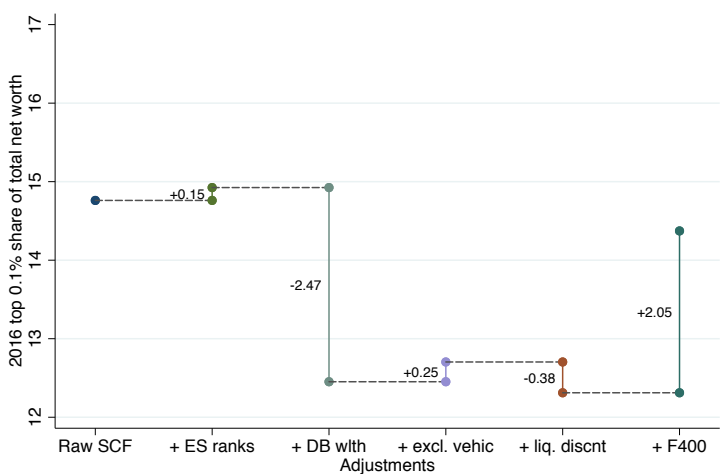

Notes: The Raw SCF specification ranks by and uses the net worth bulletin concept directly from the SCF. To obtain tax unit ranks in the SCF, we follow Saez and Zucman (2019a) in computing the number of households with wealth greater than each SCF observation, dividing this quantity by the number of US tax units in that year, and subtracting this quantity from one. To obtain equal split ranks in the SCF, we clone observations for which the respondent is married and halve net worth, then compute the number of "individuals" with wealth greater than each observation, divide this quantity by the number of US equal split individuals, and subtract this quantity from one. This procedure first converts household wealth into equal split wealth as we do in the tax data, and then adjusts the threshold to match the number of observations in the tax data. Defined benefit wealth adjustments rank by and use defined benefit wealth from Sabelhaus and Henriques Volz (2019). Liquidity discount entails subtracting off $10 \%$ of private business wealth from net worth. Panels A and B show baseline and final adjusted series, as well as series adjusted exclusively for DB wealth, tax unit rankings, and Forbes 400 wealth. Adjustments in panels $\mathrm{C}$ and $\mathrm{D}$ are successive. All Adjustments series in panels A and B are top shares after applying all adjustments from panels C and D. 
Figure A.17: Validating Housing Capitalization Approach

\section{A. Housing Assets Values Match Financial Accounts}

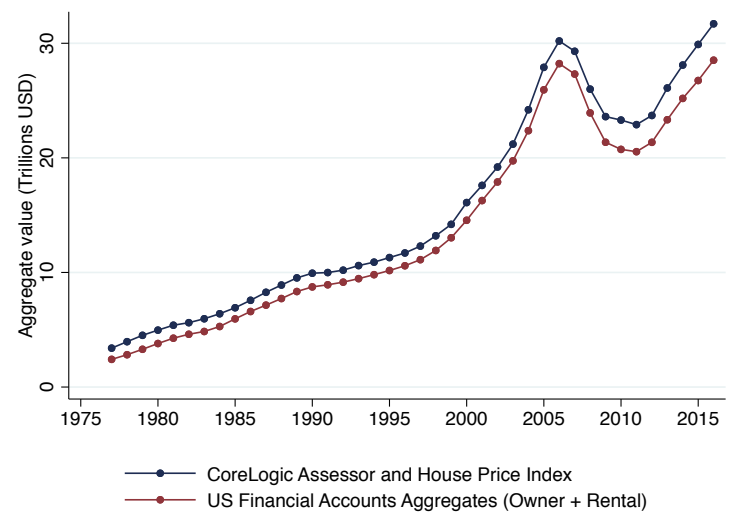

B. State Property Tax Rates Match ACS

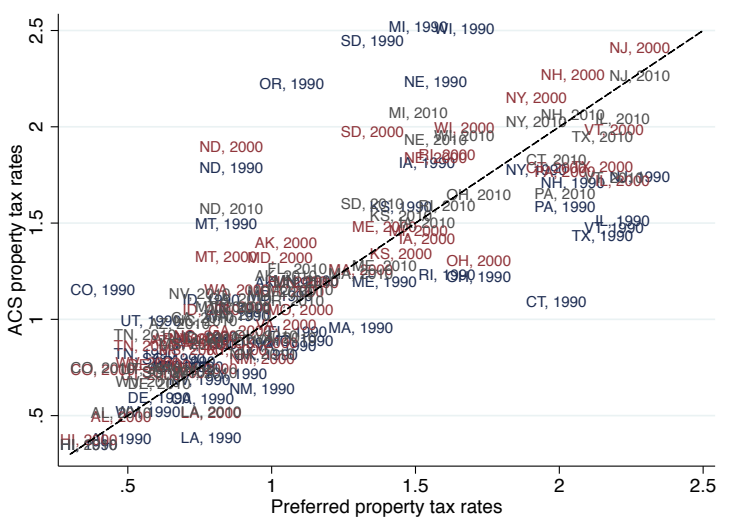

Notes: This figure shows two validation exercises for our housing capitalization approach. Panel A compares the aggregate value of housing wealth using two alternative capitalization methods: using owner and renter-occupied wealth allocated to match Financial Accounts, and using CoreLogic and Housing Price Index assessments. Panel B scatters our preferred property tax rate measure (the inverse of our housing capitalization factors) against ACS property tax rates from US Census years from Fajgelbaum, Morales, Suárez Serrato and Zidar (2019). 
Figure A.18: Sensitivity of Age Group Wealth Shares to Mortality Rates in Top 0.1\%

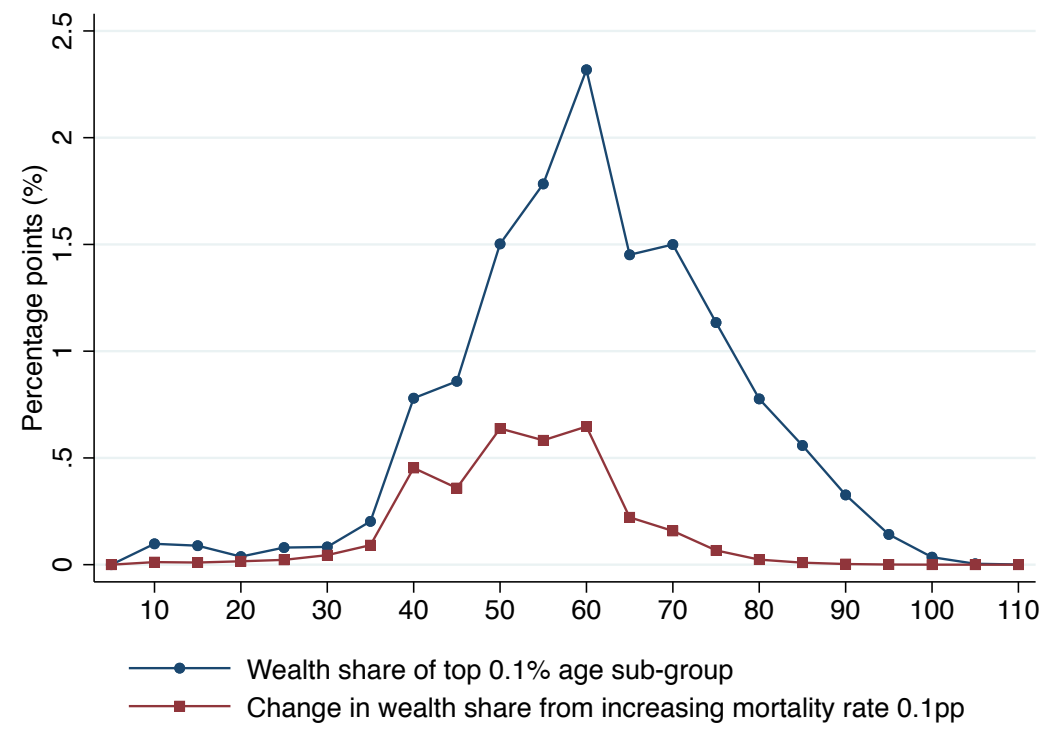

Notes: This figure plots the wealth shares of age groups within the top $0.1 \%$ of the wealth distribution in estate tax data. For example, a value of $2 \%$ for age group 51-55 means that those individuals in this age group collectively hold $2 \%$ of total household wealth. It also shows the change in estimated wealth share resulting from a 0.1 percentage point increase in mortality rates for each age group. Specifically, the bottom series is our estate tax wealth share estimate minus the "perturbed" estimate. For example, a value of $0.5 \%$ for the group 51-55 would indicate that if we raised the mortality rate by 0.001 for everyone in the age group, the estimated wealth share would drop by $0.5 \%$ of total household wealth. The two series are the mean across years from 1998 to 2016. 
Figure A.19: Top 0.1\% Wealth Shares using Estate Tax Data

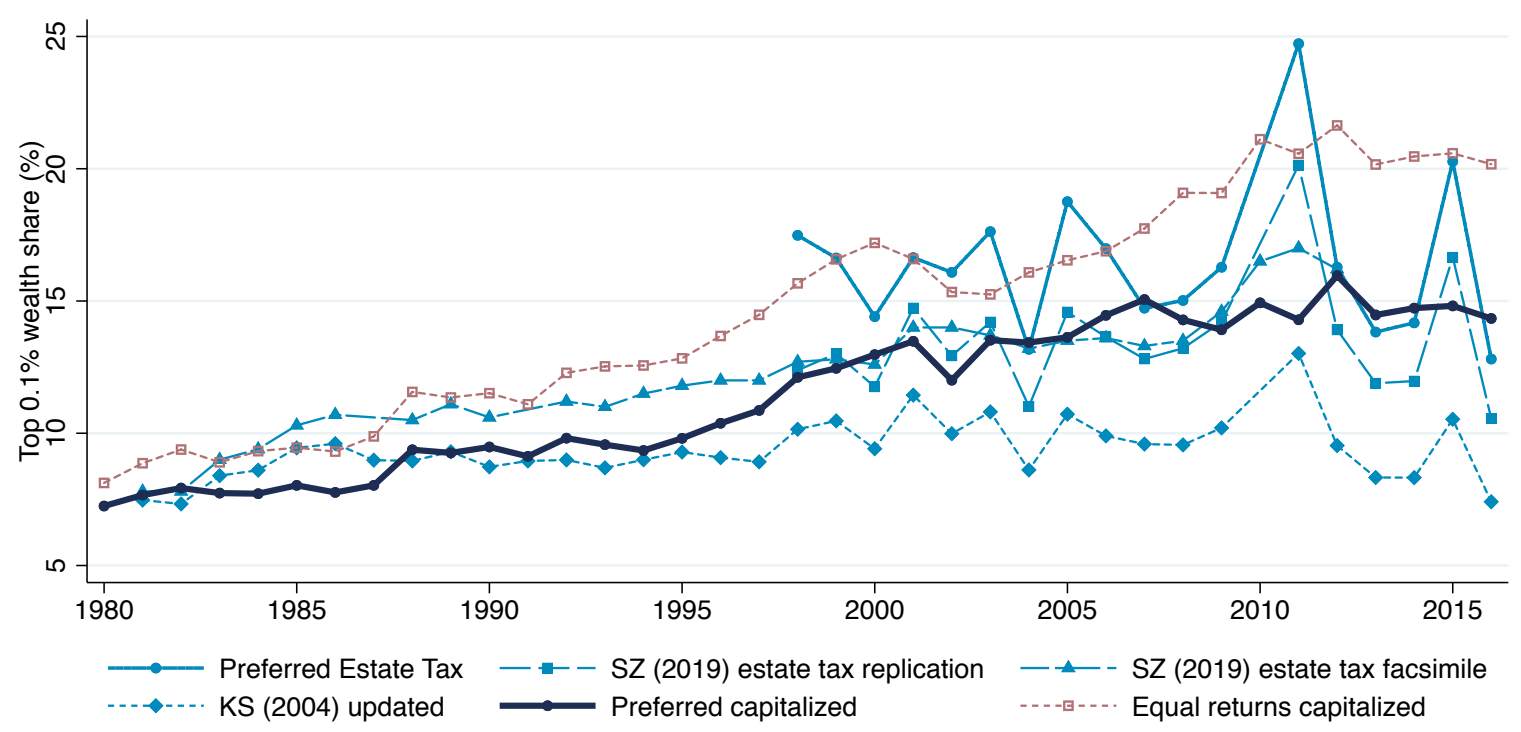

Notes: This figure plots top $0.1 \%$ wealth shares in estate tax data under four different approaches. First, Preferred Estate Tax uses estate tax data with our mortality rates, as defined in Section 10.3.4. Second, SZ (2019) estate tax replication uses our implementation of Saez and Zucman (2019a)'s methodology for updating mortality differentials. Third, SZ (2019) estate tax facsimile plots a copied series from their published figure, which differs from the replication series because it smooths estimates across years. For example, there is a data point in 2010, although the estate tax was temporarily abolished that year. Fourth, KS (2004) updated follows the approach in Kopczuk and Saez (2004b), updated in Saez and Zucman (2016) and then by us through 2016. Prior to 1995, we use the Kopczuk and Saez (2004b) estate tax series from the appendix in Saez and Zucman (2016). The figure also shows top 0.1\% wealth shares in our preferred capitalized series and under equal returns. 


\section{B Appendix Tables}


Table B.1: Industrial Composition of Top-0.1-Owned Pass-through Firm Value (2016)

\begin{tabular}{|c|c|c|c|c|c|c|c|}
\hline Rank & Industry (NAICS) & $\mathrm{S}+\mathrm{P}$ Value $(\$)$ & Returns $(\%)$ & Value/Firm (\$) & Value/Owner $(\$)$ & S Value & P Value \\
\hline 1 & Other professional/technical svc (5419) & 392.8 & 19.8 & 1.4 & 7.6 & 285.5 & 107.4 \\
\hline 2 & Restaurants (7225) & 366.5 & 3.8 & 1.6 & 4.6 & 230.8 & 135.7 \\
\hline 3 & Activities related to real estate $(5313)$ & 336.2 & 4.8 & 0.6 & 0.7 & 63.0 & 273.2 \\
\hline 4 & Other financial investment actvty (5239) & 256.1 & 23.6 & 1.0 & 0.1 & 109.5 & 192.9 \\
\hline 5 & Other investment pools/funds (5259) & 208.7 & 1.8 & 3.7 & 0.4 & 7.4 & 201.3 \\
\hline 6 & Other specialty trade cntrctr (2389) & 199.7 & 9.8 & 1.1 & 21.7 & 172.8 & 26.9 \\
\hline 7 & Legal svc $(5411)$ & 178.1 & 37.1 & 1.4 & 2.8 & 48.3 & 129.8 \\
\hline 8 & Oil/gas extraction (2111) & 161.1 & 3.4 & 3.4 & 0.2 & 23.9 & 137.2 \\
\hline 9 & Offices of physicians (6211) & 131.7 & 21.0 & 1.0 & 3.2 & 88.9 & 42.8 \\
\hline 10 & Accounting/bookkeeping svc (5412) & 126.7 & 13.4 & 1.3 & 5.4 & 40.6 & 86.0 \\
\hline 11 & Automobile dealers (4411) & 122.1 & 7.9 & 2.9 & 7.3 & 97.5 & 24.6 \\
\hline 12 & Traveler acmdtn (7211) & 120.8 & 3.4 & 2.2 & 2.3 & 38.2 & 82.6 \\
\hline 13 & Computer sys design/related svc (5415) & 120.1 & 9.2 & 0.8 & 5.1 & 89.2 & 30.9 \\
\hline 14 & Other telecommunications (5179) & 113.1 & 22.8 & 9.2 & 30.4 & 10.0 & 103.2 \\
\hline 15 & Other pipeline trnsprt (4869) & 112.5 & 1.7 & 225.8 & 0.2 & 0.8 & 111.7 \\
\hline 16 & Security contracts broker (5231) & 106.7 & 2.7 & 6.6 & 0.3 & 11.2 & 95.6 \\
\hline 17 & Misc. durable goods merch whlsl (4239) & 100.4 & 8.1 & 1.7 & 10.8 & 79.4 & 21.0 \\
\hline 18 & General freight trucking (4841) & 89.1 & 6.4 & 0.8 & 13.2 & 73.4 & 15.7 \\
\hline 19 & Nonresidential building constr (2362) & 86.1 & 11.7 & 2.0 & 8.4 & 68.9 & 17.1 \\
\hline 20 & Nondepository credit intrmd (5222) & 85.9 & 5.2 & 3.5 & 2.6 & 40.0 & 45.8 \\
\hline 21 & Building foundation/exterior cntrctr (2381) & 84.5 & 10.5 & 0.7 & 28.6 & 73.8 & 10.6 \\
\hline 22 & Depository credit intrmd (5221) & 83.8 & 3.3 & 44.7 & 4.6 & 79.7 & 4.1 \\
\hline 23 & Residential building constr (2361) & 83.1 & 14.2 & 0.5 & 4.5 & 55.1 & 27.9 \\
\hline 24 & Other miscellaneous mfg. (3399) & 76.0 & 8.9 & 2.2 & 4.6 & 55.9 & 20.0 \\
\hline 25 & Building equipment cntrctr (2382) & 71.2 & 18.1 & 0.6 & 12.8 & 63.9 & 7.2 \\
\hline 26 & Other miscellaneous store retailers (4539) & 70.1 & 6.1 & 1.0 & 15.2 & 57.2 & 13.0 \\
\hline 27 & Building material/supp dealers (4441) & 67.2 & 6.8 & 3.3 & 29.0 & 60.7 & 6.5 \\
\hline 28 & Petroleum merch whlsl (4247) & 66.1 & 1.1 & 18.2 & 0.2 & 25.8 & 40.3 \\
\hline 29 & Other motor vehicle dealers (4412) & 64.5 & 3.4 & 5.1 & 28.4 & 53.0 & 11.6 \\
\hline 30 & Nursing and residential care facilities (6230) & 63.3 & 2.4 & 2.9 & 3.5 & 25.5 & 37.8 \\
\hline \multicolumn{2}{|c|}{ Aggregate } & 7429 & 8.8 & 4.0 & 8.6 & 4379 & 3145 \\
\hline
\end{tabular}

Notes: This table presents statistics on the value of top $0.1 \%$-owned pass-through businesses by 4 -digit industry. The rows are sorted by the level of top pass-through value for S-corporations and partnerships. For this table, we are using data that ranks owners by fiscal income, not wealth. These estimates include firms with both non-top and top owners, so the aggregate values will exceed those based on the apportioned data. 
Table B.2: Total Housing Wealth under Heterogeneous Property Tax Capitalization (2016)

\begin{tabular}{|c|c|c|c|c|c|c|c|c|c|}
\hline \multirow[b]{2}{*}{ State } & \multicolumn{4}{|c|}{2016 Housing Wealth } & \multicolumn{4}{|c|}{2016 Housing Wealth (cont.) } & \multirow[b]{2}{*}{ Wealth / pop (K) } \\
\hline & Assets (B) & Wealth (B) & Assets / pop (K) & Wealth / pop (K) & State & Assets (B) & Wealth (B) & Assets / pop (K) & \\
\hline $\mathrm{AK}$ & 47.00 & 9.56 & 90.82 & 18.48 & MS & 84.40 & 28.77 & 53.46 & 18.22 \\
\hline $\mathrm{AL}$ & 207.04 & 76.22 & 74.78 & 27.53 & MT & 65.17 & 19.51 & 90.61 & 27.13 \\
\hline $\mathrm{AR}$ & 126.17 & 51.12 & 69.75 & 28.26 & $\mathrm{NC}$ & 655.97 & 304.46 & 106.57 & 49.46 \\
\hline $\mathrm{AZ}$ & 482.42 & 227.98 & 117.96 & 55.74 & ND & 62.52 & 37.64 & 122.14 & 73.52 \\
\hline $\mathrm{CA}$ & 7337.19 & 4664.57 & 301.17 & 191.47 & $\mathrm{NE}$ & 96.73 & 49.46 & 76.78 & 39.26 \\
\hline $\mathrm{CO}$ & 599.82 & 311.14 & 167.61 & 86.94 & $\mathrm{NH}$ & 113.33 & 54.29 & 123.11 & 58.98 \\
\hline $\mathrm{CT}$ & 336.55 & 156.35 & 146.15 & 67.89 & NJ & 990.42 & 534.00 & 167.74 & 90.44 \\
\hline $\mathrm{DC}$ & 52.32 & 9.21 & 123.17 & 21.69 & NM & 103.03 & 46.04 & 88.79 & 39.67 \\
\hline $\mathrm{DE}$ & 68.84 & 33.15 & 118.42 & 57.03 & NV & 257.08 & 126.06 & 141.29 & 69.28 \\
\hline FL & 1884.70 & 1200.33 & 147.10 & 93.68 & NY & 1651.94 & 825.31 & 131.86 & 65.88 \\
\hline GA & 563.83 & 239.07 & 94.76 & 40.18 & $\mathrm{OH}$ & 685.77 & 374.75 & 91.53 & 50.02 \\
\hline HI & 193.05 & 96.73 & 191.62 & 96.01 & OK & 179.86 & 83.28 & 77.07 & 35.68 \\
\hline IA & 184.71 & 97.71 & 92.01 & 48.67 & OR & 456.74 & 256.93 & 169.29 & 95.23 \\
\hline ID & 86.00 & 27.43 & 80.07 & 25.54 & $\mathrm{PA}$ & 810.01 & 389.53 & 94.69 & 45.53 \\
\hline IL & 921.57 & 438.18 & 111.81 & 53.16 & RI & 91.24 & 43.87 & 124.76 & 59.99 \\
\hline IN & 314.14 & 156.38 & 74.81 & 37.24 & $\mathrm{SC}$ & 261.18 & 113.32 & 86.31 & 37.45 \\
\hline $\mathrm{KS}$ & 143.66 & 62.67 & 76.81 & 33.51 & SD & 58.75 & 29.31 & 92.48 & 46.14 \\
\hline KY & 169.02 & 57.75 & 62.03 & 21.19 & $\mathrm{TN}$ & 428.64 & 241.79 & 105.05 & 59.25 \\
\hline LA & 217.09 & 87.50 & 80.22 & 32.33 & $\mathrm{TX}$ & 1572.34 & 764.40 & 94.27 & 45.83 \\
\hline MA & 845.77 & 462.98 & 182.69 & 100.01 & $\mathrm{UT}$ & 218.94 & 96.83 & 116.27 & 51.42 \\
\hline MD & 641.92 & 302.39 & 164.73 & 77.60 & VA & 662.93 & 210.80 & 123.83 & 39.37 \\
\hline ME & 92.91 & 43.18 & 105.48 & 49.02 & $\mathrm{VT}$ & 38.65 & 9.03 & 77.91 & 18.22 \\
\hline MI & 535.60 & 266.88 & 83.42 & 41.57 & WA & 1068.17 & 630.79 & 221.08 & 130.56 \\
\hline MN & 427.07 & 194.53 & 112.28 & 51.14 & WI & 415.36 & 224.80 & 102.10 & 55.26 \\
\hline $\mathrm{MO}$ & 317.56 & 151.33 & 82.70 & 39.41 & WV & 74.65 & 38.51 & 72.16 & 37.23 \\
\hline MS & 84.40 & 28.77 & 53.46 & 18.22 & WY & 34.39 & 8.37 & 86.45 & 21.05 \\
\hline MT & 65.17 & 19.51 & 90.61 & 27.13 & & & & & \\
\hline
\end{tabular}

Notes: This table summarizes total housing assets and wealth under heterogeneous property tax capitalization. Asset and wealth totals are measured in billions of 2016 dollars; per capita measures are in thousands of 2016 dollars. 
Table B.3: Prediction Error in SCF for Equity Assets by Approach

\begin{tabular}{|c|c|c|c|c|c|}
\hline \multirow{3}{*}{ Group } & \multirow{2}{*}{$\begin{array}{r}\text { Actual } \\
\text { SCF }\end{array}$} & \multicolumn{2}{|c|}{ Predicted } & \multicolumn{2}{|c|}{ Fit } \\
\hline & & SZ & SZZ & $\mathrm{SE}_{\mathrm{SZ}}$ & $\mathrm{SE}_{\mathrm{SZZ}}$ \\
\hline & (1) & $(2)$ & $(3)$ & (4) & $(5)$ \\
\hline \multicolumn{6}{|c|}{ Panel A. 2016 equity totals $(\$ \mathrm{M})$} \\
\hline Bot $90 \%$ Equity Income & 0.02 & -0.00 & 0.00 & 1.18 & 0.91 \\
\hline Top 10\% Equity Income & 0.80 & 0.83 & 0.74 & 0.00 & 0.01 \\
\hline Top 1\% Equity Income & 2.24 & 2.77 & 2.32 & 0.06 & 0.00 \\
\hline Top $0.1 \%$ Equity Income & 5.32 & 9.58 & 6.60 & 0.64 & 0.06 \\
\hline Top $0.01 \%$ Equity Income & 20.21 & 56.34 & 32.65 & 3.19 & 0.38 \\
\hline \multicolumn{4}{|c|}{ Panel mean squared error: } & 1.02 & 0.27 \\
\hline \multicolumn{6}{|c|}{ Panel B. 2016 equity portfolio shares (\%) } \\
\hline Bot $90 \%$ Equity Income & 4.49 & -0.42 & 0.22 & 1.19 & 0.90 \\
\hline Top 10\% Equity Income & 52.75 & 53.61 & 50.84 & 0.00 & 0.00 \\
\hline Top 1\% Equity Income & 46.87 & 52.19 & 47.71 & 0.01 & 0.00 \\
\hline Top $0.1 \%$ Equity Income & 37.66 & 52.12 & 42.84 & 0.15 & 0.02 \\
\hline Top $0.01 \%$ Equity Income & 29.24 & 53.53 & 40.03 & 0.69 & 0.14 \\
\hline \multicolumn{4}{|c|}{ Panel mean squared error: } & 0.41 & 0.21 \\
\hline \multicolumn{6}{|c|}{ Panel C. 2001-2016 change in equity totals $(\$ \mathrm{~T})$} \\
\hline Bot $90 \%$ Equity Income & 0.15 & 0.13 & 0.10 & 0.02 & 0.13 \\
\hline Top 10\% Equity Income & 5.74 & 3.20 & 5.23 & 0.20 & 0.01 \\
\hline Top 1\% Equity Income & 5.17 & 3.23 & 5.00 & 0.14 & 0.00 \\
\hline Top $0.1 \%$ Equity Income & 2.72 & 2.19 & 3.23 & 0.04 & 0.04 \\
\hline \multirow[t]{2}{*}{ Top $0.01 \%$ Equity Income } & 0.86 & -0.01 & 0.95 & 1.03 & 0.01 \\
\hline & \multicolumn{3}{|c|}{ Panel mean squared error: } & 0.28 & 0.04 \\
\hline \multicolumn{6}{|c|}{ Panel D. 2001-2016 change in equity portfolio shares (\%) } \\
\hline Bot $90 \%$ Equity Income & -2.95 & 0.95 & 0.24 & 1.75 & 1.17 \\
\hline Top 10\% Equity Income & 4.52 & -5.00 & 4.08 & 4.44 & 0.01 \\
\hline Top 1\% Equity Income & -7.05 & -18.80 & -9.18 & 2.78 & 0.09 \\
\hline Top $0.1 \%$ Equity Income & -10.42 & -22.28 & -12.01 & 1.29 & 0.02 \\
\hline \multirow[t]{2}{*}{ Top $0.01 \%$ Equity Income } & -12.65 & -27.51 & -21.09 & 1.38 & 0.45 \\
\hline & \multicolumn{3}{|c|}{ Panel mean squared error: } & 2.33 & 0.35 \\
\hline
\end{tabular}

Notes: This table evaluates alternative capitalization assumptions using a cross-validation approach in the SCF. Column (1) shows actual SCF wealth moments for different equity income groups, where equity income is defined as the sum of dividends and realized capital gains. Columns (2) and (3) show predicted wealth moments using different capitalization approaches. Columns (4) and (5) present a goodness-of-fit measure for each capitalization approach, defined as squared prediction error or $\left(\frac{\text { Capitalized estimate }}{\text { Estimand in SCF }}-1\right)^{2}$. Portfolio shares under each capitalization specification are computed as (Capitalized equity)/(networth + tot_pen_db vehic-equity_scf + Capitalized equity), where networth and vehic are SCF bulletin concepts, tot_pen_db is Sabelhaus-Henriques Volz defined benefit pension wealth, and equity_scf is our definition of public equity in the SCF. Equity income thresholds are taken according to the distribution of equity income in tax data. 
Table B.4: Imputed National Income Composition Across Groups (2014)

\begin{tabular}{|c|c|c|c|}
\hline \multirow[b]{2}{*}{ Income group } & \multicolumn{3}{|c|}{ Income shares } \\
\hline & Fixed Income $\quad$ C-corporation (Divs $+\mathrm{RE}$ ) & Other capital income & Labor Income \\
\hline
\end{tabular}

Panel A. Top income groups (Preferred ranks)

$\begin{array}{lcccc}\text { Full population } & 4.8 \% & 4.2 \% & 18.0 \% & 73.0 \% \\ \text { Top 10\% } & 5.7 \% & 7.4 \% & 19.2 \% & 67.6 \% \\ \text { Top 1\% } & 6.2 \% & 12.9 \% & 21.6 \% & 59.4 \% \\ \text { Top 0.1\% } & 6.1 \% & 17.7 \% & 22.2 \% & 54.0 \% \\ \text { Top } 0.01 \% & 6.2 \% & 21.8 \% & 22.2 \% & 49.9 \%\end{array}$

Panel B. Intermediate income groups (Preferred ranks)

$\begin{array}{lllll}\text { Bottom } 90 \% & 4.1 \% & 1.6 \% & 17.0 \% & 77.4 \% \\ \text { Top } 10-1 \% & 5.4 \% & 3.8 \% & 17.7 \% & 73.1 \% \\ \text { Top } 1-0.1 \% & 6.3 \% & 8.7 \% & 21.0 \% & 64.0 \% \\ \text { Top } 0.1-0.01 \% & 6.0 \% & 14.2 \% & 22.3 \% & 57.5 \% \\ \text { Top } 0.01 \% & 6.2 \% & 21.8 \% & 22.2 \% & 49.9 \%\end{array}$

Panel C. Top income groups (Equal returns ranks)

$\begin{array}{lcccc}\text { Full population } & 4.9 \% & 4.7 \% & 20.0 \% & 70.5 \% \\ \text { Top 10\% } & 7.7 \% & 8.5 \% & 24.2 \% & 59.6 \% \\ \text { Top 1\% } & 12.9 \% & 15.8 \% & 27.4 \% & 43.9 \% \\ \text { Top 0.1\% } & 17.7 \% & 23.8 \% & 25.1 \% & 33.5 \% \\ \text { Top } 0.01 \% & 21.8 \% & 30.2 \% & 23.0 \% & 25.0 \%\end{array}$

Panel D. Intermediate income groups (Equal returns ranks)

\begin{tabular}{lllll} 
Bottom $90 \%$ & $2.3 \%$ & $1.3 \%$ & $16.2 \%$ & $80.1 \%$ \\
Top $10-1 \%$ & $4.0 \%$ & $3.3 \%$ & $21.9 \%$ & $70.8 \%$ \\
Top $1-0.1 \%$ & $8.6 \%$ & $8.7 \%$ & $29.5 \%$ & $53.2 \%$ \\
Top $0.1-0.01 \%$ & $14.0 \%$ & $17.9 \%$ & $27.0 \%$ & $41.1 \%$ \\
Top $0.01 \%$ & $21.8 \%$ & $30.2 \%$ & $23.0 \%$ & $25.0 \%$ \\
\hline
\end{tabular}

Notes: This table shows 2014 imputed national income composition of fixed income, C-corporation income (including both dividends and retained earnings), other capital income, and labor income. Panels A and B rank according to preferred income definitions; panels $\mathrm{C}$ and $\mathrm{D}$ rank according to equal returns income definitions. 


\section{State-Year Housing Capitalization Factors}

To derive capitalization factors based on unequal property tax rates over time, we combine state-level data from four sources: (1) effective property tax rate data from ATTOM, (2) property tax assessor data from 2012 from DataQuick, (3) CoreLogic state-level house price indexes, and (4) state-level property tax revenues and population from the US Census of States. For itemizers, we estimate housing assets at the person-level using the formula,

$$
\hat{A}_{i t}^{\text {hou }}=\beta_{s t}^{\text {ptax }} y_{i t}^{\text {ptax }}=\frac{1}{r_{t}^{s}} \times y_{i t}^{\text {ptax }}
$$

where $r_{t}^{s}$ is the effective state-level property tax rate in year $t$ and $y_{i t}^{\text {ptax }}$ is the observed flow of property tax deductions. To estimate $r_{t}^{s}$, we separately estimate the numerator - state-level property tax revenues - and denominator - state-level housing asset values - each year.

State-level property tax revenues $\tilde{R}_{t}^{S}$ are given by,

$$
\tilde{R}_{t}^{S}=R_{\text {Census }, t}^{S} \times \theta_{R, 2012}
$$

where $R_{\text {Census,t }}^{S}$ is state-level property tax revenues from the Census of States, and $\theta_{R, 2012}$ equals $R_{\text {DataQuick,2012 }}^{S} / R_{\text {Census } 2012}^{S}$ is a time-invariant factor equaling 0.64 used to scale down Census revenues to remove commercial property taxes from the Census figures. We use 2012 as a baseline year because, for this year, we have the assessed property tax amounts from DataQuick.

State-level housing asset values are then given by,

$$
\tilde{W}_{t}^{S}=\tilde{W}_{2012}^{S} \times \frac{p_{\text {CoreLogic,t }}}{p_{\text {CoreLogic }, 2012}} \times \frac{\text { pop }}{p_{t}^{S}},
$$

where $\tilde{W}_{2012}^{S}$ equals $\left(1 / r_{\text {ATTOM }}^{S}\right) \times R_{\text {DataQuick,2012 }}^{S}$ and provides an estimate in 2012 of property values underlying assessed tax amounts, $p_{\text {CoreLogic, } t}$ is the state-level CoreLogic house price index based on a repeat-sales methodology, and $p o p_{t}^{S}$ is state-level population from the Census. We use population to proxy for the number of households and hence housing units. Adjusting the value of housing for growth in housing units allows us to apply the price index to the approximately correct underlying stock of housing units. Finally, we estimate the state-level property tax rate over time as

$$
r_{t}^{S}=\frac{\tilde{R}_{t}^{S}}{\tilde{W}_{t}^{S}}
$$

We validate this approach in two ways. First, we compare the cross-sectional property tax rates from ATTOM to those based on the Census. Second, we compare aggregate real estate values to the US Financial Accounts. Both match our estimates reasonably well (Appendix Figure A.17). 


\section{Portfolio Category Definitions in Tax Data}

\section{D.1 Overall wealth}

The variables used to construct our preferred capitalization series, or "SZZ wealth," from administrative tax data vary over the time period studied due to data availability in earlier years. Where applicable, the years a specific variable is used are indicated below. Dollars are in nominal terms in the following examples.

SZZ wealth $(2001-2016)=$

taxbond_3tier + muni + currency + ccorw_9010 + s_szz_ebitd + p_szz_ebitd + solepropw

+ ownerhome_szz + rentalhome_ini + penw_szz_age + hwdeb

2016 example $=\$ 12.6 T+\$ 1.3 T+\$ 1.2 T+\$ 11.6 T+\$ 3.9 T+\$ 3.1 T+\$ 4.8 T$

$$
+\$ 22.3 T+\$ 6.3 T+\$ 26.3 T-\$ 17.4=\$ 75.7 T
$$

- $(1980-2000)$

taxbond_3tier + muni + currency + ccorw_9010 + scorw + partw + solepropw

+ ownerhome_szz + rentalhome_ini + penw_szz_age + hwdeb

2000 example $=\$ 4.8 T+\$ 0.9 T+\$ 0.5 T+\$ 8.2 T+\$ 1.0 T+\$ 1.0 T+\$ 2.0 T$

$$
+\$ 11.2 T+\$ 3.1 T+\$ 12.6 T-\$ 8.0=\$ 37.1 T
$$

- $(1966-1979)$

taxbond_3tier + muni + currency + ccorw_9010 + scorw + partw + solepropw

+ ownerhome_ini + rentalhome_ini + hwpen + hwdeb

1979 example $=\$ 1.5 T+\$ 0.1 T+\$ 0.2 T+\$ 0.7 T+\$ 0.0 T+\$ 0.3 T+\$ 0.9 T$

$$
+\$ 2.4 T+\$ 0.9 T+\$ 1.0 T-\$ 1.5=\$ 6.5 T
$$




\section{D.2 Wealth categories}

Fixed income $=$ taxable fixed income wealth + non-taxable fixed income wealth + non-interest bearing deposits Public equities $=$ c-corporation equities $* 0.8$

Private business $=\mathrm{s}$-corp wealth + partnership wealth + sole proprietor wealth $+(\mathrm{c}$-corp equities $* 0.2)$

Net housing $=$ gross owner-occupied housing + gross rental housing + mortgage debt

Pensions $=$ pension wealth

Other = residual non-mortgage debts

\section{D.3 Wealth components}

Taxable fixed income wealth = taxbond_3tier

where taxbond_3tier is the value of taxable fixed income, using the three-tier capitalization method, where the P99.9-100 group is capitalized using the Moody's seasoned Aaa-rated corporate bond yield, the P99-99.9 group is capitalized using the 10-year Treasury constant maturity rate, and the P0-99 group assigned the remainder. Here, groups are defined using the distribution of taxable interest income.

\section{Non-taxable fixed income wealth $=$ muni}

where muni is an estimate of non-taxable (municipal) bonds from the Distributional National Accounts (DINA), calculated by Piketty, Saez and Zucman (2018), which estimate municipal bond wealth by capitalizing tax-exempt interest reported in administrative tax data.

\section{Non-interest bearing deposits = currency}

where currency is an estimate of non-interest bearing deposits from DINA. Because this wealth component does not generate income (by definition), the value is estimated from survey data. 


\section{C-Corporation equities = ccorw_9010}

where ccorw_9010 is calculated by multiplying $90 \%$ of dividend flows and $10 \%$ of capital gains by a common capitalization factor that divides total C-corporation wealth by the sum of $90 \%$ of total dividend flows and $10 \%$ of total capital gains.

\section{S-Corporation wealth $=$ s_szz_ebitd $(2001-2016)$}

$$
=\operatorname{scorw}(1966-2000)
$$

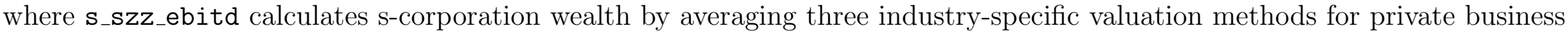
(using sales, assets, and a modification of EBITD) and allocating to individuals by ownership share, with a $10 \%$ liquidity discount. The modification of EBITD keeps only $25 \%$ of profits to account for the $75 \%$ of pass-through profits that are tied to owners' human capital (Smith, Yagan, Zidar and Zwick, 2019). scorw is the DINA s-corp equities estimate. Because s_szz_ebitd relies on administrative tax data available only after 2000, the DINA variable scorw is used for earlier years. The scorw variable is calculated by multiplying a taxpayer's S-corporation income by a capitalization factor equal to aggregate S-corporation wealth divided by aggregate s-corporation income. This process assumes that all taxpayers receive the same rate of return on their s-corporation income.

\section{Partnership wealth $=$ p_szz_ebitd $(2001-2016)$

$$
=\operatorname{partw}(1966-2000)
$$

where p_szz_ebitd calculates partnership wealth by averaging three industry-specific valuation methods for private business (using sales, assets, and a modification of EBITD) and allocating to individuals by ownership share, with a $10 \%$ liquidity discount. The EBITD modification is analogous to that for S-corporations. partw is the DINA partnership wealth estimate. Because p_szz_ebitd relies on administrative tax data available only after 2000, the DINA variable partw is used for earlier years. The partw variable is calculated by multiplying a taxpayer's partnership income by a capitalization factor equal to aggregate partnership + sole proprietorship wealth divided by aggregate partnership + sole proprietorship income. This process assumes that all taxpayers receive the same rate of return on their partnership + sole proprietorship income.

\section{Sole proprietor wealth $=$ solepropw}


where solepropw is the DINA estimate of sole proprietor business wealth. This estimate is calculated by multiplying a taxpayer's sole proprietorship income by a capitalization factor equal to aggregate partnership + sole proprietorship wealth divided by aggregate partnership + sole proprietorship income. This process assumes that all taxpayers receive the same rate of return on their partnership + sole proprietorship income.

$$
\begin{aligned}
\text { Gross owner-occupied housing } & =\text { ownerhome_szz }(1980-2016) \\
& =\text { ownerhome_ini }(1966-1979)
\end{aligned}
$$

where ownerhome_szz uses state-level property tax rates and administrative tax data on mortgage interest deductions to estimate owner-occupied housing wealth. Due to limitations in the administrative data, state-level estimates are only possible in 1980 and after. ownerhome_ini is the series from DINA and is used in the years prior to 1980.

\section{Gross rental housing $=$ rentalhome_ini}

where rentalhome_ini is the DINA estimate of gross rental housing wealth.

\section{Mortgage debt $=$ ownermort_ini + rentalmort_ini}

where ownermort_ini and rentalmort_ini are the DINA estimates of mortgages on owner-occupied and rental housing, respectively.

$$
\begin{aligned}
\text { Pension wealth } & =\text { penw_szz_age }(1980-2016) \\
& =\text { hwpen }(1966-1980)
\end{aligned}
$$

where penw_szz_age calculates pension wealth by capitalizing wages and pension income using weights that differ for peak-aged (ages 45-75) and other people. The resulting wealth is then scaled to match the Financial Accounts pension wealth total. Because this method requires precise age information available in the administrative data after 1979, the DINA pension and life insurance variable (hwpen) is used prior to 1980.

Other $=$ hwdeb $-($ ownermort_ini + rentalmort_ini $)=$ nonmort 
where hwdeb captures DINA household debts. This variable can be subdivided into owner-occupied mortgage debt ownermort_ini and rental housing mortgage debt rentalmort_ini (which are included in the net housing category), with a residual that captures non-mortgage household debts (nonmort).

\section{Renamed variables}

- penw_szz_age is denoted penw_szz_scale_v3 in the code.

- $\mathbf{s}_{-} \mathbf{s z z}_{-}$ebitd is denoted $\mathbf{s}_{-} v a l u e_{-}$avg_ebitda_red in the code.

- p_szz_ebitd is denoted p_value_avg_ebitda_red in the code. 


\section{E Portfolio Category Definitions in the SCF}

\section{E.1 Non-SCF bulletin variables}

We construct portfolio concepts from SCF bulletin wealth concepts, but supplement these measures using the following variables:

Defined benefit pension wealth $\equiv$

$$
\begin{aligned}
\text { tot_pen_db } & =\text { currec_pv_dbamt_rtot }+ \text { currec_pv_dbamt_stot }+ \text { future_pv_dbamt_rtot } \\
& + \text { future_pv_dbamt_stot }+ \text { curjob_pv_dbamt_rtot }+ \text { curjob_pv_dbamt_stot } \\
2016 \text { example } & =\$ 5.2 T+\$ 1.6 T+\$ 0.3 T+\$ 0.1 T+\$ 7.1 T+\$ 3.5 T=\$ 17.9 T
\end{aligned}
$$

where currec_pv_dbamt_rtot and currec_pv_dbamt_stot represent the present value of currently received defined benefit wealth for SCF respondent and spouse; future_pv_dbamt_rtot and future_pv_dbamt_stot represent present value of future benefits not associated with current job for respondent and spouse; and curjob_pv_dbamt_rtot and curjob_pv_dbamt_stot represent present value of future benefits associated with current job for respondent and spouse. Each of these concepts is constructed in

Other managed assets invested in equity $\equiv$

othma_equity $=\left\{\begin{array}{l}\text { annuit } \times \text { Sh. annuities inv. in equity }+ \text { trusts } \times \text { Sh. trusts inv. in equity if year } \geq 1998 \\ \text { othma } \times \text { Sh. other managed assets inv. in equity if year }<1998\end{array}\right.$

$$
2016 \text { example }=\$ 0.9 T \times 0.35+\$ 2.35 T \times 0.47=\$ 1.3 T
$$


where annuit and trusts are SCF bulletin concepts for annuities and trusts. Shares of annuities, trusts, or other managed assets invested in equity are computed from the SCF full file as:

$$
\begin{array}{r}
\text { Sh. annuit. inv. in equ. }=\left\{\begin{array}{l}
(X 6581=1)+(X 6581=3 \mid X 6581=30) \times \max (0, X 6582) / 10,000 \text { if year } \geq 2004 \\
(X 6826=1)+(X 6826=5 \mid X 6826=6) \times 0.5+(X 6826=-7) \times 0.3 \text { if year } \in[1998,2004) \\
\mathrm{N} / \mathrm{A} \text { if year }<1998
\end{array}\right. \\
\text { Sh. trusts inv. in equ. }=\left\{\begin{array}{l}
(X 6591=1)+(X 6591=3 \mid X 6591=30) \times \max (0, X 6592) / 10,000 \text { if year } \geq 2004 \\
(X 6841=1)+(X 6841=5 \mid X 6841=6) \times 0.5+(X 6841=-7) \times 0.3 \text { if year } \in[1998,2004) \\
\mathrm{N} / \mathrm{A} \text { if year }<1998
\end{array}\right. \\
\text { Sh. oth. mgd assets inv. in equ. }=\left\{\begin{array}{l}
(X 3947=1)+(X 3947=5 \mid X 3947=6) \times 0.5++(X 3947=-7) \times 0.3 \text { if year }<1998 \\
\mathrm{~N} / \mathrm{A} \text { if year } \geq 1998
\end{array}\right.
\end{array}
$$

$$
\text { Other managed assets invested in fixed income } \equiv \text { othma_fixed }=\max (0, \text { othma }- \text { othma_equity })
$$

$$
2016 \text { example }=\$ 3.2 T-\$ 1.3 T=\$ 1.9 T
$$

where othma is a bulletin SCF wealth concept representing other managed assets and othma_equity is defined as above. Our approach of splitting othma into equity and fixed income broadly follows Bricker, Henriques, Krimmel and Sabelhaus (2016), though our approach offers a refinement such that othma_equity + othma_fixed sums to othma for all SCF observations 1989$2016 . .^{57}$

\footnotetext{
${ }^{57}$ Bricker, Henriques, Krimmel and Sabelhaus (2016) generate othma_equity as the remainder of equity after subtracting off directly held equity equity in quasi-liquid retirement assets, and equity in savings accounts. This remainder, however, is not made up entirely of constituent variables of the bulletin concept othma. We instead create the othma_equity by summing only the additive components of equity which are additive components of othma.
} 


\section{E.2 Main wealth categories}

In our Modified SCF series, we define wealth as follows:

$$
\begin{aligned}
\text { Net worth } & =\text { networth }- \text { vehic }+ \text { tot_pen_db } \\
2016 \text { example } & =\$ 86.9 T-\$ 2.7 T+\$ 17.9 T=\$ 102 T
\end{aligned}
$$

where networth and vehic are SCF bulletin concepts representing total wealth and vehicles, respectively, and tot_pen_db is defined as in Section E.1.

Taxable fixed income $=\mathrm{liq}+\mathrm{cds}+$ savbnd + bond - notxbnd + nmmf - stmutf $-\frac{1}{2} \times$ comutf - tfbmutf + othma_fixed

$$
2016 \text { example }=\$ 4.9 T+\$ 0.6 T+\$ 0.1 T+\$ 1.2 T-\$ 0.8 T+\$ 9.7 T-\$ 5.9 T-\frac{1}{2} \times \$ 0.8 T-\$ 1.3 T+\$ 1.9 T=\$ 10.1 T
$$

where liq, cds, savbnd, bond, notxbnd, nmmf, stmutf, comutf, and tfbmutf are SCF bulletin concepts representing liquid

$$
\begin{aligned}
\text { Non-taxable fixed income } & =\text { notxbnd }+ \text { tfbmutf } \\
2016 \text { example } & =\$ 0.8 T+\$ 1.3 T=\$ 2.1 T
\end{aligned}
$$

where notxbnd and tfbmutf are SCF bulletin concepts representing non-taxed bonds and tax-free bond mutual funds, respectively.

$$
\begin{aligned}
\text { Equity } & =\text { stocks }+ \text { stmutf }+\frac{1}{2} \times \text { comutf }+ \text { othma_equity } \\
2016 \text { example } & =\$ 5.7 T+\$ 5.9 T+\frac{1}{2} \times \$ 0.8 T+\$ 1.3 T=\$ 13.4 T
\end{aligned}
$$


where stocks, stmutf, and comutf are SCF bulletin concepts representing stocks directly held, stock mutual funds, and combination mutual funds, respectively, and othma_equity is defined as in Section E.1.

$$
\begin{aligned}
\text { Private business } & =\text { bus }+ \text { nnresre } \\
2016 \text { example } & =\$ 19.3 T+\$ 3.7 T=\$ 23.0 T
\end{aligned}
$$

where bus and nnresre are SCF bulletin concepts representing business (with either an active or nonactive interest) and nonresidential real estate, respectively.

$$
\begin{aligned}
& \text { Pensions }=\text { retqliq }+ \text { tot_pen_db } \\
& 2016 \text { example }=\$ 15 T+\$ 17.9 T=\$ 32.9 T
\end{aligned}
$$

where retqliq is the SCF bulletin concept representing quasi-liquid retirement accounts and tot_pen_db is defined as in Section E.1.

$$
\begin{aligned}
\text { Housing } & =\text { houses }+ \text { oresre }+ \text { mrthel }+ \text { resdbt } \\
2016 \text { example } & =\$ 24.3 T+\$ 6.3 T-\$ 8.3 T-\$ 1.1 T=\$ 21 T
\end{aligned}
$$

where houses, oresre, mrthel, and resdbt are SCF bulletin concepts representing primary residence, residential property excluding primary residence (e.g. vacation homes), debt secured by primary residence, and debt secured by other residential property, respectively.

$$
\begin{aligned}
\text { Other } & =\text { cashli }+ \text { othfin }+ \text { othnf } i n-(\text { othloc }+ \text { ccbal }+ \text { install }+ \text { odebt }) \\
2016 \text { example } & =\$ 0.9 T+\$ 0.7 T+\$ 0.6 T-(\$ 0.1 T+\$ 0.3 T-\$ 2 T-\$ 0.2 T)=\$ 3.2 T
\end{aligned}
$$

where cashli, othfin, othnfin, othloc, ccbal, install, and odebt are SCF bulletin concepts representing cash value of whole life insurance, other miscellaneous financial assets, other miscellaneous non-financial assets, other lines of credit, credit card balances, installment loans, and other debt. 


\section{F Portfolio Category Definitions in the Distributional Financial Accounts (DFA)}

We define DFA wealth as follows:

$$
\begin{aligned}
\text { Networth } & =\text { Net worth }- \text { Consumer durables } \\
2016 \text { example } & =\$ 87.5 T-\$ 5.1 T=\$ 82.4 T
\end{aligned}
$$

where each component is a raw DFA portfolio concept.

Fixed income $=$ Checkable deposits and currency + Time deposits and short-term investments + Money market fund shares

$$
+ \text { Debt securities }+ \text { Mortgage assets }+ \text { Other loans and advances (assets) }
$$

$$
2016 \text { example }=\$ 1.0 T+\$ 8.7 T+\$ 1.4 T+\$ 4.4 T+\$ 0.09 T+\$ 0.8 T=\$ 16.4 T
$$

where each component is a raw DFA portfolio concept.

$$
\begin{aligned}
\text { Equity } & =0.8 \times \overline{\text { C-corp sh corp equ }} \times \text { Corporate equities and mutual funds } \\
2016 \text { example } & =0.8 \times 0.8 \times \$ 19.5 T=\$ 12.6 T
\end{aligned}
$$

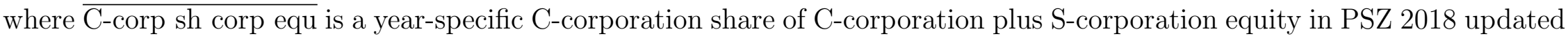
appendix files (specifically parameters.csv) and Corporation equities and mutual funds is a raw DFA portfolio concept.

Private business $=0.2 \times \overline{\mathrm{C} \text {-corp sh corp equ }} \times$ Corporate equities and mutual funds

$$
+(1-\overline{\text { C-corp sh corp equ }}) \times \text { Corporate equities and mutual funds }
$$$$
+(1-\overline{\text { Rental sh equ in non-corp biz }} \times \text { Equity in noncorporate business }
$$

$$
2016 \text { example }=0.2 \times 0.8 \times \$ 19.5 T+0.2 \times \$ 19.5 T+0.75 \times \$ 11.1 T=\$ 15.5 T
$$

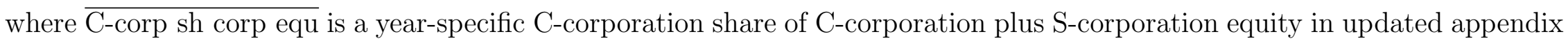
files from Piketty, Saez and Zucman (2018) (specifically parameters.csv); Rental sh equ in non-corp biz is a year-specific tenant-occupied residential real estate (net of mortgages) share of equity in non-corporate business also computed from the 
same updated appendix files; and Corporate equities and mutual funds and Equity in noncorporate business are both raw DFA portfolio concepts.

Pensions $=$ Pension entitlements

2016 example $=\$ 24 T$

where Pension entitlements is a raw DFA portfolio concept.

Housing $=$ Real estate - Home mortgages $+\overline{\text { Rental sh equ in non-corp biz }} \times$ Equity in noncorporate business 2016 example $=\$ 22.4 T-\$ 9.6 T+0.25 \times \$ 11.1 T=\$ 15.5 T$

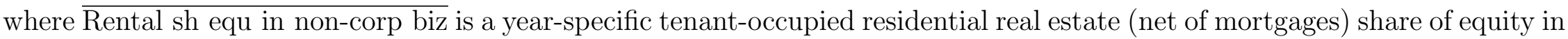
non-corporate business computed from PSZ 2018 updated appendix files and other components are raw DFA portfolio concepts.

Other $=$ Life insurance reserves + Miscellaneous assets - Consumer credit

- Depository institution loans not elsewhere classified - Other loans and advances

- Deferred and unpaid life insurance premiums

$$
2016 \text { example }=\$ 1.5 T+\$ 1.1 T-\$ 3.5 T-\$ 0.2 T-\$ 0.4 T-\$ 0.03 T=-\$ 1.5 T
$$

where each component is a raw DFA portfolio concept. 


\section{G Treatment of Forbes 400 in 2016}

This section describes how we use public data on the Forbes 400 in 2016 to assign Forbes 400 wealth to portfolio categories. De-identified administrative tax data were not used for any of our analysis of the Forbes 400 .

\section{G.1 Primary source of equity wealth}

\section{G.1.1 Public and private companies}

We start with an individual-level data file on the Forbes 400 in $2016 .^{58}$ In this file, each observation has a source and titlecompany variable which describes the primary source of each individual's wealth. We combine these variables with publicly available information regarding the listed company to assign an individual's equity wealth as deriving either from a public or private company. Our strategy is as follows:

1. If the individual's primary source of wealth is one company (according to the source and titlecompany variables), we check if this company is public or private (either now or while it was active).

2. Otherwise, if the individual accumulated their wealth at more than one company according to the source and titlecompany variables, then:

- If these companies were all public or all private, then we designate the individual as primarily public-equity-rich or private-business-rich accordingly.

- If these companies were not all of the same type, then we determine whether the private or public companies were their main source of wealth, and note judgment calls below in subsection G.2.1.

\section{G.2 Allocating wealth to portfolio categories to complement SCF}

Our general strategy for allocating Forbes 400 wealth for non-equity components is based on portfolio shares from the top $0.1 \%$ of the wealth distribution in the SCF. We then allow Forbes 400 shares of public equity and private business to vary depending on whether we designate individuals as primarily private-business-rich or public-equity-rich.

To be specific, we allocate Forbes 400 wealth to portfolio categories as follows:

1. For Forbes 400 individuals whom we designate as primarily public-equity-rich, we allocate $81 \%$ of their wealth (the combined portfolio share of private business and public equity among SCF top $0.1 \%$ wealth-holders) to public equity.

2. For Forbes 400 individuals whom we designate as primarily private-business-rich, we allocate $81 \%$ of their wealth to private business.

\footnotetext{
${ }^{58}$ We retrieve the data file forbes_20112018_bdays.dta from the website https://github.com/BITSS/ opa-wealthtax/blob/master/rawdata/forbes_20112018_bdays.dta, which was linked to on Saez and Zucman's website http://wealthtaxsimulator.org/ under the link labeled "Source code here."
} 
3. For every individual in the 2016 Forbes 400, we allocate wealth to fixed income, housing, pensions, and other assets according to the portfolio shares for those components of the top $0.1 \%$ of the SCF wealth distribution in 2016.

This allocation results in the following portfolio shares for the Forbes 400 in 2016: $42.3 \%$ public equity, $38.8 \%$ private business, $0.7 \%$ pensions, $10.2 \%$ fixed income, $4.6 \%$ housing, and $3.3 \%$ other assets.

\section{G.2.1 Public/private company judgment calls}

- No. 20 - Michael Dell - Dell public until 2013 and after 2018. Assigned public.

- No. 34 - Elon Musk - Tesla is public but other sources of wealth e.g. X.com, Zip2, SpaceX (all private). Assigned public.

- No. 44 - Dustin Markovitz - co-founder of Facebook (public) and Asana (private). Assigned public.

- No. 50 - Jan Koum - Whatsapp initially private but bought by Facebook (public). Assigned public.

- No. 78 - Travis Kalanick - Uber not public until 2019. Assigned private.

- No. 114 \& No. 115 - Santo Domingo family - much of fortune from Bavaria Brewery, which was sold in 2005 and again in 2016 and is now part of Anheuser Busch/InBev (public). Difficult to ascertain whether Bavaria Brewery was public; holding company is Santo Domingo Group (private). Assigned private.

- No. 118 - Sumner Redstone - majority owner of National Amusements theater chain (private) but through NA are majority shareholders of ViacomCBS (public). Assigned public.

- No. 132 - Karen Pritzker - Marmon Holdings (private) and Hyatt hotels (public). Assigned public.

- No. 146 - H Ross Perot Sr - EDS and Perot Systems both public until 2009 when they were bought. Assigned public.

- No. 147 - James Jannard - Oakley went public in 1995, then bought by Luxottica Group in 2007; Red Digital Camera is private. Assigned public.

- No. 155 - Walter Scott Jr - former CEO of Peter Kiewit Sons' Incorporated (private), but was also chairman of Level 3 Communications (public). Assigned private.

- No. 172 - Helen Johnson-Leipold - inherited S.C. Johnson \& Son shares (private). But since 1999, chairman and CEO of Johnson Outdoors (public). Assigned public.

- No. 189 - Steven Udvar-Hazy - Former Chairman and CEO of ILFC until 2010 (private at that point); now CEO of Air Lease Corporation (public). Assigned public. 
- No. 191 \& 193- Anthony \& JB Pritzker - similar to Karen Pritzker; also managing partner of Pritzker Group (private). Assigned public.

- No. 192 - Roger Wang - chairman of Golden Eagle International Group (private) but also founder and main shareholder of Golden Eagle Retail Group, which went public in 2006. Assigned public.

- No. 216 - David Rockefeller Sr - Complex portfolio. Assigned private.

- No. 234 - Wilbur Ross Jr - was part of Rothschild \& Co (public) for a while. Founded WL Ross \& Co which (private). Assigned private.

- No. 244 - Ken Langone - Home Depot main source of wealth. Assigned public.

- No. 250 - A Jerrold Perenchio - chairman and CEO of Univision while it was public. But also lots of other businesses, several of which private. Assigned public.

- No. 258 - Steve Wynn - Mirage Resorts was private; sold in 2000, then started Wynn Resorts, which went public in 2002. Assigned public.

- No. 303 - Bill Gross - PIMCO acquired by Allianz SE in 2000; Janus Capital Group, where he worked from 2014, was public. Assigned private.

- No. 315 - Thomas Siebel - Siebel Systems was a publicly traded company 1996-2006; c3.ai is private as is his holding company First Virtual Group. Assigned public.

- No. 317 - Noam Gottesman - GLG partners IPO in 2007, bought by Man group in 2010. TOMS capital is private. Assigned private.

- No. 348 - Dan Snyder - bought Snyder Communications in 1996 and sold in 2000; then bought Washington Redskins. Assigned public.

- No. 378 - Amy Wyss - Synthes primary source of wealth, which was public from 1996 until Johnson \& Johnson bought it in 2012. Assigned public.

- No. 390 - Vincent Viola - many businesses, some public. Assigned public.

- No. 419 - Rocco Commisso - founder and CEO of Mediacom, which was public until Commisso bought it in 2011, now private. Assigned private.

- No. 423 - Ernest Garcia II - largest shareholder of Carvana (public as of 2017) and owns and runs DriveTime Automotive (private). Assigned private.

- No. 425 - H Ross Perot Jr - Perot Systems was public until 2009. Hillwood private; Perot holdings private. Assigned public.

- No. 451 - Chris Larsen - Founded Prosper (private), Ripple (public) and e-Loan (which was public). Assigned public. 


\section{H Other Data Sources}

In addition to administrative tax data, SCF data, and DFA data, we also use several other series in our analysis:

- Interest rates on 10-year Treasury bonds from the Board of Governors of the Federal Reserve System. Retrieved from FRED Economic Data via freduse using series code DGS10. Archived on January 27th, 2020. Collapsed to yield annual averages.

- Interest rates on Aaa bonds from Moody's. Retrieved from FRED Economic Data via freduse using series code AAA. Retrieved and archived on January 27th, 2020. Collapsed to yield annual averages.

- Interest rates on deposits from Drechsler, Savov and Schnabl (2017) data, retrieved from correspondence with authors on October 15th, 2019.

- Kopczuk and Saez (2004a) estate tax series shown in figure 1 retrieved from Saez and Zucman (2016) "Other Estimates" appendix tables.

- National income in current dollars from the Bureau of Economic Analysis. Retrieved from FRED Economic Data via freduse using series code A032RC1A027NBEA. Archived on January 27th, 2020. Scaled into billions.

- State-level GDP in current dollars from the Bureau of Economic Analysis table SAGDP2. Retrieved from https://apps.bea.gov/itable/iTable.cfm?ReqID=70\&step=1. Archived on March 12th, 2020.

- Statistics of Income (SOI) Corporate Sample from the Internal Revenue Service (IRS). Stratified random sample of US corporate income tax returns. See Zwick and Mahon (2017) and Yagan (2015) for further discussion. 


\section{Liquidity Discount: Replication and Extension of Koeplin, Sarin, and Shapiro (2000)}

This appendix explains our replication of Koeplin, Sarin and Shapiro (2000) (henceforth KSS), which studies whether the value of private companies reflects an illiquidity discount. This appendix also discusses our extension of their analysis to include data after 1998.

\section{I.1 Creating a Transactions Sample}

To construct the sample, we first identify all acquisitions of US companies on Thomson One (formerly on SDC Platinum) between 1984 and 2019. KSS restrict the sample to those acquisitions where necessary financial historical data were available. We take this restriction to mean that KSS drop all transactions which have a missing value for any of the variables they use. We also follow KSS in dropping transactions of financial and public utility firms. Ultimately, our sample consists of 167 private firm transactions from 1984-2019, and 113 private firm transactions from 1984-1998. Our sample is somewhat larger than that of KSS, which consists of 84 transactions over the period 1984-1998.

We then endeavor to compare each private firm transaction to a comparable public company acquisition. We do so according to the following algorithm:

1. For each private firm transaction, we attempt to identify an acquisition of a public company in the same year and in the same 4-digit industry.

2. If there was more than one such comparable acquired public company, we use the public company closest in sales to the private company in question.

3. If there was no public company transaction in the same year and same 4-digit industry, we attempt to find a comparable transaction in the same year and 3-digit industry.

4. If this is also unsuccessful, we repeat the above step for the same 2-digit and then 1-digit industry.

This matching strategy matches some private company transactions to the same public company transaction.

\section{I.2 Calculating the Discount}

KSS focus on four multiples:

- EBIT multiple: Ratio of enterprise value to EBIT. EBIT is defined as earnings before interest income, interest expense, non-operating income, taxes and minority interest for the last 12 months ending on the date of the most current financial information prior to the announcement of the transaction.

- EBITDA multiple: Ratio of enterprise value to EBITDA. EBITDA is defined as earnings before interest, taxes, depreciation and amortization for the last 12 months ending on the date of the most current financial information prior to the transaction. 
- Book multiple: Ratio of enterprise value to book value. Book value is defined, as in KSS, as short-term debt + long-term debt + shareholders' equity as of the date of the most current financial information prior to the announcement of the transaction.

- Sales multiple: Ratio of enterprise value to net sales. Net sales is defined as revenue after taking into account returned goods and allowances for price reductions for the last 12 months ending on the date of the most recent financial information prior to the announcement of the transaction. If net sales are not available, total revenues are used instead.

Tables I.1 and I.2 present mean and median multiples for two sample periods, 1984-2019 and 1984-1998, respectively. Specifically, following KSS, we:

1. Calculate the mean (median) multiple for all private companies and for all public companies

2. Calculate the private company discount from the mean (median) multiple of the private target companies and the comparable mean (median) multiple of the public target companies.

The discount column is calculated from the group means or medians using the following formula:

$$
\text { Private company discount }=1-\frac{\text { Private company multiple }}{\text { Public company multiple }}
$$

\section{I.3 Results}

Overall, our estimates are similar to KSS once we restrict the sample to earlier years. In later years, the private company discount appears to have fallen somewhat.

Focusing on the full sample results, means and medians differ substantially. Because the median is more robust to outliers, we prefer median-based measures. Observing the median, we see evidence of a private company discount associated with EBITDA multiples on the order of $6 \%$ to $9 \%$, though we cannot rule out a discount of zero. This discount estimate is

smaller than that of KSS, which was around $12 \%$. Based on this evidence, we use $10 \%$ as an approximate liquidity discount for pass-through firms. 
Table I.1: Private Company Discounts of Sample Transactions 1984-2019

\begin{tabular}{lcccccc}
\hline & \multicolumn{2}{c}{ Private Targets } & \multicolumn{2}{c}{ Public Targets } & \multicolumn{2}{c}{ Discount } \\
& Mean & Median & Mean & Median & Mean & Median \\
\hline Enterprise Value/EBIT & 20.67 & 12.71 & 51.74 & 14.52 & 60.05 & 12.47 \\
Enterprise Value/EBITDA & 10.86 & 8.87 & 11.62 & 9.71 & 6.54 & 8.65 \\
Enterprise Value/Book Value & 3.50 & 2.45 & 2.56 & 1.98 & $-36.72^{* * *}$ & -23.74 \\
Enterprise Value/Sales & 4.62 & 1.13 & 1.99 & 1.15 & -132.16 & 1.74 \\
\hline
\end{tabular}

Notes: This table presents mean and median multiples for the sample period 1984-2019. Discounts are computed following equation 12 . We test whether the private company discounts we measure for means are distinct from zero using a $t$-test on the equality of means for the private and public company multiples. We test whether the private company discounts we measure for medians are distinct from zero using a t-test on the equality of medians for the private and public company multiples.

Table I.2: Private Company Discounts of Sample Transactions 1984-1998

\begin{tabular}{lcccccc}
\hline & \multicolumn{2}{c}{ Private Targets } & \multicolumn{2}{c}{ Public Targets } & \multicolumn{2}{c}{ Discount } \\
& Mean & Median & Mean & Median & Mean & Median \\
\hline Enterprise Value/EBIT & 17.45 & 12.07 & 24.17 & 14.52 & 27.80 & 16.87 \\
Enterprise Value/EBITDA & 10.45 & 8.19 & 11.93 & 9.34 & 12.41 & 12.31 \\
Enterprise Value/Book Value & 3.64 & 2.43 & 2.67 & 2.21 & $-36.33^{* *}$ & -9.95 \\
Enterprise Value/Sales & 1.50 & 1.12 & 2.05 & 1.07 & $26.83^{* *}$ & -4.67 \\
\hline
\end{tabular}

Notes: This table is the same as table I.1, except it uses only transactions from 1984 to 1998, following KSS. 


\section{J Response to "Comments on Smith, Zidar, Zwick (2019)"}

We are grateful to Saez and Zucman for their constructive and thoughtful comments in Saez and Zucman (2020). We respond to each of the four main comments in this note. We list the comments in bold and our responses in plain text. The four topics are: (1) the appropriate rates of return for fixed income assets for the rich; (2) the wealth of the richest 400 people across data sources and approaches; (3) consistency with the SCF in terms of the rise of wealth concentration; and (4) projected revenue from a wealth tax.

We summarize our responses here and then discuss each point in more detail. On (1), we first reconcile our results and then show how conclusions change when ranking by flows rather than by stocks. We then show that our approach performs better in a goodness-of-fit sense than the proposed alternative and especially relative to the equal-returns approach. On (2), we investigate how the Forbes 400 compares to different capitalization approaches in Section 10.3.2, showing that Forbes-based estimates of the total wealth and number of billionaires fall in between the equal-returns estimates and our preferred estimates, and that the Forbes data are more consistent with our preferred top wealth shares using Pareto techniques. On (3), we discuss in Sections 10.2 and 10.3.1 plausible reconciliations for each apparent discrepancy between our data and the SCF and clarify the nature of remaining uncertainty. In terms of the level, trends, and composition, our preferred series is generally closer to the SCF than the equal-returns approach. On (4), the preliminary wealth estimates discussed in Saez and Zucman (2020) showed larger gaps than our updated version, which uses new data, includes all of our refinements, and estimates statistics at the tax-unit level in 2016. As discussed above, there remain large gaps due to differences in estimated wealth concentration.

\section{J.1 Interest Rate of the Rich}

First, SZZ assume that the interest rate earned by the rich is the Moody's Aaa rate (6\% on average in the $2000 \mathrm{~s}, 4 \%$ in the 2010s). This is inconsistent with the existing evidence (from the SCF and matched estates-income tax data data) which shows that the interest rate of the wealthy (around 3\% in the 2000s, 2\% in the 2010s) is about twice lower than assumed by SZZ. As a result, SZZ under-estimate the fixed-income claims owned by the wealthy by a factor of about 2.

We thank them for pushing us to clarify our discussion and approach for incorporating heterogeneous returns. There remains some disagreement about which capitalization factor to use and for whom. One important distinction is that we focus on the interest rates of those who have substantial taxable interest income (i.e., $E($ r $\mid$ rank(income) $>$ P99.9) and SZ focus on the interest rates of those who have substantial wealth (i.e., $E(r \mid$ rank(wealth) >P99.9). People who receive large flows of interest income need not be the same people as those who have substantial wealth. Appendix Figure A.15 replicates the SZ figure using wealth ranks and shows how results differ when ranking by interest income flows. It illustrates that when ranking by flows, the Aaa rate closely tracks both the top $0.1 \%$ group in the SCF as well as in the estate tax data.

We focus on interest rates of those with substantial income for two main reasons. First, 
the capitalization approach takes income flows as an input and produces wealth estimates as an output. Since the U.S. does not tax wealth, we only have administrative data on income and not on wealth. Thus, it is not feasible to rank by wealth within the tax data, so focusing on observable measures (i.e., interest rates conditional on flows) is more practically useful than focusing on unobservable measures (i.e., interest rates conditional on stocks). Second, fixed income wealth is a small share of top wealth in the SCF $(14.7 \%)$, so the top $0.1 \%$ in wealth (i.e., $\operatorname{rank}($ wealth $)>$ P99.9) are typically at the top for other reasons, such as the value of their private business or stock holdings, which are unrelated to their fixed income returns. The presence of business owners at the top of the wealth distribution attenuates the average interest rate among the wealthy, and is not directly informative about the appropriate capitalization rate for those with substantial interest income flows.

The true relationship between stocks and flows for fixed income appears concave, not linear. The primary difference between our fixed income estimates and SZ's fixed income estimates is that SZ use a linear stock-flow relationship and we use a step function that reflects the fact that those with high flows tend to enjoy higher rates of return (since those with high flows have fixed income portfolios with a smaller share of deposits and a higher share of higher yielding bonds and loans). For example, consider the two models for fixed income assets as a function of taxable interest income $y_{i, 2016}^{\text {fix }}$ in 2016.

$$
\begin{aligned}
\hat{A}_{i, 2016}^{f i x, S Z} & =124 \times y_{i, 2016}^{f i x} \\
\hat{A}_{i, 2016}^{f i x, S Z Z} & = \begin{cases}27 \times y_{i, 2016}^{f i x} & \text { if } P_{i, 2016}^{f i x} \geq 99.9 \\
54 \times y_{i, 2016}^{f i x} & \text { if } 99.9>P_{i, 2016}^{f i x} \geq 99 \\
443 \times y_{i, 2016}^{f i x} & \text { if } 99>P_{i, 2016}^{f i x}\end{cases}
\end{aligned}
$$

where $\hat{A}_{i, 2016}^{f i x, X}$ are the model predictions for SZ and SZZ in 2016 as a function of taxable interest income $y_{i, 2016}^{f i x}$. For the SZ model in equation (13), 124 is the ratio of total taxable interest income to total fixed income assets in the Financial Accounts. Those with a dollar of taxable interest income are predicted to have $\$ 124$ dollars of fixed income assets. For the SZZ model in equation (14), 27 is $\frac{1}{r_{A a a, 2016}}, 54$ is $\frac{1}{r_{U S T, 2016}}$, and 443 is the capitalization factor for the bottom $99 \%$ in the taxable interest income distribution which ensures that total fixed income assets add up to the same Financial Accounts aggregate. ${ }^{59}$ Thus, a dollar of taxable interest income maps to different predictions about fixed income assets depending on how large their income flows are. Figure $4 \mathrm{~B}$ shows that using different rates for these three groups provides a reasonable approximation of actual interest rates in datasets that have both stock and flow information - the estate tax data and the SCF.

We evaluate these alternative assumptions empirically using a cross-validation approach in the SCF. The two models make predictions about fixed income assets and we find that allowing those with large flows to have lower capitalization factors - and Aaa rates at the very top - does a substantially better job fitting the data in datasets in which we can observe both stocks and flows.

\footnotetext{
${ }^{59}$ The rate for the bottom group is also consistent with a larger fixed-income-portfolio share in very low yield deposits. See Figure 4A.
} 
The left panel of Figure 13C compares actual fixed income wealth in the SCF to predicted fixed income wealth using the equal-returns approach of Saez and Zucman (2016) of equation (13) versus our approach of equation (14). Predicted fixed income wealth under equal returns vastly exceeds SCF wealth with a prediction error that increases with actual wealth. In 2016, the average top 1\% household in the SCF has $\$ 1.8 \mathrm{M}$ of actual fixed income wealth, whereas the equal returns estimate is $\$ 5.3 \mathrm{M}$ or $194 \%$ too high. For the top $0.1 \%$ and top $0.01 \%$, actual wealth is $\$ 6.5 \mathrm{M}$ and $\$ 29.6 \mathrm{M}$, respectively, whereas the equal-returns estimate is $\$ 28.2 \mathrm{M}$ and $\$ 136.3 \mathrm{M}$, respectively. The corresponding prediction errors are $334 \%$ and $360 \%$, respectively, because the linear model does not fit the concave relationship between stocks and flows.

Table 3 expands this analysis to additional moments; for five different interest income flow groups, we compare average fixed income levels, fixed income portfolio shares, the change in fixed income levels from 2001 to 2016, and the change in fixed income portfolio shares. Using a mean-squared-error metric, our model provides a better fit than both the Saez and Zucman (2016) equal-returns approach and the Saez and Zucman (2020) proposal of applying a lower rate like the UST10 to the top 1\%. This result holds across all four moments on average and for most subgroups, with the most pronounced gains at the top. The UST10 approach considerably improves model fit relative to the equal-returns approach, however it underperforms our estimates by overstating estimated wealth for the top $0.1 \%$ and $0.01 \%$.

\section{J.2 Wealth of the Richest}

Second, the SZZ methodology delivers an estimate of wealth for the top 400 richest Americans which is only $40 \%$ of the Forbes 400 total.

We thank them for highlighting the importance of comparisons to the Forbes 400 statistics. We agree and have tried to more accurately convey the difficulty and uncertainty involved with estimating the collective wealth of the top 400 and billionaires in the revised draft, and how our numbers compare to Forbes 400 estimates. We thank them for pushing us on this point - it helped improve the paper.

Ultimately, it is unclear how accurate the Forbes 400 list really is. First, when Raub, Johnson and Newcomb (2010) link the Forbes 400 data to the estate tax data, they only find about half of that wealth in the administrative data. It's hard to determine how much of this gap is due to bias in the Forbes data versus tax avoidance and evasion, which are also likely quite substantial. Second, as mentioned in Saez and Zucman (2020), there are cases in which individuals have substantially overstated their wealth on the Forbes 400. Third, many of the Forbes 400, those in the Bloomberg billionaires list, or top 400 units in the SCF have substantial shares of wealth in private firms, which are difficult to value. ${ }^{60}$ Because our private business estimates use administrative data, our private business estimates are likely more accurate than publicly available estimates. That said, we now explicitly acknowledge that the capitalization approach is likely less accurate for those whose wealth is primarily in public equities, especially if the stock-flow relationship becomes convex at the very top (e.g., if there are more Warren Buffett types who have large stocks and low flows than the Bill Gates types who have large stocks but got a lot of dividends and/or capital gains).

\footnotetext{
${ }^{60}$ Indeed the Bloomberg list has an accuracy rating system that reflects these difficulties: https://www . bloomberg.com/billionaires/methodology/
} 
We have added Section 10.3.2 that highlights these considerations and shows how our estimates compare to the Forbes 400.

We show that in terms of the number of billionaires and their collective wealth, statistics from the Forbes 400 fall in between our estimates and those from the equal-return approach of Saez and Zucman (2016). The Forbes 400 numbers, when combined with a standard distributional assumption, imply that there were about 911 billionaires with $\$ 3.1 \mathrm{~T}$ in collective wealth (Saez and Zucman, 2019c). ${ }^{61}$ The equal-returns approach gives 1,250 billionaires with $\$ 3.7 \mathrm{~T}$, and our preferred series gives 640 billionaires with $\$ 1.7 \mathrm{~T}$ overall. In terms of counts and dollars in 2016, the equal-returns approach is $149 \%$ and $123 \%$ of the Forbes-based estimates, and our preferred approach is $76 \%$ and $57 \%$ of the Forbes 400 counts and dollars, respectively.

In terms of top shares, we also point out in Section 10.3.2 that the Forbes-400-based Pareto parameter of 1.4 in 2016 implies top $0.1 \%$, top 1\%, and top $10 \%$ wealth shares of $13.9 \%, 26.8 \%$, and 51.8\%, respectively. ${ }^{62}$ Comparing these shares to those in Table 1 reveals that top shares from our preferred series $(14.3 \%, 29.6 \%, 65.6 \%)$ line up more closely with these Forbes-400-implied top shares than do those from the equal-returns approach of Saez and Zucman (2016) (20.2\%, 38.1\%, 72.3\%).

In terms of composition, our results are consistent with the Forbes 400 in that equity plays a central role and fixed income does not. Moreover, in terms of private business valuations, our approach may be better than Forbes, which relies on a combination of self-reported values and limited public data on private firms.

We conclude Section 10.3.2 as follows "while it is possible that the Forbes estimates are overstated for the reasons above, estimates from our preferred specification may need to be scaled up to match the true unobserved wealth of the wealthiest 400." We hope our direct quantitative comparison, qualitative discussion of uncertainty regarding the accuracy of the Forbes 400 estimates, and description of the sensitivity of Pareto extrapolations help address this concern.

\section{J.3 Consistency with SCF}

Third, the SZZ methodology is not consistent with the rise in wealth concentration seen in the other key data source on wealth in the US, the Survey of Consumer Finances.

We provide a thorough reconciliation of approaches and datasets in Sections 10.2 and 10.3. In Section 10.3.1, we discuss plausible reconciliations for each apparent discrepancy between our data and the SCF and clarify the nature of remaining uncertainty.

Appendix Figure A.16 illustrates how adjustments to the SCF affect the evolution of top shares. The SCF series in Saez and Zucman (2020) series makes one set of adjustments to

\footnotetext{
${ }^{61}$ Footnote 52 notes that the same method applied to 2016 Forbes data gives 669 and $\$ 2.4 \mathrm{~T}$ with the $15 \%$ avoidance and evasion adjustment as in Saez and Zucman (2019c), and 839 and $\$ 3$ T without any adjustments. We use the raw 2016 estimates below to obtain the estimates of $149 \%(=1250 / 839)$, 123\% $(=3.7 / 3), 76 \%(=640 / 839)$, and $57 \%(=1.7 / 3)$.

${ }^{62}$ Given the 2016 estimate of the Pareto parameter of $a=1.4$ and the assumption that top wealth is Pareto distributed, the top $p$ percentile's share of wealth in 2016 is $\left(\frac{p}{100}\right)^{\frac{1.4-1}{1.4}}$. See equation 1 in https: //economics.mit.edu/files/10517 for details.
} 
make the series more comparable to tax-unit based series, but similar steps can be taken to produce an equal-split series that is more directly comparable to our preferred series (and that of Piketty, Saez and Zucman (2018)). Appendix Figure A.16A and A.16B show how these adjustments, as well as other adjustments such as including the Forbes 400, affect the top $1 \%$ and top $0.1 \%$ shares, respectively. Appendix Figure A.16C highlights the main adjustments in 2016 and shows that for the top 1\% series, the tax unit adjustment adds 4.82 pp whereas Appendix Figure A.16D shows that the equal-split adjustment only raises the top $1 \%$ share by $0.95 \mathrm{pp}$. Overall, our preferred series more closely resembles the SCF series when using the equal-split adjustment instead of the tax-unit adjustment.

In terms of the specific point regarding the percentage point change in top wealth shares in the Saez and Zucman (2020) SCF series versus our preferred series, we now present Appendix Figure A.3, which decomposes the change in top shares by component for our preferred series and the equal-returns series from 1989-2016. It shows that nearly half of the growth of the top share in the equal-returns series is driven by fixed income, whereas, in the raw SCF, less than one fifth of the change in top 1 and $0.1 \%$ shares from 1989 to 2016 comes from fixed income. ${ }^{63}$

Finally, in terms of consistency with the SCF, we now provide comparisons and goodness of fit measures that show that our measures are more consistent with the SCF than equalreturns measures in terms of a wide range of other moments. Figure 14 shows that our preferred estimates, especially of top fixed income wealth, are much closer to the SCF as well as the DFA. In terms of goodness of fit, Figure 13C, Table 3, and Appendix Table B.3 all generally show a much better fit relative to the equal-return series.

\section{J.4 Revenue from wealth tax on the richest}

Fourth, SZZ under-estimate wealth tax revenue by a factor of about 2, partly because of too low wealth levels at the top, partly because they simulate a tax on wealth at the adult level (with equal split of assets between spouses) rather than at the tax unit level.

The preliminary wealth estimates discussed in Saez and Zucman (2020) showed larger gaps than our updated version, which uses new data, includes all of our refinements, and estimates statistics at the tax-unit level in 2016. The remaining gaps discussed in Section 9.2 represent differences in estimated wealth concentration.

\footnotetext{
${ }^{63}$ For the top 1\%, public equity's contribution to top share growth from 1989 to 2016 is three times as large as fixed income's contribution. For the top $0.1 \%$, public and private equity both account for a larger contribution to growth for the top $0.1 \%$ than fixed income does in the raw SCF data.
} 